US Army Corps

of Engineers

Waterways Experiment

Station

Repair, Evaluation, Maintenance, and Rehabilitation Research Program

\title{
Effects of Short Polymeric Fibers on Crack Development in Clays
}

by Stacy Shulley, Dov Leshchinsky, Hoe I. Ling, University of Delaware

Approved For Public Release; Distribution Is Unlimited

Prepared for Headquarters, U.S. Army Corps of Engineers

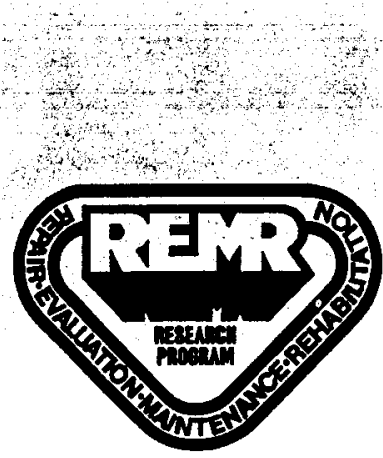


The contents of this report are not to be used for advertising, publication, or promotional purposes. Citation of trade names does not constitute an official endorsement or approval of the use of such commercial products.

The findings of this report are not to be construed as an official Department of the Army position, unless so designated by other authorized documents. 


\section{Effects of Short Polymeric Fibers on Crack Development in Clays}

by Stacy Shulley, Dov Leshchinsky, Hoe I. Ling

University of Delaware

Department of Civil Engineering

Newark, DE 19716

Final report

Approved for public release; distribution is unlimited

Prepared for U.S. Army Corps of Engineers

Washington, DC 20314-1000

Under Contract No. DACW39-95-K-0055

Work Unit 32646 


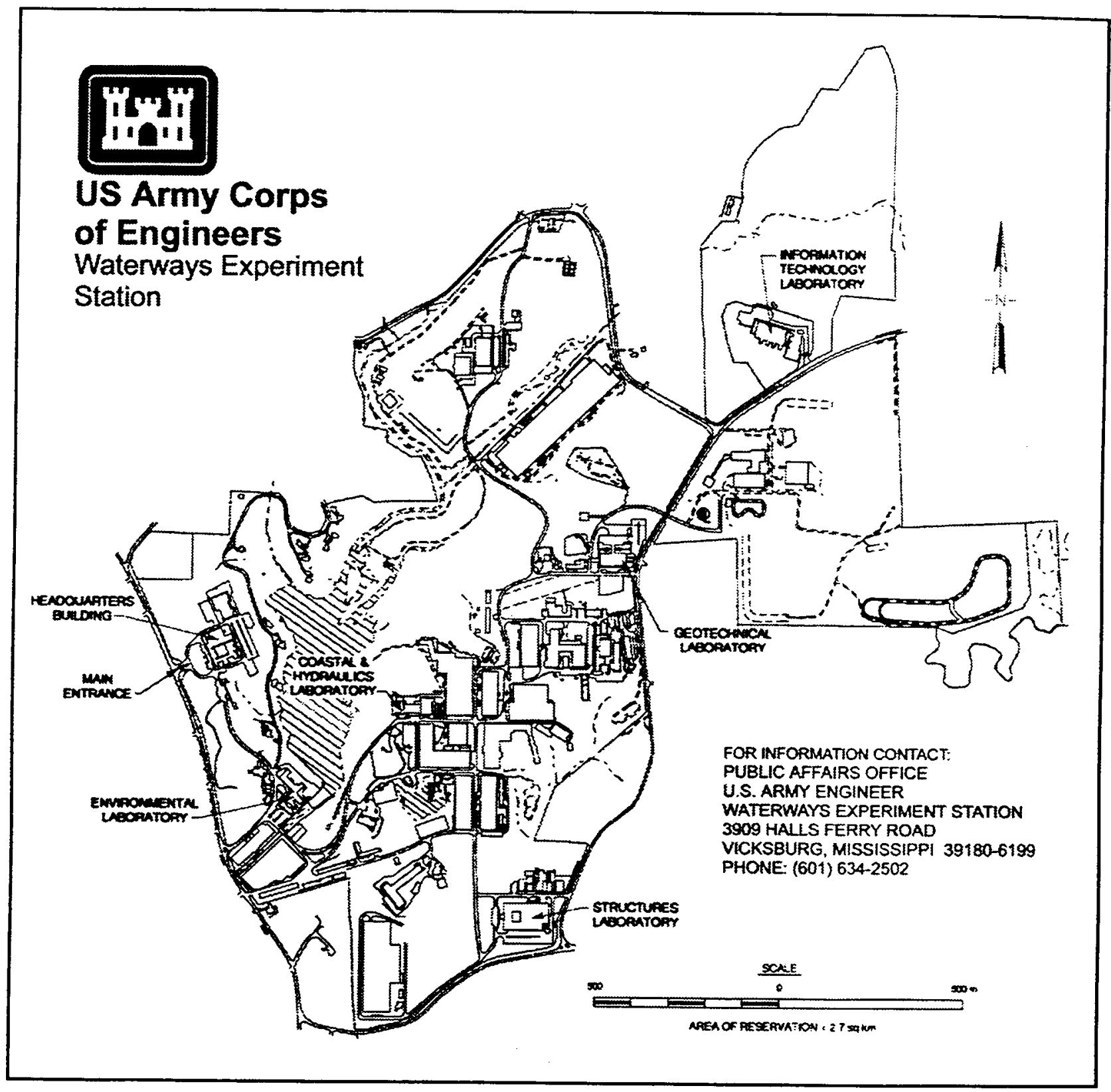

\section{Waterways Experiment Station Cataloging-in-Publication Data}

Shulley-Ziegler, Stacy.

Effects of short polymeric fibers on crack development in clays / by Stacy Shulley, Dov Leshchinsky, Hoe I. Ling ; prepared for U.S. Army Corps of Engineers.

102 p. : ill. ; $28 \mathrm{~cm}$. - (Technical report ; REMR-GT-25)

Includes bibliographic references.

1. Polypropylene fibers - Testing. 2. Levees. 3. Clay soils - Testing. 4. Slopes (Soil mechanics) I. Leshchinsky, Dov. II. Ling, Hoe I. III. United States. Army. Corps of Engineers. IV. U.S. Army Engineer Waterways Experiment Station. V. Repair, Evaluation, Maintenance, and Rehabilitation Research Program. VI. Title. VII. Series: Technical report (U.S. Army Engineer Waterways Experiment Station) ; REMR-GT-25.

TA7 W34 no.REMR-GT-25 


\section{Contents}

Preface $\ldots \ldots \ldots \ldots \ldots \ldots \ldots \ldots \ldots \ldots \ldots \ldots \ldots$ vi

1-Introduction $\ldots \ldots \ldots \ldots \ldots \ldots \ldots \ldots \ldots \ldots \ldots \ldots$

2-Literature Review $\ldots \ldots \ldots \ldots \ldots \ldots \ldots \ldots \ldots \ldots \ldots \ldots$

Sloughing and Shallow Slide Failures of Levees . . . . . . . . . 3

Tensile Reinforcement of Sand . . . . . . . . . . . . . . . . . 3

Tensile Reinforcement of Clays . . . . . . . . . . . . . 4

Use of Fibrillated Polypropylene Fibers in Reinforcing Clays . . . . 4

3-Materials, Specimen Preparation, and Testing Procedures $\ldots \ldots .6$

Development of Testing Program $\ldots \ldots \ldots \ldots \ldots \ldots 6$

Materials ...................... 6

Laboratory prepared soils $\ldots \ldots \ldots \ldots \ldots \ldots \ldots \ldots$

Natural soils $\ldots \ldots \ldots \ldots \ldots \ldots \ldots \ldots \ldots \ldots \ldots \ldots, 9$

Fibers . . . . . . . . . . . . . . . . . . . 9

Distilled water $\ldots \ldots \ldots \ldots \ldots \ldots \ldots \ldots \ldots . \ldots \ldots$

Sample Preparation and Testing Methods $\ldots \ldots \ldots \ldots \ldots \ldots 10$

Volume change/cracking test $\ldots \ldots \ldots \ldots \ldots \ldots \ldots \ldots 11$

Unconfined compression test $\ldots \ldots \ldots \ldots \ldots \ldots \ldots \ldots$

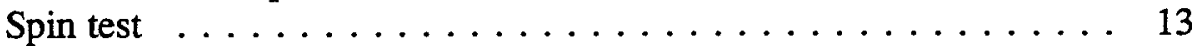

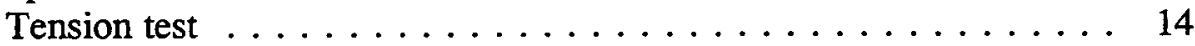

4-Results of Testing Program $\ldots \ldots \ldots \ldots \ldots \ldots \ldots \ldots$

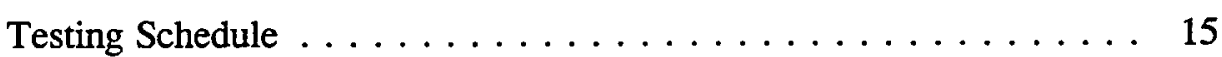

Crack Test Results . . . . . . . . . . . . . . . . . . 15

Laboratory-prepared soils $\ldots \ldots \ldots \ldots \ldots \ldots \ldots \ldots \ldots 15$

Natural soils . . . . . . . . . . . . . . . . . . . 19

Volume Change Test Results . . . . . . . . . . . . . . 20

Laboratory-prepared soils $\ldots \ldots \ldots \ldots \ldots \ldots \ldots \ldots \ldots$

Natural soils . . . . . . . . . . . . . . . . . 20

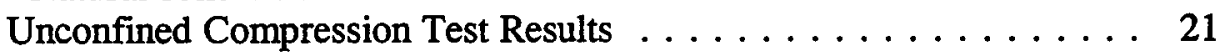

Laboratory-prepared soils $\ldots \ldots \ldots \ldots \ldots \ldots \ldots \ldots \ldots 21$

Natural soils . . . . . . . . . . . . . . . . 22

Spin Test Results . . . . . . . . . . . . . . . . . 22

Laboratory-prepared soils $\ldots \ldots \ldots \ldots \ldots \ldots \ldots \ldots \ldots 22$

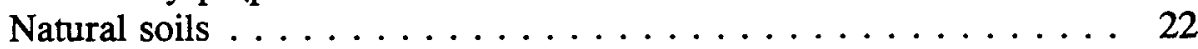

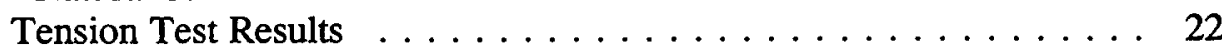

Laboratory-prepared soils $\ldots \ldots \ldots \ldots \ldots \ldots \ldots \ldots . \ldots \ldots$ 
Natural soils . . . . . . . . . . . . . . . . 23

5-Interpretation of Results $\ldots \ldots \ldots \ldots \ldots \ldots \ldots$

Effect of Fibers . . . . . . . . . . . . . . . . . 26

Effect of fibers on crack development as a function of PI . . . . . 26

Effect of fibers on crack development as a function of wet/dry

cycles ....................... 26

Effect of fibers on volume change associated with shrink/swell . . . 27

Effect of fibers on the unconfined strength of clay . . . . . . . . 27

Effectiveness of fibers in reducing clay surface disintegration

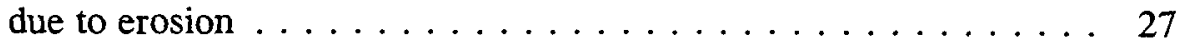

Effect of fibers on the tensile strength of clay . . . . . . . 27

Optimal Fiber Content . . . . . . . . . . . . . . . . . 28

Relevance of Synthetic Clay Tests Results to Natural Clays . . . . . . . 28

Investigation of the Effectiveness of the Fibrillated Fiber Structure . . 28

6 -Conclusions and Recommendations . . . . . . . . . . . . 31

References ...................... 33

Figures 1-64

SF 298

\section{List of Tables}

Table 1. Atterberg Limits of Kaolinite, Calcium Bentonite, and

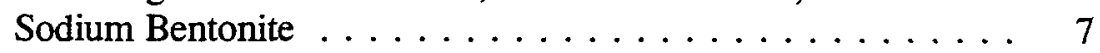

Table 2. Mixture Proportions for Laboratory-Prepared Soil

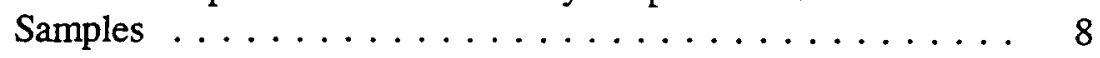

Table 3. Maximum Dry Density and Optimum Moisture Content for Laboratory-Prepared Soil Samples . . . . . . . . . 8

Table 4. Atterberg Limits, Maximum Dry Density, and Optimum Moisture Content of Natural Soil Samples ......... 9

Table 5. Properties of Fibrillated Polypropylene Fibers . . . . . . . . 10 .

Table 6. Testing Schedule for Volume Change/Cracking Test Using Laboratory-Prepared Soil Samples . . . . . . . . . . 16

Table 7. Testing Schedule for Volume Change/Cracking Test Using Natural Soil Samples . . . . . . . . . . . . . . . 16

Table 8. Testing Schedule for Unconfined Compression Test Using Laboratory-Prepared Soil Samples . . . . . . . . . . . 17

Table 9. Testing Schedule for Spin Test Using Laboratory-Prepared Soil Samples . . . . . . . . . . . . . . . . . . 17

Table 10. Testing Schedule for Spin Test Using Natural Soil Samples . . 17 
Table 11. Testing Schedule for Tension Test Using Laboratory-Prepared Soil Samples . . . . . . . . . . . . . . . . 18

Table 12. Testing Schedule for Tension Test Using Natural Soil

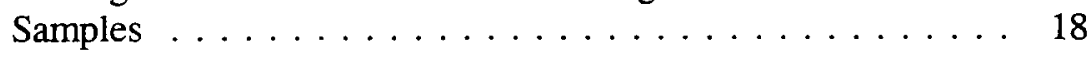

Table 13. Tension Test Results for Laboratory-Prepared Soils . . . . . . 24

Table 14. Tension Test Results for Natural Soils . . . . . . . . . . . . 25

Table 15. Comparison of Cracking Test Results Using Screen Fibers and Fibrillated Fibers: PI $=60$, Drying Cycle $1 \ldots \ldots 30$

Table 16. Comparison of Tension Test Results Using Screen Fibers and Fibrillated Fibers: PI $=60 \ldots \ldots \ldots \ldots \ldots$ 


\section{Preface}

The work described in this report was authorized by Headquarters, U.S. Army Corps of Engineers (HQUSACE), as part of the Geotechnical Problem Area of the Repair, Evaluation, Maintenance, and Rehabilitation (REMR) Research Program. The work was performed under Civil Works Unit 32646, "Levee Rehabilitation." The REMR Technical Monitor was Mr. Arthur H. Walz (CECW-EG).

Dr. Tony C. Liu (CERD-C) was the REMR Coordinator at the Directorate of Research and Development, HQUSACE. Mr. Harold Tohlen (CECW-O) and Dr. Liu served as the REMR Overview Committee. The REMR Program Manager was Mr. William F. McCleese, U.S. Army Engineer Waterways Experiment Station (WES). Mr. W. Milton Myers, Geotechnical Laboratory (GL), WES, was the Problem Area Leader.

The study was performed by Stacy Shulley, Research Assistant, Department of Civil Engineering, University of Delaware, Newark; Dr. Dov Leshchinsky, Leshchinsky, Inc.; and Dr. Hoe I. Ling, Assistant Professor, Department of Civil Engineering, University of Delaware, under Contract No. DACW-94-C0073 to WES. Dr. Edward B. Perry, Soil and Rock Mechanics Division (S\&RMD), Geotechnical Laboratory (GL) was Principal Investigator. The work was conducted under the general supervision of Dr. Don C. Banks, Chief, S\&RMD, and Dr. William F. Marcuson III, Director, GL.

Director of WES during the conduct of this study and preparation of the report was Dr. Robert W. Whalin.

The contents of this report are not to be used for advertising, publication, or promotional purposes. Citation of trade names does not constitute an official endorsement or approval of the use of such commercial products. 


\section{Introduction}

Many earth structures such as levees and highway embankments are constructed of clayey soils which have a tendency to shrink and swell when subjected to cycles of drying and wetting. During dry periods, clay near the surface of the slope shrinks, resulting in desiccation cracks. These cracks have been observed to penetrate to a depth of 1.5 to $2 \mathrm{~m}$ ( 5 to $7 \mathrm{ft}$ ) into a slope. Deep cracks expose the interior of the soil mass, thus allowing further cracking to occur.

When subsequent wetting of the slope occurs due to rainfall, the extensive network of cracks and fissures created due to clay shrinkage allows for rapid percolation of rain water. As the cracks fill with water, the exposed clay surface along the cracks swells, the clay softens, and the strength of the clay along the cracks and fissures decreases.

Over time, the seasonal shrinking and swelling may result in slope failure. The structure may have been designed with a sufficient factor of safety against rotational failure. However, the increase in driving forces (resulting from the gain in the clay weight due to water absorption and the presence of hydrostatic forces due to water filling up portions of the cracks) coupled with the decrease in the shear strength of the clay along the cracks throughout the soil mass results in a decrease of the factor of safety against shallow failures leading eventually to sloughing and shallow slides.

One possible solution to this problem is the use of a lime admixture in the clay comprising the slope. The addition of lime reduces the plasticity of the clay and thus reduces its tendency to produce shrinkage cracks. Another possible solution involves the inclusion of randomly distributed tensile reinforcement elements in the clay. Such elements are available as short polypropylene fibers. The purpose of this research is to assess the feasibility of using these fibers to reduce the development of desiccation cracks in clay.

Runoff and erosion due to rainfall may damage levees. The erosive forces of running water gradually remove soil particles from the slope surface and over time may result in failure due to sloughing. Therefore, the effectiveness of fibers in reducing water erosion damage will also be considered.

The objectives of this research are to study the following seven topics: 
a. Effect of fiber inclusion on the development of cracks as a function of the plasticity index (PI) of the clay.

$b$. Effect of fiber inclusion on the development of cracks as a function of wet/dry cycle.

c. Effect of fibers in reducing the volume change associated with shrink/swell.

$d$. Effect of fibers on the unconfined strength of the clay.

$e$. Effectiveness of fibers in reducing clay surface disintegration due to water erosion.

$f$. Effect of fibers on the tensile strength of clay.

g. Optimal fiber content in terms of workability, compaction, strength, and effectiveness in reducing desiccation cracking. 


\section{Literature Review}

\section{Sloughing and Shallow Slide Failures of Levees}

Many levees are constructed of clays which limit through seepage. In several areas of the United States, such as Texas, Mississippi, and Louisiana, the in situ clays are very highly plastic. Levees constructed of highly plastic clays are susceptible to failure due to continuous cycles of shrinking and swelling which lead to desiccation cracking and subsequent reduction of shear strength.

Shallow sliding or sloughing is the mode of failure most often seen in clay levees. These slides usually occur on the riverside slopes which typically are constructed with a $1 \mathrm{~V}: 4 \mathrm{H}$ slope. The typical slide can be defined as a shallow slide whose maximum depth to the slip plane varies between 1.2 to $2.4 \mathrm{~m}$ ( 4 to $8 \mathrm{ft}$ ) and whose failure is triggered by heavy rainfall after an extended period of weathering. The zone of weathering that develops usually extends to a depth of 1.5 to $2 \mathrm{~m}$ ( 5 to $7 \mathrm{ft}$ ). The slides occur primarily between the riverside crown and a point midway down the slope and range in length from 30.5 to $91.4 \mathrm{~m}$ (100 to $300 \mathrm{ft}$ ) along the crown, as shown in Figure 1 (Fleming, Sills, and Stewart 1994).

Sills et al. (1983) conducted a study of the soils comprising levee slopes that failed in the Vicksburg, Mississippi district. It appeared that a limiting value of PI was associated with materials susceptible to slough slides on $1 \mathrm{~V}: 4 \mathrm{H}$ riverside levee slopes. No slides occurred in areas where the PI was less than 27 and very few where the PI was between 27 and 40 . It was concluded that materials susceptible to slough slides may be characterized as having a liquid limit (LL) greater than 60 and a PI greater than 40.

\section{Tensile Reinforcement of Sand}

There has been some study on the use of short tensile reinforcement fibers in sand. Ranajan, Vasan, and Charan (1994) conducted a series of triaxial compression tests to study the stress-strain behavior of plastic-fiber-reinforced sands. The results showed that fibers served to increase the peak shear strength and reduce the loss of post-peak stress (i.e., provide residual strength). They also found that the principal stress envelopes for 
fiber-reinforced sand were bilinear having a break at a confining stress below which the fibers tend to slip or pull-out.

The mechanism by which tensile reinforcing elements interact with granular soils is friction. An overburden pressure must be present in order for this frictional resistance to develop. For this reason, studies involving the reinforcement of sands are not relevant to the problem being investigated in this research. The application of tensile reinforcement being considered in this study is for near the surface of a slope. Near the surface, negligible overburden pressures are present; therefore, no frictional resistance can develop. The tensile reinforcing elements must interact by some other mechanism with the soil.

\section{Tensile Reinforcement of Clays}

The inclusion of short tensile reinforcement elements in clay has been studied and analyzed. Andersland and Khattak (1979) studied the effect of adding pure cellulose pulp fibers on the shear strength and stress-strain behavior of kaolinite clay. The results from triaxial tests showed that fiber inclusion increased the peak strength and ductility of kaolinite under all testing conditions.

Maher and Ho (1994) considered the influence of several different types of fibers (polypropylene, glass, and softwood pulp) of varying lengths on the strength and ductility of kaolinite ( $P I=15, L L=45)$. They found that the inclusion of fibers increased the peak compressive strength and ductility of kaolinite, as well as increased the splitting tensile strength.

Vallejo and Yoo (1995) extended these studies to consider the effect of tensile reinforcement on clay $(\mathrm{PI}=30, \mathrm{LL}=58$ ) that already contained fissures. They found that by inserting short steel fibers in a direction perpendicular to the direction of crack propagation, the shear strength of the clay was increased.

\section{Use of Fibrillated Polypropylene Fibers in Reinforcing Clays}

Few studies considering the use of fibrillated polypropylene fibers as reinforcement in clays have been conducted. Al Wahab and El-Kedrah (1995) studied the use of fibers in reducing tension cracking in a low plasticity clay ( $\mathrm{PI}=26, \mathrm{LL}=54$ ) used for liner systems at waste disposal facilities. They concluded that, under controlled compaction moisture, the inclusion of fibers reduces both the amount of cracking and the amount of shrink/swell for the type of clay considered. Furthermore, when subjected to an increasing number of shrink/swell cycles (swell cycles conducted with a seating pressure applied), the amount of cracking decreased exponentially. 
Further study was conducted by Al Wahab and Al-Qurna (1995) to evaluate the strength of a silty clay ( $\mathrm{PI}=7, \mathrm{LL}=23$ ) at several fiber content levels. The results of unconfined compression tests showed that with controlled compaction moisture not exceeding 2 percent above optimum, the soil containing fibers had increased strength, ductility, and toughness. The limiting fiber content for maximum strength benefits was close to 1 percent (by percent of dry weight of soil). The optimum fiber content may vary with soil type.

A third study conducted by AI Wahab and Heckel (1995) found that the use of fibrillated polypropylene fibers increased the static and dynamic energy absorption capacities, the resilient strain, and the number of cycles to failure of a low-plasticity silty clay loam $(\mathrm{PI}=8.5, \mathrm{LL}=39)$. The soil resilient modulus and the permanent strain were also reduced.

Each of these studies considered only clays with low plasticities. For many of the levees and other earth structures built in the southern United States, clays with much higher plasticities, and therefore a greater tendency to develop desiccation cracks, are used. Therefore, the relevance of some of the aforementioned results must be verified for high plasticity clays. 


\section{Materials, Specimen Preparation, and Testing Procedures}

\section{Development of Testing Program}

The purpose of this research was to assess the effects of fiber inclusion on several aspects of the performance of clays. The tendency of a clay to shrink and swell, and hence to develop cracks, increases with the PI of the clay. Therefore, in order to evaluate the effects of fiber inclusion on clays in general, clays with varying plasticity need to be tested. The most easily repeatable method of obtaining a wide range of clays was to make "synthetic" clays in the laboratory by combining stock clays such as kaolinite and bentonite. In this chapter, the process of preparing clays of varying plasticity is described.

Once tests were conducted on the synthetic clays, the relevance of the results to natural clays was determined by repeating some of the tests on several soil samples obtained in the field. This was important so that the conclusions drawn from the tests on the synthetic clays could be generalized to include clays that might be encountered in the field.

This chapter also discusses the methods used in preparing soil samples and the four types of tests used to quantify the effects of fiber inclusion on clays.

\section{Materials}

\section{Laboratory prepared soils}

Soils with a wide range of plasticity were prepared in the lab by mixing different proportions of kaolinite, calcium bentonite, and sodium bentonite. The kaolinite was obtained from Albion Kaolinite Company in Hephzibah, Georgia, and the two types of bentonite were both obtained from American Colloid Company in Arlington Heights, Illinois. 
The Atterberg Limits for each of the individual clays were determined following ASTM 4318-84, "Standard test method for liquid limits, plastic limits and plastic index of soils" (ASTM 1992b). These values are given in Table 1.

\begin{tabular}{|c|c|c|c|}
\hline \multicolumn{4}{|c|}{$\begin{array}{l}\text { Table } 1 \\
\text { Atterberg Limits of Kaolinite, Calcium Bentonite, and Sodium } \\
\text { Bentonite }\end{array}$} \\
\hline Clay & Liquid Limit & Plastic Limit & Plasticity Index \\
\hline Kaolinite & 56 & 32 & 24 \\
\hline Calcium bentonite & 103 & 42 & 61 \\
\hline Sodium bentonite & 433 & 43 & 390 \\
\hline
\end{tabular}

Synthetic clays with a PI of 25 to 100 were prepared by mixing kaolinite, calcium bentonite, and/or sodium bentonite. For each mixture, the LL, plastic limit (PL), and PI were determined. A kaolinite - calcium bentonite mixture produced soils with a PI ranging from 25 to 60 . Figure 2 shows the experimentally determined LL and PI versus the percent, by weight, of calcium bentonite in the mixture. Soils with a PI ranging from 60 to 100 were prepared by mixing kaolinite, calcium bentonite, and sodium bentonite. For these mixtures, the amount of kaolinite was kept at a constant of 15 percent, by weight, of the total mixture; only the amount of sodium bentonite and calcium bentonite was changed in each mixture. Figure 3 shows the LL and PI versus the percent sodium bentonite in mixture.

From these experimentally produced plots, the mixtures that would provide 10 soils with the desired PI were chosen. This range of PI simulates the realistic range of clays encountered in the field. Table 2 shows the mixture proportions for soils with the desired plasticity indices.

For each laboratory prepared soil, the maximum dry density and the optimum moisture content were then determined following ASTM D 698-91, "Laboratory compaction characteristics of soil using standard effort" (ASTM 1992a). The compactive effort was produced using a motorized mechanical soil compactor with a sector face rammer, manufactured by Soiltest (Model $\mathrm{CN}-4235$ ). Table 3 shows the experimentally determined maximum dry density and optimum moisture content for each of the ten laboratory prepared soils.

Based on the experimentally determined PI and LL, each of the prepared soils was classified in accordance with the Unified Soil Classification System (USCS) following ASTM 2487-90, "Standard method for classification of soils for engineering purposes" (ASTM 1992c). Each soil was plotted on the USCS plasticity chart, as shown in Figure 4. The soils with a PI of 25 to 50, plotted slightly below the A-line, would be classified as $\mathrm{MH}-\mathrm{CH}$, plastic silty clay. The soils with a PI of 60 and greater, plotted either on or above the A-line, would be classified as $\mathrm{CH}$, fat clays. 


\begin{tabular}{|l|l|l|l|l|l||}
\hline $\begin{array}{l}\text { Table 2 } \\
\text { Mixture Proportions for Laboratory-Prepared Soil Samples }\end{array}$ \\
\hline \begin{tabular}{|l|l|l|l|l||} 
Plasticity \\
Index
\end{tabular} & Plastic Limit & Liquid Limit & $\begin{array}{l}\text { Kaolinite } \\
\text { Percent }\end{array}$ & $\begin{array}{l}\text { Calcium } \\
\text { Bentonite } \\
\text { Percent }\end{array}$ & $\begin{array}{l}\text { Sodium } \\
\text { Bentonite } \\
\text { Percent }\end{array}$ \\
\hline 25 & 33 & 58 & 80 & 20 & - \\
\hline 30 & 34 & 64 & 69 & 31 & - \\
\hline 35 & 35 & 70 & 58 & 42 & - \\
\hline 40 & 37 & 77 & 46 & 54 & - \\
\hline 50 & 39 & 89 & 23 & 77 & - \\
\hline 60 & 42 & 102 & 15 & 77 & 8 \\
\hline 70 & 40 & 110 & 15 & 71 & 14 \\
\hline 80 & 39 & 119 & 15 & 67 & 18 \\
\hline 90 & 40 & 130 & 15 & 63 & 22 \\
\hline 100 & 40 & 140 & -15 & 61 & 24 \\
\hline
\end{tabular}

\begin{tabular}{|l|l|l|}
\hline $\begin{array}{l}\text { Table 3 } \\
\text { Maximum Dry Density and Optimum Moisture Content for } \\
\text { Laboratory-Prepared Soil Samples }\end{array}$ \\
\hline \hline & Maximum Dry Density, $\mathbf{k N} / \mathbf{m}^{3}$ & $\begin{array}{l}\text { Optimum Moisture Content } \\
\text { Percent }\end{array}$ \\
\hline \hline 25 & 13.9 & 29 \\
\hline 30 & 13.5 & 30 \\
\hline 35 & 13.3 & 35 \\
\hline 40 & 12.8 & 36 \\
\hline 50 & 12.1 & 39 \\
\hline 60 & 11.7 & 36 \\
\hline 70 & 11.6 & 35 \\
\hline 80 & 11.5 & 37 \\
\hline 90 & 11.5 & 40 \\
\hline 100 & 11.4 & 41 \\
\hline \hline See Table 2 for mixture proportions of Kaolinite, Calcium Bentonite, and Sodium Bentonite. \\
\hline
\end{tabular}




\section{Natural soils}

In order to verify the relevance of the test results obtained using the laboratory-prepared soils described above, several natural clays (i.e., field samples) were tested as well. The four natural clay samples used are referred to as follows: (a) "Yazoo" clay from Jackson, Mississippi; (b) "Silver Creek" clay from Fort Worth, Texas; (c) "Dallas 1" from Dallas, Texas; and (d) "Dallas 2" from Dallas, Texas.

For each of the four natural soils, the Atterberg limits, the maximum dry density, and the optimum moisture content were determined following ASTM standard procedures noted in the previous section. Table 4 lists these properties of the natural soils.

The soils were classified using the USCS plasticity chart, shown in Figure 5. The Yazoo and Dallas 1 samples are classified as $\mathrm{CH}$, fat clays, the Silver Creek sample is classified as CL, a lean clay, and the Dallas 2 sample is classified as $\mathrm{MH}-\mathrm{CH}$, a plastic, silty clay.

\begin{tabular}{|c|c|c|c|c|c|}
\hline \multicolumn{6}{|c|}{$\begin{array}{l}\text { Table } 4 \\
\text { Atterberg Limits, Maximum Dry Density, and Optimum Moisture } \\
\text { Content of Natural Soil Samples }\end{array}$} \\
\hline Clay & $\begin{array}{l}\text { Plasticity } \\
\text { Index }\end{array}$ & $\begin{array}{l}\text { Plastic } \\
\text { Limit }\end{array}$ & $\begin{array}{l}\text { Liquid } \\
\text { Limit }\end{array}$ & $\begin{array}{l}\text { Maximum Dry } \\
\text { Density, } \mathbf{k N} / \mathbf{m}^{3}\end{array}$ & $\begin{array}{l}\text { Optimum Moisture } \\
\text { Content Percent }\end{array}$ \\
\hline Yazoo & 60 & 26 & 86 & 14.0 & 26.0 \\
\hline Silver Creek & 16 & 17 & 33 & 17.9 & 14.0 \\
\hline Dallas 1 & 49 & 22 & 71 & 15.7 & 14.5 \\
\hline Dallas 2 & 27 & 35 & 62 & 13.8 & 30.0 \\
\hline
\end{tabular}

Fibers

Discrete, fibrillated, polypropylene fiber bundles were used throughout this study. The fiber bundles were manufactured in such a way that when stretched perpendicularly to the direction of the long chain polymer, a miniature mesh with a diamond shaped pattern is formed. When mixed with the soil, the fibers should spread open and disperse into net, grid, or fiber configurations (Synthetic Industries 1993). The fiber bundles, shown both in their original form and spread open in Figure 6, were nominally $25 \mathrm{~mm}$ (1.0 in.) long, $2.54 \mathrm{~mm}$ (0.1 in.) wide, and approximately $0.254 \mathrm{~mm}(0.01 \mathrm{in}$.) thick. Each fiber bundle consisted of 7 to 10 interconnected fibers, each approximately $25.4 \mathrm{~mm}$ ( $1 \mathrm{in}$.) long and $0.889 \mathrm{~mm}(0.035 \mathrm{in}$.) wide. The properties of the fibers are listed in Table 5. These fibers are resistant to ultraviolet degradation and are inert. 


\begin{tabular}{|l|c|}
\hline $\begin{array}{l}\text { Table } \mathbf{5} \\
\text { Properties of Fibrillated Polypropylene Fibers (Synthetic Industries } \\
\text { 1993) }\end{array}$ \\
\hline \hline Specific gravity & $0.9 \mathrm{~g} / \mathrm{cm}^{3}$ \\
\hline Tensile strength & $45,000 \mathrm{psi}$ \\
\hline Tensile elongation & $15 \mathrm{percent}$ \\
\hline Young's modulus & $700,000 \mathrm{psi}$ \\
\hline \hline To convert psi to kilopascals multiply by 6.8947579. \\
\hline
\end{tabular}

The amount of fibers added to the soil ranged from 0 percent to 1.0 percent by dry weight of the soil. Most tests were conducted with three different fiber content levels of 0 percent, 0.1 percent, and 0.3 percent.

\section{Distilled water}

In order to eliminate any effects of unknown elements present in tap water, distilled water was used for all characterization and testing of the clayey soils, unless otherwise noted. The distilled water was prepared in the laboratory using a Barnstead Mega Pure ${ }^{\circledR}$ water still.

\section{Sample Preparation and Testing Methods}

For each type of test conducted, the soil was prepared following one of two similar procedures. In the first procedure, all mixing of the soil and fibers was done by hand. For the laboratory-prepared soils, the appropriate proportions of dry kaolinite, calcium bentonite, and/or sodium bentonite were weighed and mixed thoroughly by hand. For the natural soils, an appropriate amount of the soil was pulverized and put thorough a No. 10 sieve. Then, either the natural or laboratory-prepared soil was gradually mixed with the appropriate amount of distilled water to bring its moisture level to 2 percent or above the optimum moisture content. If fibers were to be included in the sample, they were weighed out and mixed by hand into the wet soil. Figure 7 shows a typical batch of soil containing 0.3 percent fibers mixed by hand. The complete mixture was then covered tightly with plastic wrap and allowed to cure for $24 \mathrm{hr}$. This curing process allowed for a more even distribution of moisture throughout the soil.

The first procedure, mixing the soil by hand, made it difficult to get the fibers distributed evenly throughout the soil; the fibers tended to open slightly and then clump together, resulting in an uneven distribution throughout the soil. When used in the field, the fibers are mixed more uniformly into the soil by passing over an area of soil and fibers several times with a rotary-pulverizer mixing machine. Therefore, in order to more effectively model in the 
laboratory the performance of the fibers in the field, a second mixing procedure involved the use of a mechanical mixer to blend the soil.

The device used to blend the soil was a Lancaster K-Lab Hi-Intensive Mixer $^{\circledR}$ (Figure 8). This mixer has a clockwise rotating 305-mm- (12-in.-) diam pan that pulls the material into a counterclockwise spinning rotor. Using this method, the appropriate proportions of dry soil were placed in the mixer and were mixed for $15 \mathrm{sec}$ with a rotor speed of $1,500 \mathrm{rpm}$ and a pan speed of $13 \mathrm{rpm}$. Then, the amount of water that was needed to raise the moisture content to 3.5 percent above optimum was added gradually through the access hole in the top of the mixer. (Note that the soil samples prepared using this method had a higher moisture content than those prepared using the hand-mixing method. At 2 percent above optimum moisture content, the fibers would open, clump together, and wrap around the rotor blade instead of being mixed into the soil. In order to get effective results with the mixer, the slightly higher moisture content of 3.5 percent above optimum was necessary). When adding the water, the pan speed was increased to $27 \mathrm{rpm}$. After all the water was added, mixing continued for $30 \mathrm{sec}$. Then the mixer was stopped and any soil buildup was removed from the rotor blades and scraping mechanism. If fibers were to be added to the mix, they were weighed out and surface wetted. Mixing was resumed with a rotor speed of $750 \mathrm{rpm}$ and a pan speed of $27 \mathrm{rpm}$, while the fibers were added gradually to the soil through the access hole. After all the fibers were added, the rotor blades and scraper were again cleaned, and mixing was resumed for $30 \mathrm{sec}$ with the rotor speed increased to $1,500 \mathrm{rpm}$. After this mixing sequence, the soil was placed in a pan, tightly covered in plastic wrap, and allowed to cure for $24 \mathrm{hr}$. Figure 9 shows a typical soil batch mixed by machine with a fiber content of 0.3 percent. Inspection of the mixture showed that the high-speed mixing action caused the fiber bundles to be separated and dispersed so that individual fibers were mixed throughout the soil. The rotor blades did not do any apparent damage to the fibers. The fiber-soil mixture that resulted from using the mixer was much more uniform than that attained by hand mixing. It resembled the uniformity of mixture typically obtained in the field (based on photographs taken during construction).

\section{Volume change/cracking test}

For this test, each specimen was formed by compacting soil into a standard Proctor mold (101.6 mm (4 in.) in diam and $71.2 \mathrm{~mm}$ (4.58 in.) in height) to 95 percent of maximum dry density. All compaction was done in three approximately equal lifts using a motorized hammer.

For each soil at each fiber content level, four specimens were prepared in four separate standard Proctor molds. Then, each specimen was subjected to a different number of drying/wetting cycles. The drying cycle consisted of placing the specimen, in an oven at $120^{\circ} \mathrm{F}\left(48.9^{\circ} \mathrm{C}\right)$ for a period of $24 \mathrm{hr}$. For each wet cycle, the specimen contained in the mold was submerged in distilled water at room temperature for a period of $24 \mathrm{hr}$. These cycles were needed to verify whether the performance of the fibers changes with wet/dry conditions. 
The testing schedule for each set of four specimens is schematically illustrated in Figure 10. As shown, specimen 1 was compacted, ejected from the Proctor mold, and placed in the oven for drying cycle 1 . At the end of $24 \mathrm{hr}$, it was measured for volume change and cracking. At that point, specimen 1 was photographed and stored for later reference; it was no longer used in the testing sequence.

Specimen 2 was prepared at the same time as specimen 1; however, it was left in the Proctor mold and placed in the oven for drying cycle 1. At the end of $24 \mathrm{hr}$ it was removed from the oven, and with the mold and collar still in place, was submerged in distilled water. (The mold and collar were left in place to keep the specimen from falling apart in the water. Without the stability and containment provided by the mold, the specimen would have disintegrated in less than $30 \mathrm{~min}$ ). After a $24-\mathrm{hr}$ soak, specimen 2 was removed from the water, ejected from the mold, and placed in the oven for drying cycle 2 . After $24 \mathrm{hr}$, it was removed from the oven, measured, photographed, and stored. At that point, specimen 2 had been through two drying cycles, data had been recorded, and the specimen was not used for any further testing.

Similarly, specimens 3 and 4 were made at the same time as specimens 1 and 2 and were subjected to cycles of drying and wetting. Each specimen was ejected from the mold only before the start of its last drying cycle. At the end of the last drying cycle, each specimen was measured, photographed, and stored.

For each specimen, two types of data were collected. First, volume changes were recorded at the end of each drying and wetting cycle. The height of each specimen was measured as well as the circumference at three locations along the height of the specimen. After the height and average diameter of the specimen were determined, the volume was then calculated. Percent-ofvolume change was recorded as the difference between the measured volume and the initial volume, divided by the initial volume of the specimen.

The other information gathered from the specimen at the end of its last drying cycle was the amount of surface cracking that occurred. To quantify the amount of cracking, the cracks were measured along the cylindrical face of the specimen. Calipers were used to measure the width and to approximate the length of each crack. As shown in Figure 11, first a quadrant of the specimen was marked off. The total area of cracks was measured as the sum of the length times the width of each crack on the surface of the quadrant, multiplied by four to give the area of cracks on the entire cylindrical surface. This procedure of only considering the cracks on one quarter of the specimen was verified and found to be in good agreement with the measurement of cracks over the entire cylindrical surface of the specimen. The maximum crack width and the average crack width were also noted. 


\section{Unconfined compression test}

Each specimen for this test was formed by compacting soils with a motorized hammer into a standard Proctor mold to 95 percent of maximum dry density. For each soil at each fiber-content level, two specimens were prepared.

To obtain a specimen with a height-to-diam ratio in a range appropriate for unconfined compression tests, a brass sampling tube was pressed into the compacted soil still in the mold. Then the specimen was carefully extracted from the brass sampling tube. The specimen sizes used were $46.9 \mathrm{~mm}$ (1.85 in.) in diam, $116.3 \mathrm{~mm}$ (4.58 in.) in height and $73.6 \mathrm{~mm}$ (2.9 in.) in diam, $165.1 \mathrm{~mm}$ (6.5 in.) in height. These specimens had height-to-diameter ratios of 2.5 and 2.25 , respectively. Two different diameters of specimens were considered in order to see if the specimen size in relation to the 25.4-mm (1-in.) length of the fibers would have any effect on the resulting strength of the soil.

After the specimen was extracted, it was wrapped in plastic wrap to prevent drying until it was tested. The test was conducted using an unconfined compression loading frame manufactured by Geotest (model number S2013). The unconfined compression test was controlled at a strain rate of 2 percent of the initial height of the specimen per minute. Deflection and load data were collected during each test.

\section{Spin test}

The spin test apparatus consists of a variable speed electric motor mounted on top of a tripod stand (Richter 1992 and Leshchinsky, Richter, and Fowler (1991). Below the motor, a shaft extends to a clamp where the specimen is placed and secured during the test. After the specimen is clamped in place, it is lowered and submerged into a 10-gal plastic tub filled with clear, potable tap water. (Preliminary tests run in both distilled water and tap water showed similar results. Therefore, due to the quantity of water necessary, only tap water was used for all the spin tests). Figures 12 and 13 are schematic diagrams of the apparatus.

To prepare a specimen for this test, soil was compacted to 95 percent of maximum dry density in a standard Proctor mold using a motorized hammer. After compaction, each specimen was extracted and weighed. For each soil at each fiber-content level, four identical specimens were prepared.

To conduct a test, the motor was operated at a constant speed, spinning the submerged specimen on its axis for a measured time increment. At the end of the selected spinning time, the portion of the specimen remaining was lifted out of the water and removed from the clamp. The specimen was then weighed and placed in the oven to dry. For most of the tests conducted, four different exposure times of $5,10,15$, and $20 \mathrm{~min}$ were used. The results were assumed to indicate the susceptibility of the clay and fiber mixture to water-erosive forces. 
The spinning velocity, chosen to simulate surface run-off (i.e., the relative velocity between water and the surface of the specimen), was set at $0.3048 \mathrm{~m} / \mathrm{sec}(1 \mathrm{ft} / \mathrm{s})$ relative tangential velocity (53 rotations per $\mathrm{min}$ ). This spinning velocity was kept constant for testing of all the soils.

It should be noted that this test exaggerates erosive force since the spinning of the specimen adds centrifugal force. The outward acceleration generated by the spinning is about $1.8 \mathrm{~m} / \mathrm{sec}^{2}\left(6 \mathrm{ft} / \mathrm{sec}^{2}\right)$, whereas gravity is $9.8 \mathrm{~m} / \mathrm{sec}^{2}$ $\left(32.3 \mathrm{ft} / \mathrm{sec}^{2}\right)$. Consequently, the soil on the surface of the specimen is subjected to centrifugal force as well as shear due to the water drag force. Therefore, the spin tests should be considered only as index tests; their value is limited to a comparison of clays that do or do not contain fibers.

\section{Tension test}

The tension test apparatus consists of a specially designed tensile test fixture installed in a direct shear testing machine to utilize the existing mechanisms for tensile load application. The instrumented direct shear apparatus used was manufactured by Geotest (model number S2215). The tensile test fixture (Figure 14) was a modification of the fixture used by Leavell and Peters (1987).

To prepare each test specimen, soil was compacted by hand into the fixture to approximately 95 percent of maximum dry density. The appropriate amount of soil was weighed out and was compacted into the fixture in three lifts. A plate that fit inside the fixture was placed on top of each soil layer and tamped to the desired thickness by hand using a mallet. Then, the specimen was covered with plastic wrap and allowed to cure for $24 \mathrm{hr}$ to allow for redistribution of moisture within the specimen so it would become more uniform. When ready to test, the specimen was placed in the direct shear machine with each end of the fixture connected to the loading mechanism in the direct shear apparatus by bolts. Then the side pieces of the fixture (which lock the fixture as one unit, preventing accidental tensile load from being induced into the soil) were removed, thus allowing the two ends of the fixture to be pulled apart by the direct shear machine. Figure 15 shows a tension test in progress. All tension tests were conducted at a displacement rate of 0.015 in. per min. During each test, tensile load and displacement were recorded. 


\section{Results of Testing Program}

\section{Testing Schedule}

Tables 6 through 12 detail the types and quantity of tests conducted. Each table specifies whether the tests were conducted on the laboratory-prepared soils or on natural soils. The tables are divided to indicate which tests were conducted using soil that was mixed by hand or soil that was mixed by machine.

\section{Crack Test Results}

\section{Laboratory-prepared soils}

As seen in Table 6, laboratory-prepared soils with a PI ranging from 40 to 100 were used for these tests. Preliminary tests showed that for soils with a PI of 30 or less, only hairline cracks, if any at all, developed; therefore, tests to determine the effect of fiber inclusion on crack development were not relevant to low plasticity soils.

The amount of cracking that occurred on the surface of each specimen was quantified in several ways. First, the approximate width and the length of each crack were measured, and the total area of cracks at the surface was calculated. Using this value, the amount of cracking could be reported as the total area of cracks divided by the surface area of the cylindrical specimen. Figures 16 through 19 are plots of the percent cracking versus the PI of the hand-mixed soil for each of the four drying cycles. It is apparent in these plots that for drying cycles 1 and 2 , the amount of cracking that occurred increased with an increase in the PI of the soil. This observation agrees with the increase in shrink/swell potential with increase in PI.

For drying cycle 1 (Figure 16), it is also apparent that an increase in fiber content corresponded to a decrease in the percent cracking for soil with a PI of 50 or greater. However, for drying cycles 2, 3, and 4 (Figures 17-19) such a trend was not evident. 


\begin{tabular}{|c|c|c|c|c|}
\hline \multicolumn{5}{|c|}{$\begin{array}{l}\text { Table } 6 \\
\text { Testing Schedule for Volume Change/Cracking Test Using } \\
\text { Laboratory-Prepared Soil Samples }\end{array}$} \\
\hline Type of Mixing & Plasticity Index & $\begin{array}{l}\text { Fiber Content } \\
\text { Percent }\end{array}$ & $\begin{array}{l}\text { Number of Dry } \\
\text { Cycles }\end{array}$ & $\begin{array}{l}\text { Specimens Per } \\
\text { Cycle }\end{array}$ \\
\hline \multirow[t]{6}{*}{ Hand-mixed } & 30 & 0 & 2 & 1 \\
\hline & 40 & $\begin{array}{l}0 \\
0.1 \\
0.3\end{array}$ & $\begin{array}{l}4 \\
4 \\
4\end{array}$ & $\begin{array}{l}1 \\
1 \\
1\end{array}$ \\
\hline & 50 & $\begin{array}{l}0 \\
0.1 \\
0.3\end{array}$ & $\begin{array}{l}4 \\
4 \\
4\end{array}$ & $\begin{array}{l}1 \\
1 \\
1\end{array}$ \\
\hline & 60 & $\begin{array}{l}0 \\
0.1 \\
0.3 \\
1.0\end{array}$ & $\begin{array}{l}4 \\
4 \\
4 \\
4\end{array}$ & $\begin{array}{l}1 \\
1 \\
1 \\
1\end{array}$ \\
\hline & 80 & $\begin{array}{l}0 \\
0.1 \\
0.3 \\
\end{array}$ & $\begin{array}{l}4 \\
4 \\
4\end{array}$ & $\begin{array}{l}1 \\
1 \\
1\end{array}$ \\
\hline & 100 & $\begin{array}{l}0 \\
0.1 \\
0.3\end{array}$ & $\begin{array}{l}4 \\
4 \\
4\end{array}$ & $\begin{array}{l}1 \\
1 \\
1\end{array}$ \\
\hline \multirow[t]{3}{*}{ Machine-mixed } & 50 & $\begin{array}{l}0 \\
0.1 \\
0.3\end{array}$ & $\begin{array}{l}3 \\
3 \\
3\end{array}$ & $\begin{array}{l}1 \\
1 \\
1\end{array}$ \\
\hline & 60 & $\begin{array}{l}0 \\
0.1 \\
0.3 \\
\end{array}$ & $\begin{array}{l}3 \\
3 \\
3 \\
\end{array}$ & $\begin{array}{l}1 \\
1 \\
1 \\
\end{array}$ \\
\hline & 100 & $\begin{array}{l}0 \\
0.1 \\
0.3 \\
\end{array}$ & $\begin{array}{l}3 \\
3 \\
3\end{array}$ & $\begin{array}{l}1 \\
1 \\
1\end{array}$ \\
\hline
\end{tabular}

\section{Table 7}

Testing Schedule for Volume Change/Cracking Test Using Natural Soil Samples

\begin{tabular}{||l|l|l|l|l||}
\hline Type of Mixing & Soil Type & $\begin{array}{l}\text { Fiber Content } \\
\text { Percent }\end{array}$ & $\begin{array}{l}\text { Number of Dry } \\
\text { Cycles }\end{array}$ & $\begin{array}{l}\text { Specimens Per } \\
\text { Cycle }\end{array}$ \\
\hline \hline Hand-mixed & Silver Creek & 0 & 2 & 1 \\
& $(\mathrm{PI}=16)$ & 0 & 3 & 1 \\
& Yazoo & 0 & 3 & 1 \\
& $(\mathrm{PI}=60)$ & 0.1 & 3 & 1 \\
& 0.3 & 3 & 1 \\
& Dallas 1 & 0 & 3 & 1 \\
\cline { 2 - 5 } & $(\mathrm{PI}=49)$ & 0.1 & 3 & 1 \\
& & 0.3 & 3 & 1 \\
\cline { 2 - 5 } & Dallas 2 & 0 & 3 & 3 \\
\hline
\end{tabular}




\begin{tabular}{|c|c|c|c|}
\hline \multicolumn{4}{|c|}{$\begin{array}{l}\text { Table } 8 \\
\text { Testing Schedule for Unconfined Compression Test Using } \\
\text { Laboratory-Prepared Soil Samples }\end{array}$} \\
\hline $\begin{array}{l}\text { Type of } \\
\text { Mixing }\end{array}$ & Plasticity Index & $\begin{array}{l}\text { Fiber Content } \\
\text { Percent }\end{array}$ & Number of Specimens \\
\hline \multirow[t]{4}{*}{ Hand-mixed } & 30 & $\begin{array}{l}0 \\
0.1 \\
0.3\end{array}$ & $\begin{array}{l}2 \\
2 \\
2\end{array}$ \\
\hline & 60 & $\begin{array}{l}0 \\
0.1 \\
0.3 \\
1.0\end{array}$ & $\begin{array}{l}2 \\
2 \\
2 \\
2\end{array}$ \\
\hline & 100 & $\begin{array}{l}0 \\
0.1 \\
0.3\end{array}$ & $\begin{array}{l}2 \\
2 \\
2\end{array}$ \\
\hline & $60+10$ percent sand & $\begin{array}{l}0 \\
0.1 \\
0.3\end{array}$ & $\begin{array}{l}2 \\
2 \\
2\end{array}$ \\
\hline
\end{tabular}

\begin{tabular}{|c|c|c|c|}
\hline \multicolumn{4}{|c|}{$\begin{array}{l}\text { Table } 9 \\
\text { Testing Schedule for Spin Test Using Laboratory-Prepared Soi } \\
\text { Samples }\end{array}$} \\
\hline $\begin{array}{l}\text { Type of } \\
\text { Mixing }\end{array}$ & Plasticity Index & $\begin{array}{l}\text { Fiber Content } \\
\text { Percent }\end{array}$ & $\begin{array}{l}\text { Number of Time } \\
\text { increments }\end{array}$ \\
\hline \multirow[t]{3}{*}{ Hand-mixed } & 30 & $\begin{array}{l}0 \\
0.1 \\
0.3\end{array}$ & $\begin{array}{l}4 \\
4 \\
4\end{array}$ \\
\hline & 60 & $\begin{array}{l}0 \\
0.1 \\
0.3 \\
1.0\end{array}$ & $\begin{array}{l}4 \\
4 \\
4 \\
4\end{array}$ \\
\hline & 100 & $\begin{array}{l}0 \\
0.1 \\
0.3\end{array}$ & $\begin{array}{l}4 \\
4 \\
4\end{array}$ \\
\hline
\end{tabular}

\begin{tabular}{|l|l|l|l||}
\hline \multicolumn{2}{|l||}{$\begin{array}{l}\text { Table } 10 \\
\text { Testing Schedule for Spin Test Using Natural Soil Samples }\end{array}$} \\
\hline \hline \begin{tabular}{l|l||} 
Type of \\
Mixing
\end{tabular} & Soil Type & $\begin{array}{l}\text { Fiber Content } \\
\text { Percent }\end{array}$ & $\begin{array}{l}\text { Number of Time } \\
\text { Increments }\end{array}$ \\
\hline \hline \multirow{3}{*}{ Hand-mixed } & Silver Creek & 0 & 3 \\
& (PI = 16) & 0.1 & 3 \\
& & 0.3 & 3 \\
\cline { 2 - 4 } & Dallas 1 & 0 & 3 \\
& (PI $=49)$ & 0.1 & 3 \\
& & 0.3 & 3 \\
\cline { 2 - 4 } & Dallas 2 & 0 & 3 \\
& (PI = 27) & 0.1 & 3 \\
\hline
\end{tabular}




\begin{tabular}{|c|c|c|c|}
\hline \multicolumn{4}{|c|}{$\begin{array}{l}\text { Table } 11 \\
\text { Testing Schedule for Tension Test Using Laboratory-Prepared Soil } \\
\text { Samples }\end{array}$} \\
\hline Type of Mixing & Plasticity Index & $\begin{array}{l}\text { Fiber Content } \\
\text { Percent }\end{array}$ & Number of Specimens \\
\hline \multirow[t]{3}{*}{ Hand-mixed } & 30 & $\begin{array}{l}0 \\
0.1 \\
0.3\end{array}$ & $\begin{array}{l}2 \\
2 \\
2\end{array}$ \\
\hline & 60 & $\begin{array}{l}0 \\
0.1 \\
0.3\end{array}$ & $\begin{array}{l}2 \\
2 \\
2\end{array}$ \\
\hline & 100 & $\begin{array}{l}0 \\
0.1 \\
0.3\end{array}$ & $\begin{array}{l}2 \\
2 \\
2\end{array}$ \\
\hline \multirow[t]{3}{*}{ Machine-mixed } & 30 & $\begin{array}{l}0 \\
0.1 \\
0.3\end{array}$ & $\begin{array}{l}2 \\
2 \\
2\end{array}$ \\
\hline & 60 & $\begin{array}{l}0 \\
0.1 \\
0.3\end{array}$ & $\begin{array}{l}2 \\
2 \\
2\end{array}$ \\
\hline & 100 & $\begin{array}{l}0 \\
0.1 \\
0.3 \\
\end{array}$ & $\begin{array}{l}2 \\
2 \\
2 \\
\end{array}$ \\
\hline
\end{tabular}

\begin{tabular}{|c|c|c|c|}
\hline \multicolumn{4}{|c|}{$\begin{array}{l}\text { Table } 12 \\
\text { Testing Schedule for Tension Test Using Natural Soil Samples }\end{array}$} \\
\hline $\begin{array}{l}\text { Type of } \\
\text { Mixing }\end{array}$ & Soil Type & $\begin{array}{l}\text { Fiber Content } \\
\text { Percent }\end{array}$ & Number of Specimens \\
\hline \multirow[t]{4}{*}{ Hand-mixed } & $\begin{array}{l}\text { Silver Creek } \\
(P \mid=16)\end{array}$ & $\begin{array}{l}0 \\
0.1 \\
0.3\end{array}$ & $\begin{array}{l}2 \\
2 \\
2\end{array}$ \\
\hline & $\begin{array}{l}Y a z 00 \\
(P I=60)\end{array}$ & $\begin{array}{l}0 \\
0.1 \\
0.3\end{array}$ & $\begin{array}{l}2 \\
2 \\
2\end{array}$ \\
\hline & $\begin{array}{l}\text { Dallas } 1 \\
(P I=49)\end{array}$ & $\begin{array}{l}0 \\
0.1 \\
0.3\end{array}$ & $\begin{array}{l}2 \\
2 \\
2\end{array}$ \\
\hline & $\begin{array}{l}\text { Dallas } 2 \\
(P I=27)\end{array}$ & $\begin{array}{l}0 \\
0.1 \\
0.3\end{array}$ & $\begin{array}{l}2 \\
2 \\
2\end{array}$ \\
\hline
\end{tabular}

Visual observation of the hand-mixed specimens at the end of each drying cycle indicated that there was a difference in the cracks that developed in specimens with no fibers versus specimens containing fibers. For specimens without fibers, a few wide cracks developed along the surface. For specimens of the same soil with fibers included, numerous cracks developed having smaller width and length. Figures 20 through 22 illustrate this difference in crack size. The wider a crack is at the surface, the deeper it penetrates into the soil; 
therefore, the cracks that formed in the specimens containing fibers did not penetrate very deeply into the specimen. This was verified by "dissecting" some of the specimens at the end of the drying cycles. Specimens without fibers would often fall apart when lifted because the wide cracks that formed penetrated nearly all the way across the specimen. However, the specimens containing fibers remained intact when lifted because the many narrow cracks were shallow, extending usually less than $25.4 \mathrm{~mm}$ ( 1 in.) into the specimen. These specimens, when dry, were often difficult to break apart by hand.

Based on these observations, it was thought that perhaps a different method of quantifying the crack development results should be used to more accurately reflect the observed pattern of cracking. By only considering the surface area of cracks, the numbers sometimes indicated that the specimens with fibers were more cracked than those specimens with no fibers. In fact, this quantification reveals little about the more important effect of the fibers on the depth of crack penetration into the clay. Since it was not possible to measure the depth directly, the average crack width was used as an indicator for the penetration depth.

Figures 23 through 27 report the average crack width versus the drying cycle for each type of soil. This method of quantifying the cracks slightly augments the previous presentation of results. Together, both presentations somewhat convey the results that were observed visually. However, as evident from the figures, some results still show little difference in behavior with and without fibers.

In order to determine if the degree of uniformity of the mixing would have an effect on the cracking of the specimen, several tests were repeated using a machine-mixed soil sample instead of the hand-mixed sample. It should be noted again that the machine-mixed soils had a higher moisture content to facilitate the mixing process. (This higher moisture content also more closely approximates the conditions under which the fibers would be utilized in the field). Because of this difference in moisture content, the hand-mixed sample results cannot be compared directly to the machine-mixed sample results. However, the results of the machine-mixed specimens (Figures 28-33), follow a trend very similar to the results of the hand-mixed specimens. For the first drying cycle only, the addition of fibers resulted in a decrease in the percent cracking. Similar visual observations were noted as well. (In the first drying cycle, the fibers seemed to decrease the depth of crack penetration).

\section{Natural soils}

- A sequence similar to the crack tests on the laboratory-prepared soil samples was conducted on the natural clay soils. Due to the limited amount of soil available, only three drying cycles were conducted for each hand-mixed soil at each fiber-content level. It was observed in the crack tests with the synthetic clays that there was not much difference between the results for cycles $3 \mathrm{D}$ and 4D; thus, omitting the fourth drying cycle for the natural soils was not of much concern. 
The Silver Creek clay has a low PI $(\mathrm{PI}=16)$, and, as expected, only a few hairline cracks developed on the specimens during the drying cycles. Therefore, the Silver Creek clay was not used for the cracking tests.

Figures 34 through 36 show the percent cracking for each of the soils at the end of each drying cycle. These results consistently indicate that the inclusion of fibers decreases the percent cracking that occurs. Figures 37 through 39 show the average crack width versus the drying cycle for the three clays that were tested.

For the Dallas 1 clay, some difficulty arose in obtaining a compacted specimen with a smooth surface. When the cycle 1D specimen was ejected from the compaction mold, the cylindrical surface was covered with small voids. This was the result of trying to compact the small clumps of the clay that formed as the water content of the sample was raised to 2 percent above optimum. The clay balls would flatten out as the soil was compacted; however, there would still be some voids remaining. Therefore, when the specimen was dried, it was impossible to tell the cracks that had occurred during drying from those that were present initially. Also, these results were not really comparable to the cracking results from well prepared specimens. Therefore, the cycle 1D results for the Dallas 1 specimen are not reported.

\section{Volume Change Test Results}

\section{Laboratory-prepared soils}

At the end of its final drying cycle, the diameter and height of each specimen was measured and the volume was determined. For almost all the handmixed soils, the volume at the end of the drying cycles was less than the initial volume of the specimen. The percent decrease in volume of each specimen was calculated and is presented in Figures 40 through 43. From these plots it appears that the results are scattered. That is, for a given soil, the inclusion of fibers has no noticeable effect on the percent volume change that occurs as the specimen goes through wet and dry cycles.

The volume measurements were also recorded for specimens prepared from the machine-mixed soils. The results are similarly scattered.

\section{Natural soils}

Volume change tests conducted using the natural soils provided results very similar to those obtained using the synthetic soils. Figures 44 through 46 show the percent change in volume for each soil at the end of each drying cycle. For a given soil at the end of a given drying cycle, the inclusion of fibers had no consistent effect on the volume change of the specimen. The only difference between these results and the results for the volume change test on the synthetic soils was that in some cases the natural soils showed a net increase in volume instead of a net decrease. 


\section{Unconfined Compression Test Results}

\section{Laboratory-prepared soils}

Specimen preparation, as described in the previous chapter, proved to be time consuming and quite difficult for all of the types of soils used. The problems arose in extracting a smaller diameter specimen from compacted soil. This method of obtaining a specimen was chosen over simply compacting soil into a smaller mold in order to have a sample that would be most representative of the clay-fiber mixture used in the cracking/volume change tests. However, the specimen would typically either break during the extraction process, or the brass sampling tube would not enter the compacted soil straight, and the resulting specimen after extraction would not have flat ends. In addition, in pushing the brass sampling tube into compacted soil containing fibers, the fibers along the area being cut would be dragged through the soil by the advancing edge of the sampling tube. Hence, the smaller specimen, after extraction, would sometimes have voids and striations along the sides where the fibers were pulled out.

Tests were conducted on the least damaged of the prepared specimens. The results of the tests conducted on 2-in.-diam specimens are shown in Figures 47 through 50. Based on these results, the inclusion of fibers has no apparent effect on the unconfined strength of the clay. Figures 47 and 48 indicate that the addition of fibers to soils with a PI of 30 and 60 slightly decreases the ultimate strength of the specimens. This decrease in strength may be related to the poor quality of the extracted specimens containing fibers. However, the addition of fibers to the soil with a PI of 100 resulted in an increase in strength (Figure 49).

In one set of tests, 10 percent sand (poorly graded, USCS classification SP) by dry weight of the clay was added to see if increasing the friction angle of the specimen under undrained conditions (i.e., rapid loading) would improve the effect of the fibers in the soil. Figure 50 shows that once again, a slight decrease in strength was seen with the inclusion of fibers.

In order to see if the size of the specimen had an influence on the effectiveness of the fibers, a set of tests was run on a larger specimen with a 7.62-cm (3-in.) diam. Figure 51 shows that the results obtained were quite similar to those tests conducted on 5.08-cm- (2-in.-) diam specimens. The soils with fibers included showed a decrease in strength. The ultimate strength was quite similar for the 5.08-cm and 7.62-cm (2-in. and 3-in.) specimens. At a fiber content of 0.1 percent, the specimens failed at a stress of $140.7 \mathrm{pscm}$ ( $55.4 \mathrm{psi}$ ) and $133 \mathrm{pscm}$ ( $52.4 \mathrm{psi}$ ), respectively; at a fiber content of 0.3 percent, the specimens failed at $140.7 \mathrm{pscm}$ (54.4 psi) and $134.1 \mathrm{pscm}$ (52.8 psi), respectively. 


\section{Natural soils}

Unconfined compression tests were attempted with two of the natural soils, but due to problems with specimen preparation, no worthwhile results were obtained. The same problems encountered in preparing and extracting specimens with the synthetic clays were encountered with the natural clays.

\section{Spin Test Results}

\section{Laboratory-prepared soils}

This series of tests showed that the inclusion of fibers had very little effect on surface degradation due to water erosion. Figures 52 through 54 show the percent of material remaining (i.e, the percent of the specimen not eroded away) versus time for each soil tested.

\section{Natural soils}

Figures 55 through 57 show the results of the spin test for the three natural soils tested. The inclusion of fibers led to a slight decrease in the amount of soil eroded for the Silver Creek $(\mathrm{PI}=16)$ and Dallas $1(\mathrm{PI}=49)$ specimens, but for the Dallas $2(P I=27)$ specimen the inclusion of fibers showed no effect. Generally, the erosion resistance of a soil increases with an increase in PI. However, there are numerous variables such as type and amount of cations, composition of soil (percentage of sand, silt, clay), type and amount of clay mineral (kaolinite, illite, montmorillonite) which can influence the erodibility of a natural soil (Perry 1975).

\section{Tension Test Results}

Several problems were encountered during the preparation and testing of the tensile specimens. First, there was some difficulty with compacting the soil into the tensile fixture. The removable side pieces, which held the two halves of the fixture together during specimen preparation, were not able to withstand the force that was necessary to compact the soil to a high density. During the compaction process, the side pieces would either be forced out of place or the pins holding the side piece and locking the two halves of the fixture together would break, thereby allowing the fixture to split apart prior to testing. Preparing a uniformly compacted, intact specimen was very difficult. This problem was solved by manufacturing a clamp that would hold the fixture firmly together, thus making the fixture strong enough to withstand the blows needed to compact the soil.

A second problem arose in testing the specimens. The fixture, designed to fit into the direct shear testing machine for loading purposes, had a tendency to rotate during the test. Rotation of the specimen changes the type of failure 
being considered; uniaxial tensile strength is no longer being measured if the specimen is rotating. This problem was difficult to fix without completely redesigning and manufacturing new tensile fixtures. Attempts were made to eliminate the rotation of the existing tensile fixtures, but in many of the tests conducted, some rotation still occurred.

The results that are presented here are from the few, most successful tests for which it is felt that very little to no rotation occurred.

\section{Laboratory-prepared soils}

The results of the tensile tests conducted on the laboratory-prepared soils are summarized in Table 13. From these results, which are an average of at least two test results for each soil type at each fiber-content level, it can be seen that for the hand-mixed soils the inclusion of fibers increases the tensile strength of the soil. Due to the small quantity of tests conducted and the uncertainty of the results of the test, the increase in tensile strength could not be quantified with confidence; however, a definite trend can be seen in the results and was observed during the testing. Another effect of fiber inclusion can be seen from plotting the tensile stress versus the elongation of the specimen as shown in Figures 58 through 63 . These plots show that the fibers provide strength to the soil after large displacement (i.e., after a tension crack has formed). Specimens with no fibers would reach a peak strength and then the strength dropped to zero; specimens containing fibers would reach a slightly higher peak strength and then gradually lose strength as the fibers would be pulled out of the soil. (This simulated mechanism is similar to a pullout test used for geosynthetics, for example, to assess their tensile reinforcement contribution).

Tensile tests were also conducted on soil that was prepared using the machine-mixed method to see if the uniformity of the soil-fiber mix had an effect on the tensile strength of the soil. As seen in Table 13, a slight increase in the tensile strength occurred for the soils with a PI of 30 and 100, but for the soil with a PI of 60 , there was no increase in the strength. Once again, the problems with the testing fixture must be noted when interpreting these results. Based on visual observations of the tests, it would be concluded that the machine-mixed samples had a tensile strength that was the same or slightly higher than the hand-mixed samples.

\section{Natural soils}

Table 14 summarizes the results of the tensile tests on the four natural clays. These results reinforce the results of the tests on the laboratoryprepared soils; the inclusion of fibers causes a slight increase in the tensile strength of soil. Plots of the stress versus elongation reveal similar results; the specimens containing fibers had some residual strength due to the fibers holding the two pieces of the cracked specimen together, while those containing no fibers would break along the induced tensile crack with the contribution of the soil's tensile strength disappearing abruptly. 


\begin{tabular}{|c|c|c|c|}
\hline \multicolumn{4}{|c|}{$\begin{array}{l}\text { Table } 13 \\
\text { Tension Test Results for Laboratory-Prepared Soils }\end{array}$} \\
\hline \multirow[b]{2}{*}{ Plasticity Index } & \multirow{2}{*}{$\begin{array}{l}\text { Fiber Content } \\
\text { Percent }\end{array}$} & \multicolumn{2}{|c|}{ Tensile Strength, psi' } \\
\hline & & Hand-Mixed & Machine-Mixed \\
\hline \multirow[t]{3}{*}{30} & 0 & 1.50 & 1.75 \\
\hline & 0.1 & 1.69 & 2.29 \\
\hline & 0.3 & 1.69 & 2.59 \\
\hline \multirow[t]{3}{*}{60} & 0 & 2.85 & 1.80 \\
\hline & 0.1 & 3.62 & 3.05 \\
\hline & 0.3 & 4.16 & 2.38 \\
\hline \multirow[t]{3}{*}{100} & 0 & 1.01 & 1.10 \\
\hline & 0.1 & 2.40 & 3.54 \\
\hline & 0.3 & 5.30 & 5.56 \\
\hline
\end{tabular}




\begin{tabular}{|c|c|c|c|}
\hline \multirow[b]{2}{*}{ Clay } & \multirow[b]{2}{*}{ Fiber Content Percent } & \multicolumn{2}{|c|}{ Tensile Strength, psi ${ }^{1}$} \\
\hline & & Hand-Mixed & Machine-Mixed ${ }^{2}$ \\
\hline \multirow[t]{3}{*}{ Silver Creek $(P I=16)$} & 0 & 2.86 & - \\
\hline & 0.1 & 3.76 & -- \\
\hline & 0.3 & 3.14 & .. \\
\hline \multirow[t]{3}{*}{ Yazoo $(P \mid=60)$} & 0 & 2.03 & -- \\
\hline & 0.1 & 2.10 & -. \\
\hline & 0.3 & 2.82 & -- \\
\hline \multirow[t]{3}{*}{ Dallas $1(P \mid=49)$} & 0 & 1.54 & -- \\
\hline & 0.1 & 1.44 & -- \\
\hline & 0.3 & 2.53 & -. \\
\hline \multirow[t]{3}{*}{ Dallas $2(P I=27)$} & 0 & 1.58 & -- \\
\hline & 0.1 & 2.39 & -- \\
\hline & 0.3 & 2.29 & -- \\
\hline
\end{tabular}




\section{Interpretation of Results}

\section{Effect of Fibers}

\section{Effect of fibers on crack development as a function of PI}

The tendency of cracks to develop in clays without any added fibers increases with an increase in the PI of the clay. This trend was supported by visual observations, as well as the percent cracking measurements. However, for clays containing fibers, this trend was not consistent. For the hand-mixed soils at a dosage of 0.3 percent fibers, the amount of cracking did not increase for clays with a PI ranging from 50 to 100 . This trend is evident for drying cycles 1 and 2, and was observed visually during the tests. It is reasonable to assume that the depth of crack penetration is related to the width of the crack at the surface (i.e., the wider a crack is at the surface, the deeper it penetrates into the clay). Hence, a fiber content of 0.3 percent decreased the depth of crack penetration. Visual observation revealed that the addition of fibers caused numerous small cracks to develop; however, these cracks were surficial, extending less than 1 in. into the clay.

Machine mixing of the soil provided a more uniform mixture with the fibers spread open and dispersed. This had a slight effect on the cracking results. Less cracking occurred with the machine-mixed samples over a range of plasticities. In addition, the amount of cracking that occurred decreased with an increasing PI when fibers were included in the soil.

Therefore, when mixed uniformly with clay, the fibers are most effective at reducing the depth of desiccation cracking in high plasticity clays.

\section{Effect of fibers on crack development as a function of wet/dry cycles}

For the clay without fibers, the size and number of cracks was higher in drying cycles 2,3 , and 4 than for drying cycle 1 . The results of drying cycles three and four were quite similar indicating that, for this index test, no substantial change occurs in the specimens after three drying cycles. This same trend was seen for the clay containing fibers. In fact, for some of the specimens in drying cycles 3 and 4 , the clay containing fibers cracked just as much or more than the clay with no fibers. Furthermore, the degree of uniformity of 
mixing had no effect on this result; the hand-mixed and machine-mixed samples showed similar results. Therefore, the fibers were not effective in decreasing the amount of crack propagation due to wet/dry cycling.

It again should be noted that the test method used here was not intended to model an earth structure in the field. The test was simply used as an index test to compare the performance of a given clay sample under certain, easily repeatable conditions that might be similar to those encountered in the field. These wet/dry cycles represent a period of heavy rainfall followed by dry spells. To fully understand the effect that fibers may have on crack development in an embankment, a different type of test would have to be conducted.

\section{Effect of fibers on volume change associated with shrink/swell}

The inclusion of fibers had no consistent effect on the shrink/swell potential of the different clays. The uniformity of the mix, the plasticity of the clay, and the number of wet/dry cycles had no effect on the results.

\section{Effect of fibers on the unconfined strength of clay}

The inclusion of fibers had no apparent effect on the unconfined strength of the clay. However, the small quantity of tests conducted and the quality of the specimens prepared must be considered in making this conclusion.

\section{Effectiveness of fibers in reducing clay surface disintegration due to erosion}

The inclusion of distinct fibers, at any dosage level, had no consistent effect on the amount of soil that disintegrated due to water erosion.

\section{Effect of fibers on the tensile strength of clay}

The inclusion of fibers increased the tensile strength of the clays throughout the range of plasticities. For these tests, the uniformity of the mix was important; for laboratory prepared soils, the machine-mixed samples showed a slight increase in strength over the hand-mixed samples.

Another effect of fiber inclusion on the tensile strength of clay was the way in which the clay failed. Specimens with no fibers would reach a peak strength, fail abruptly (i.e., form a crack), and quickly loose strength. The specimens containing fibers exhibited ductile behavior after the specimen cracked at a peak strength. This was due to the fibers mobilizing their tensile resistance in holding the two parts of the cracked specimen together.

Due to limitations of the specimen preparation and testing methods, the tension tests were not performed on specimens that had undergone wet/dry cycling. Therefore, the results presented in the previous chapter only represent the 
effect of the fibers on clay that has not undergone cycling and desiccation cracking.

\section{Optimal Fiber Content}

In this study, tests were conducted using fiber content levels of 0.1 percent, 0.3 percent, and in a few cases, 1.0 percent. Based on the tests conducted and results presented in the previous chapter, the optimal fiber content is 0.3 percent of the dry weight of the soil. This dosage level provided the best combination of workability, increase in tensile strength, and effectiveness in reducing the amount of desiccation cracking.

\section{Relevance of Synthetic Clay Test Results to Natural Clays}

In order to generalize the results of this research, some of the tests conducted using laboratory prepared clays were repeated using natural clay samples. For all of the tests, very similar trends are seen for both the synthetic clays and the natural clays. Therefore, it can be concluded that the more extensive experiments conducted on the wide range of plasticities of synthetic clays are relevant to clays that may be encountered in the field.

\section{Investigation of the Effectiveness of the Fibrillated Fiber Structure}

The effectiveness of the fibrillated fibers depends upon how the fibers interact with different clays. The mechanism by which the fibrillated fibers interact with the soil at low normal stresses is purely adhesion. Cracks develop at and near the soil surface and therefore there is negligible overburden pressure and little frictional resistance can occur between the fiber and the soil, even under drained conditions. Therefore, when a tensile force is applied to the fibers, such as that which occurs as a drying clay shrinks and desiccation cracks develop, the only mechanism that allows the fibers to develop pull out resistance is adhesion. The amount of adhesion that occurs for each fiber is related to the surface area of the fiber. The surface area of fibers intersecting a potential crack is quite small; hence, not much tensile force is needed to overcome the adhesion and pull the fiber out of the soil. Thus, the tensile strength of the fiber itself is not being taken advantage of because the tensile force in the fiber can never increase beyond the adhesion that it forms with the soil. In other words, the tensile resistance or anchorage strength that the smooth, short fibers could develop in clay is quite small, especially when compared with the tensile strength of the fibers. 
To increase the tensile resistance of the fibers mixed in the soil and thus further reduce the crack formation, there needs to be a better interaction between the fibers and soil. The frictional resistance cannot be increased because when fibers are used near the surface of an embankment, little overburden pressure would be present. The adhesion between the fiber and soil could be raised by increasing the surface area of each fiber by making them wider or longer. Such fibers were not available and therefore could not be tested. Another way of improving the interaction would be to use a fiber that resists pullout by having cross pieces connecting several fibers, as in a grid formation. For this type of fiber to be pulled out of the clay, the soil in front of the cross pieces would need to move in order to allow the longitudinal fibers to move; consequently, soil passive resistance in front of the cross pieces would need to be overcome. In this mechanism, therefore, bearing capacity due to the cohesive strength of the soil is being employed in addition to the adhesion between the fibers and soil.

In order to test this hypothesis, a small grid-like fiber was created using fine mesh charcoal fiberglass window screening material. The screen was cut into pieces with a length of $2.54 \mathrm{~cm}$ ( 1 in.) (the same as the fibrillated fibers) and a width of $0.5 \mathrm{~cm}(0.20 \mathrm{in}$.) as shown in Figure 64 . At this width, each "screen fiber" had three to four longitudinal fibers connected by 16 to 17 cross pieces. These screen fibers were then used for a series of cracking/volume change tests and tension tests, conducted in the same manner as the tests with the fibrillated fibers.

The screen fibers had a density of approximately three times that of the fibrillated polypropylene fibers. Therefore, in order to allow some comparison between the results of these tests with the previously presented results, a dosage of 0.3 percent by weight of screen fibers was used as an equivalent to the dosage of 0.1 percent by weight of fibrillated fibers; similarly, a dosage of 0.9 percent of screen fibers was assumed to be comparable to 0.3 percent by weight of fibrillated fibers. These dosages produced about the same number of reinforcing fibers for both the screen fiber and the fibrillated fiber samples. All screen fiber tests were conducted with machine mixed laboratory prepared soil with a PI of 60 .

The results of the cracking test (Table 15) indicated that with the inclusion of the screen fibers, both the percent cracking and the average crack width were less than that for the specimens with the fibrillated fibers.

The tension test results (Table 16) showed that the inclusion of screen fibers increased the tensile strength of the soil by approximately the same amount as the fibrillated fibers did.

Based on these results, the screen fibers are more effective at decreasing the amount of desiccation cracking and increasing the tensile strength of the clay than the fibrillated fibers. This indicates that the design of the fibrillated fibers could be modified and optimized to better interact with clays. 
Table 15

Comparison of Cracking Test Results Using Screen Fibers and Fibrillated Fibers: $\mathrm{PI}=60$, Drying Cycle 1

\begin{tabular}{||l|l|l|l|l|l|l||}
\hline \multirow{2}{*}{$\begin{array}{l}\text { Fiber } \\
\text { Content } \\
\text { Percent }\end{array}$} & \multicolumn{2}{|c|}{ Screen Fibers } & \multicolumn{4}{c|}{ Fibrillated Fibers } \\
\cline { 2 - 7 } & $\begin{array}{l}\text { Percent } \\
\text { Cracking }\end{array}$ & $\begin{array}{l}\text { Average } \\
\text { Crack } \\
\text { Width (in. }{ }^{1} \text { ) }\end{array}$ & $\begin{array}{l}\text { Percent } \\
\text { Cracking }\end{array}$ & $\begin{array}{l}\text { Average } \\
\text { Crack } \\
\text { Width (in.) }\end{array}$ & $\begin{array}{l}\text { Percent } \\
\text { Cracking }\end{array}$ & $\begin{array}{l}\text { Average } \\
\text { Crack } \\
\text { Width (in.) }\end{array}$ \\
\hline \hline 0.1 & 0.5 & 0.03 & 5.5 & 0.05 & 1.0 & 0.06 \\
\hline 0.3 & 0.4 & 0.02 & 4.7 & 0.05 & 0.45 & 0.06 \\
\hline \hline
\end{tabular}

\section{Table 16}

Comparison of Tension Test Results Using Screen Fibers and Fibrillated Fibers: $\mathrm{PI}=60$

\begin{tabular}{||l|l|l|l|}
\hline \multirow{3}{*}{$\begin{array}{l}\text { Fibers Content } \\
\text { Percent }\end{array}$} & \multicolumn{3}{|c|}{ Tensile Strength, psi' } \\
\cline { 2 - 4 } & Screen Fibers & \multicolumn{2}{|c|}{ Fibrillated Fibers } \\
\cline { 2 - 4 } & Hand-Mixed & Machine-Mixed \\
\hline 0.1 & 2.33 & 3.62 & 3.05 \\
\hline 0.3 & 4.57 & 4.16 & 2.38 \\
\hline \hline 1 To convert psi to kilopascals multiply by 6.8947579. \\
\hline
\end{tabular}




\section{Conclusions and Recommendations}

In the preceding chapters, research objectives were presented and an experimental program which attempted to fulfill these objectives was discussed. The primary objective was to study whether the inclusion of discrete tensile elements, specifically polypropylene fibers, could reduce the desiccation cracking and increase the strength of clays. Synthetic clays prepared under controlled laboratory conditions, as well as natural clays obtained from the field, were used to investigate the potential use of fibrillated polypropylene fibers over a range of clay plasticity. In addition, different methods of mixing the fibers and the soil were used to determine the effect of the degree of uniformity of the mix on the experimental results.

Based on the results of the testing program, it was concluded that there is some potential for the use of fibrillated fibers with clays. The fibers are effective in reducing the amount of desiccation cracking that occurs in clays subjected to drying. However, when subjected to wet/dry cycles attempting to simulate environmental conditions, the effectiveness of the fibers is not as evident. The inclusion of fibers also increased the tensile strength of the clay and provided a ductile behavior that was not present in the specimens without fibers. The best results were obtained with the fiber dosage of 0.3 percent mixed uniformly with a mechanical mixer.

The experimental results showed that fibers had no effect in reducing clay surface disintegration due to water erosion and did not increase the unconfined strength of the clay.

Modification and improvement of the testing methods used in this research may lead to improved quantification of the effects of fiber inclusion. In particular, a method of monitoring directly the depth of crack penetration would better indicate to what degree fibers reduce desiccation cracking. Improvement is also needed in the tensile test fixture in order to consistently assure that only uniaxial tensile loads (and not rotational loads) are being applied.

Additional testing is also necessary to better understand the effect of fiber inclusion on desiccation cracking of clayey earth structures. Tests that better model the structure and its exposure to environmental conditions would provide valuable information about the performance of the fibers. Field testing, such 
as a clay embankment constructed with sections containing different fiber contents, is necessary to verify the laboratory results.

The effectiveness of the fibers in strengthening the soil and reducing desiccation cracking is limited by the mechanism by which each fiber interacts with the soil. This was demonstrated through the use of grid-like screen fibers, that interacted better with the soil and were developed for demonstration purposes by the researchers. This screen fiber was more effective at reducing the amount of cracking and increasing the tensile strength of the clay than the fibrillated fiber. Thus, the usefulness of the fibrillated fiber might be improved if it could interact more effectively with clays that are subjected to negligible overburden pressure.

It is recommended that the structure of the fibrillated fibers be optimized through further research. Longer fibers with a different texture or surface coating may provide better adhesion between the fiber and the soil and thus increase the tensile resistance to pull the fiber out of the soil. This optimization study should involve using a modified tensile strength fixture that would eliminate the possibility of rotation occurring during the test. 


\section{References}

Al Wahab, R. M., and Al-Qurna, H. H. (1995). "Fiber reinforced soils for application in earth structures." Proceedings of Geosynthetics 95. Nashville, TN.

Al Wahab, R. M., and El-Kedrah, M. M. (1995). "Using fibers to reduce tension cracks and shrink/swell in compacted clays." Proceedings of Geoenvironment 2000. New Orleans, LA.

Al Wahab, R. M., and Heckel, G. B. (1995). "Static and dynamic strength properties of a fiber-reinforced compacted cohesive soil." Proceedings of the 3rd International Conference on Recent Advances in Geotechnical Earthquake Engineering and Soil Dynamics, St. Louis, MO. Vol 3.

American Society for Testing and Materials. (1992a). "Laboratory compaction characteristics of soil using standard effort," ASTM D698-91, Philadelphia, PA.

. (1992b). "Standard test method for liquid limits, plastic limits, and plastic index of soils," ASTM 4318-84, Philadelphia, PA.

. (1992c). "Standard method for classification of soils for engineering purposes,” ASTM 2487-90, Philadelphia, PA.

Andersland, O. B., and Khattak, A. S. (1979). "Shear strength of kaolinite/ fiber soil mixture." Proceedings of the 1st International Conference on Soil Reinforcement, Paris, France. Vol 1.

Fleming, Jr., R. L., Sills, G. L., and Stewart, Jr., E. S. (1994). "Lime stabilization of levee slopes." Proceedings of REMR Workshop on Levee Rehabilitation compiled by E. B. Perry, U.S. Army Engineer Waterways Experiment Station, Vicksburg, MS. 79-87.

Leavell, D. A., and Peters, J. F. (1987). "Uniaxial tensile test for soil," Technical Report GL-87-10, U.S. Army Engineer Waterways Experiment Station, Vicksburg, MS. 
Leshchinsky, D., Richter, S. D., and Fowler, J. (1992). "Clay lumps and simulated hydraulic transport conditions," Geotechnical Testing Journal, ASTM, 15(4), 393-98.

Maher, M. H., and Ho, Y. C. (1994). "Mechanical properties of kaolinite/ fiber soil composite," Journal of Geotechnical Engineering. 120(8), 1381-93.

Perry, E. B. (1975). "Piping in earth dams constructed of dispersive clay; Literature review and design of laboratory tests," Technical Report S-75-15, U.S. Army Engineer Waterways Experiment Station, Vicksburg, MS.

Ranjan, G., Vasan, R. M., and Charan, H. D. (1994). "Behavior of plasticfiber-reinforced sand," Geotextiles and Geomembranes, 13, 555-65.

Richter, S. (1991). "Degradation of clay under hydraulic transport conditions," M.S. thesis, University of Delaware, Newark.

Sills, G. L., Templeton, A. E., Fleming, R. L., and Cooley, L. A. (1983). "Long term strength reduction and slough slides in Mississippi River levees," Technical Report, U.S. Army Engineer Waterways Experiment Station, Vicksburg, MS.

Vallejo, L. E., and Yoo, H. (1995). "Reinforcement of fissured clays by short steel fibers," Transportation Research Record No. 1474, National Academy Press, Washington, DC. 


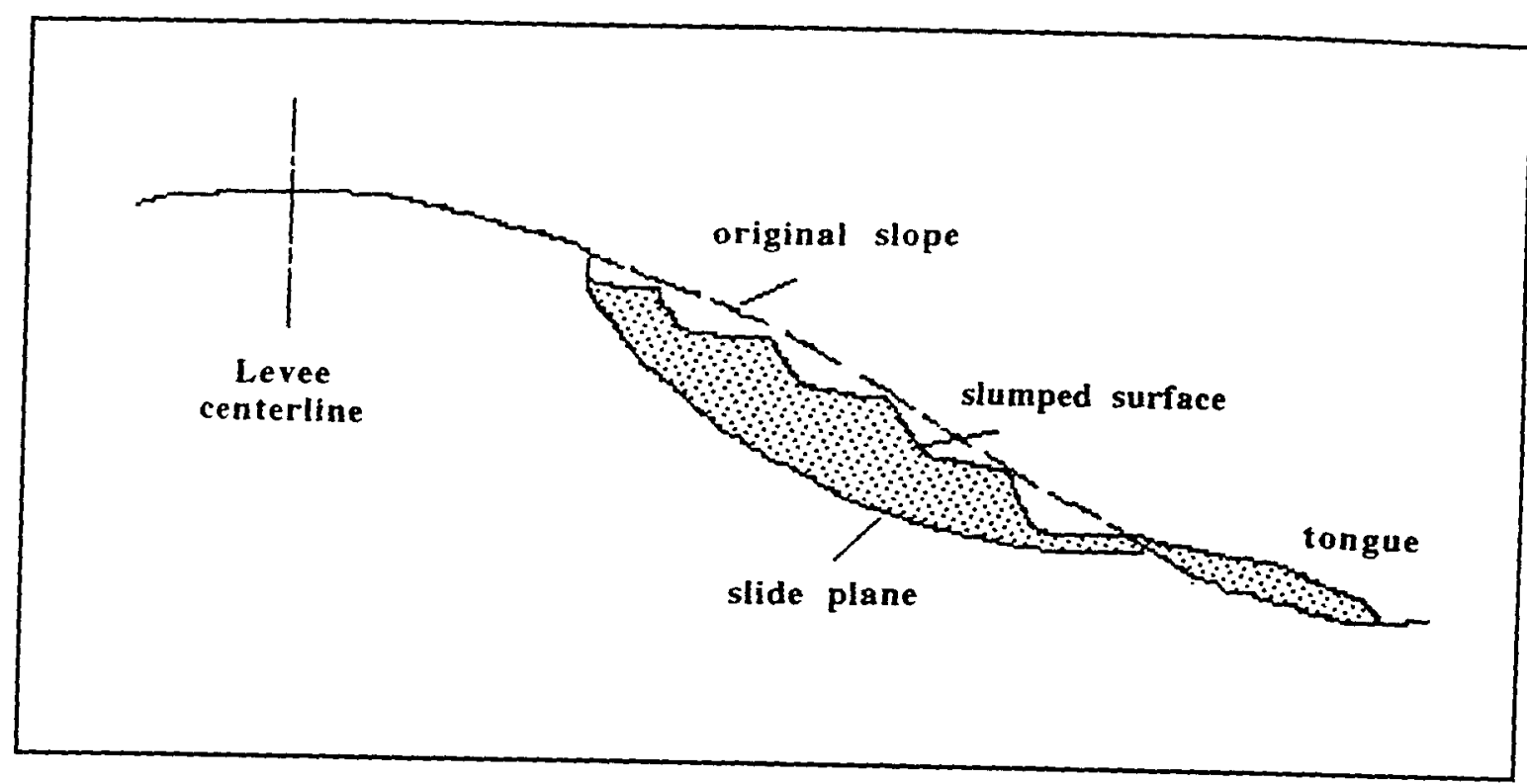

Figure 1. Typical levee failure in clay (Fleming, Sills, and Stewart 1994)

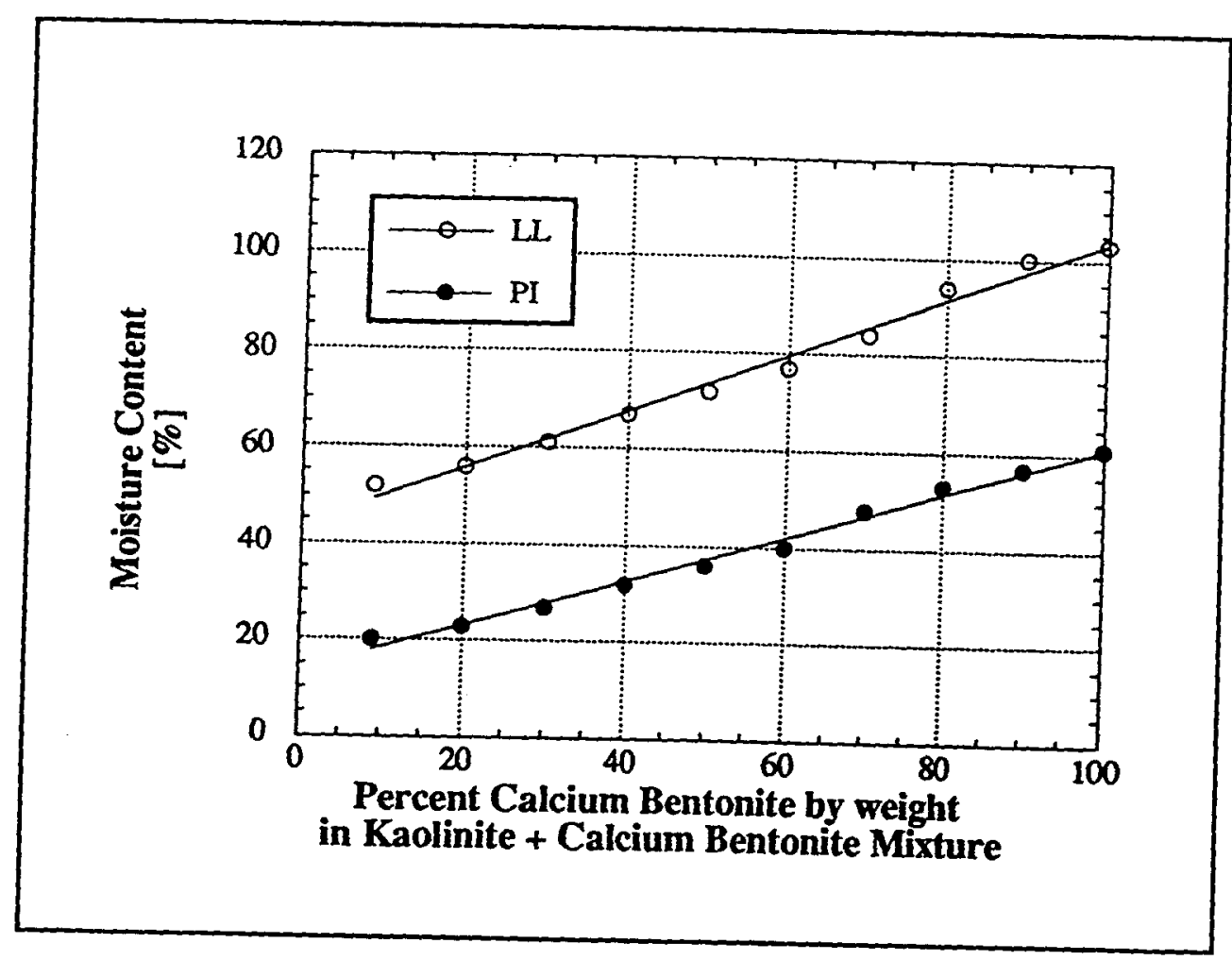

Figure 2. Liquid limit and plasticity index versus percent calcium bentonite in kaolinite and calcium bentonite mixture 


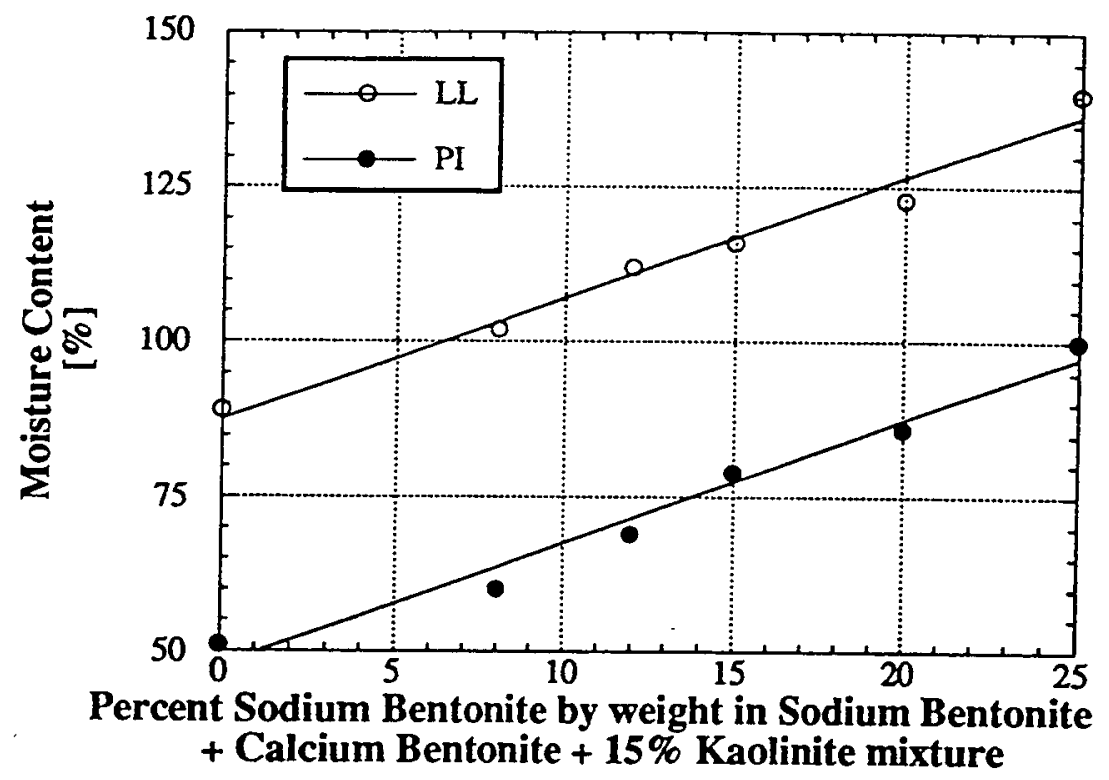

Figure 3. Liquid limit and plasticity index versus percent sodium bentonite in mixture with calcium bentonite and 15 percent kaolinite

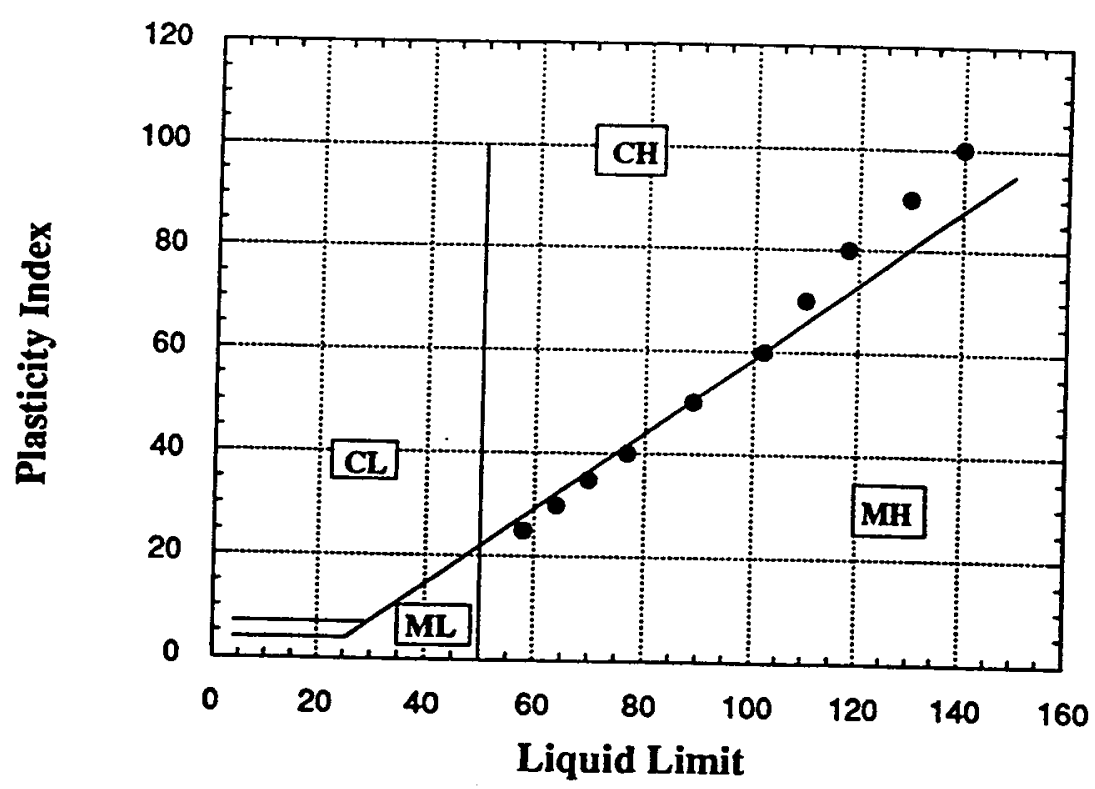

Figure 4. USCS plasticity chart classifying laboratory-prepared soils 


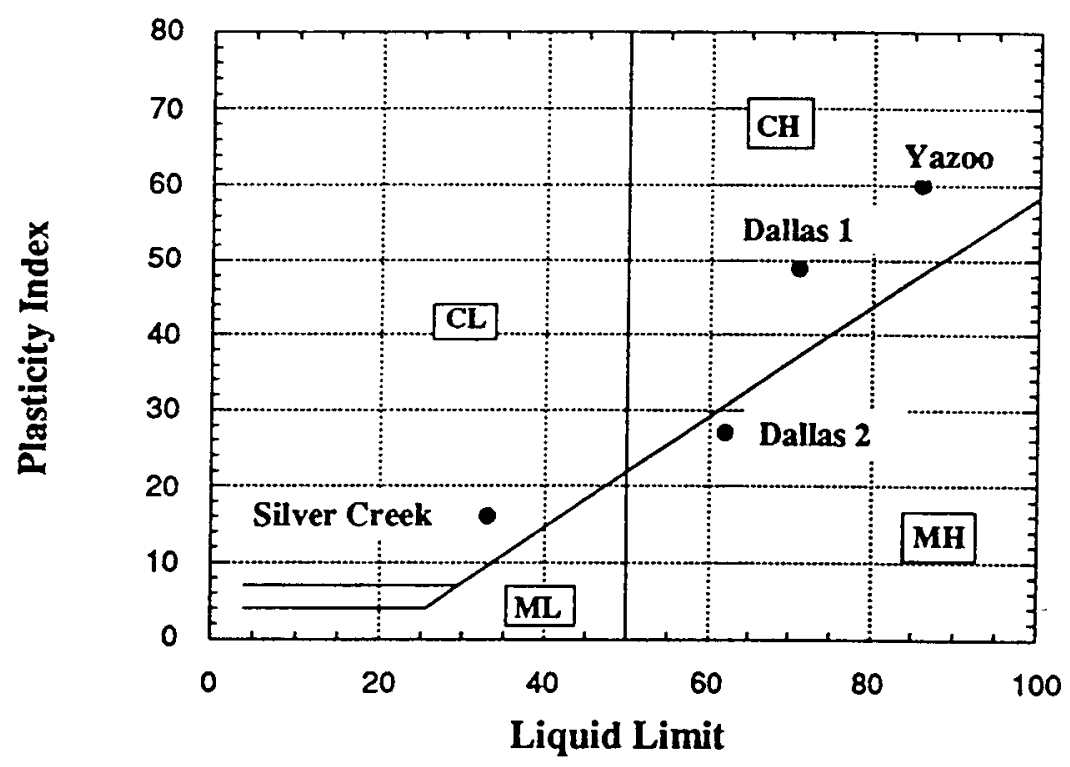

Figure 5. USCS plasticity chart classifying natural soil samples
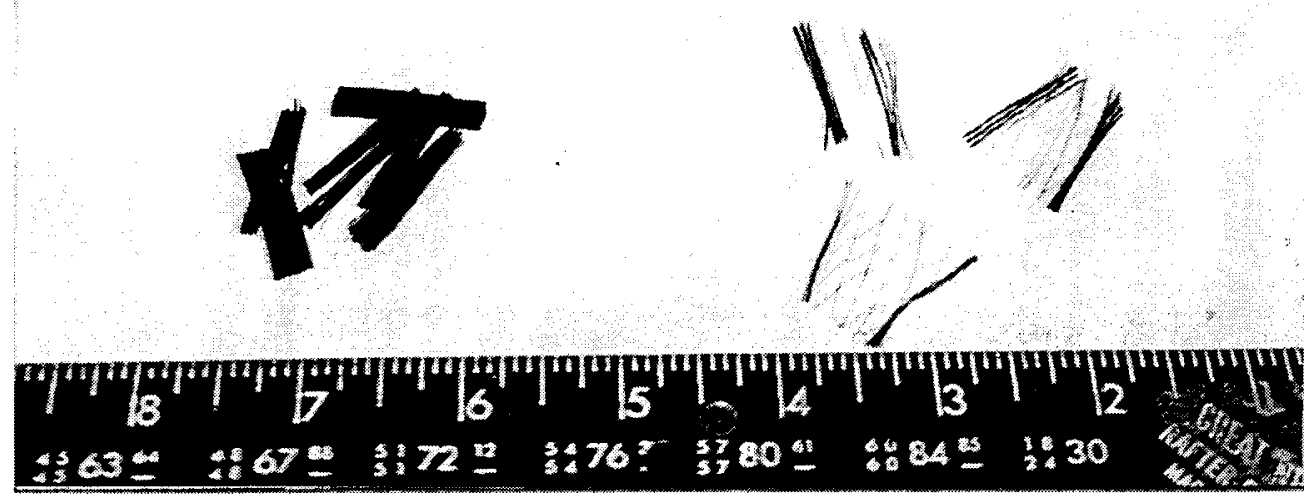

Figure 6. Fibrillated polypropylene fiber bundles 


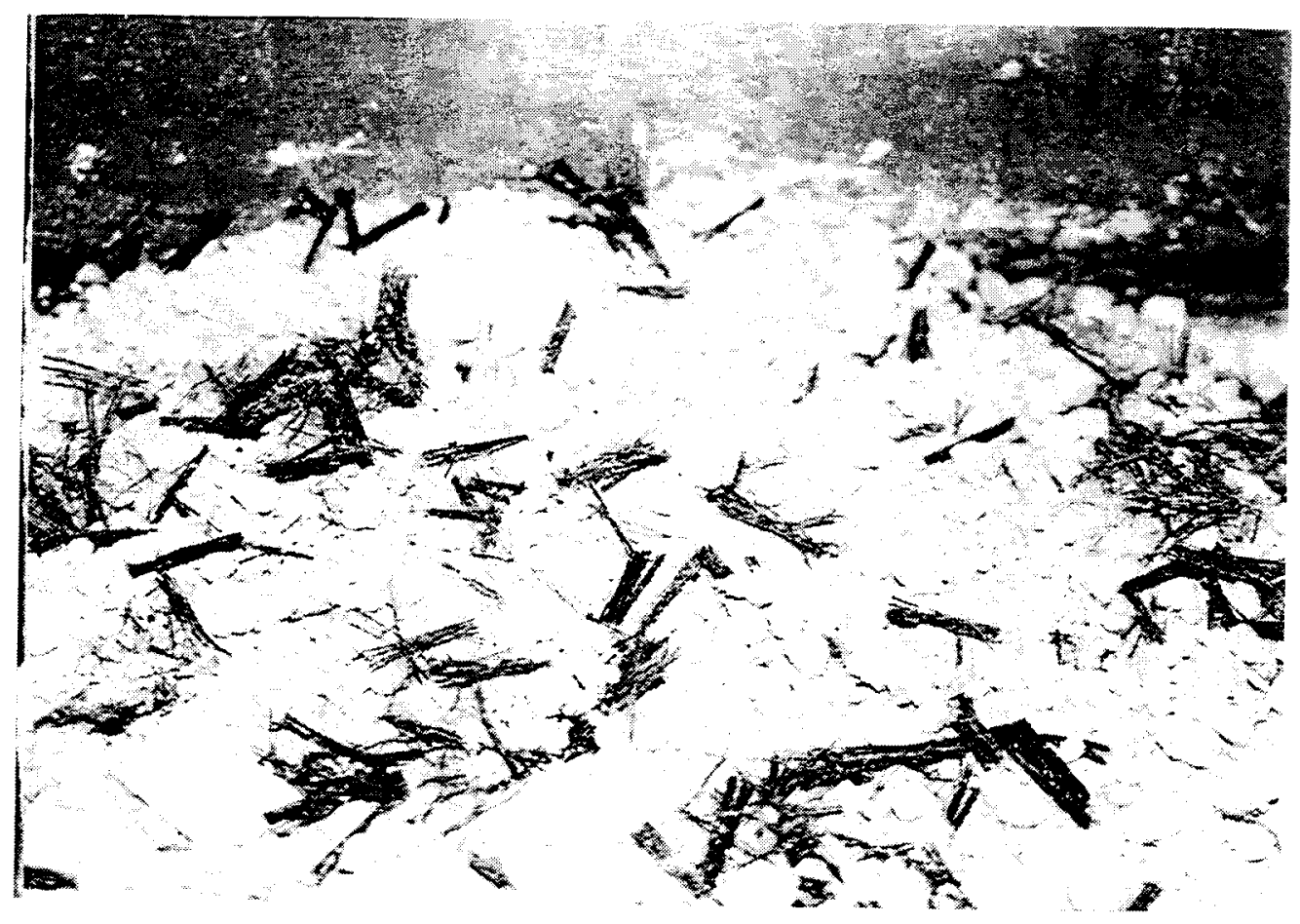

Figure 7. Hand-mixed soil with 0.3 percent fiber content 


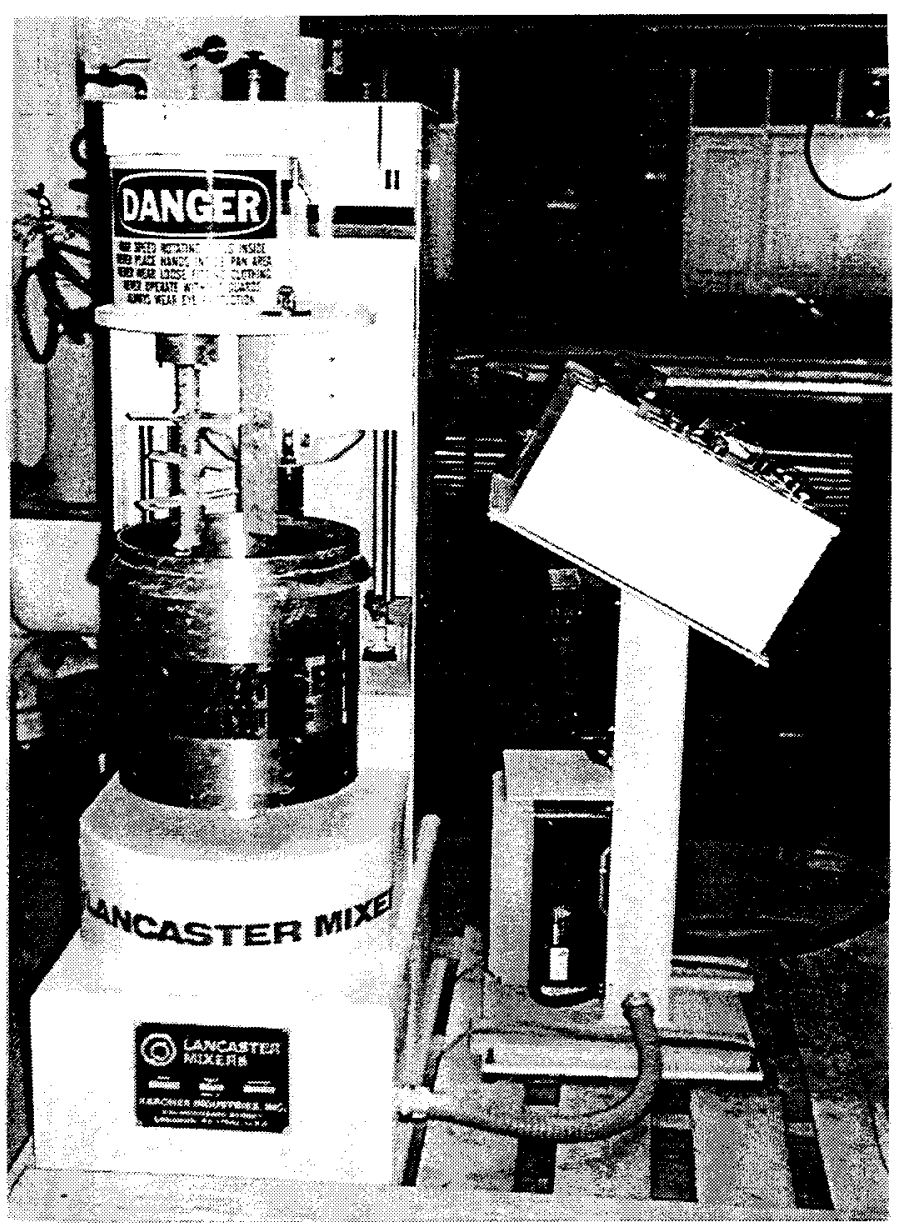

Figure 8. Lancaster K-Lab Hi-Intensive Mixer ${ }^{\circledR}$ 


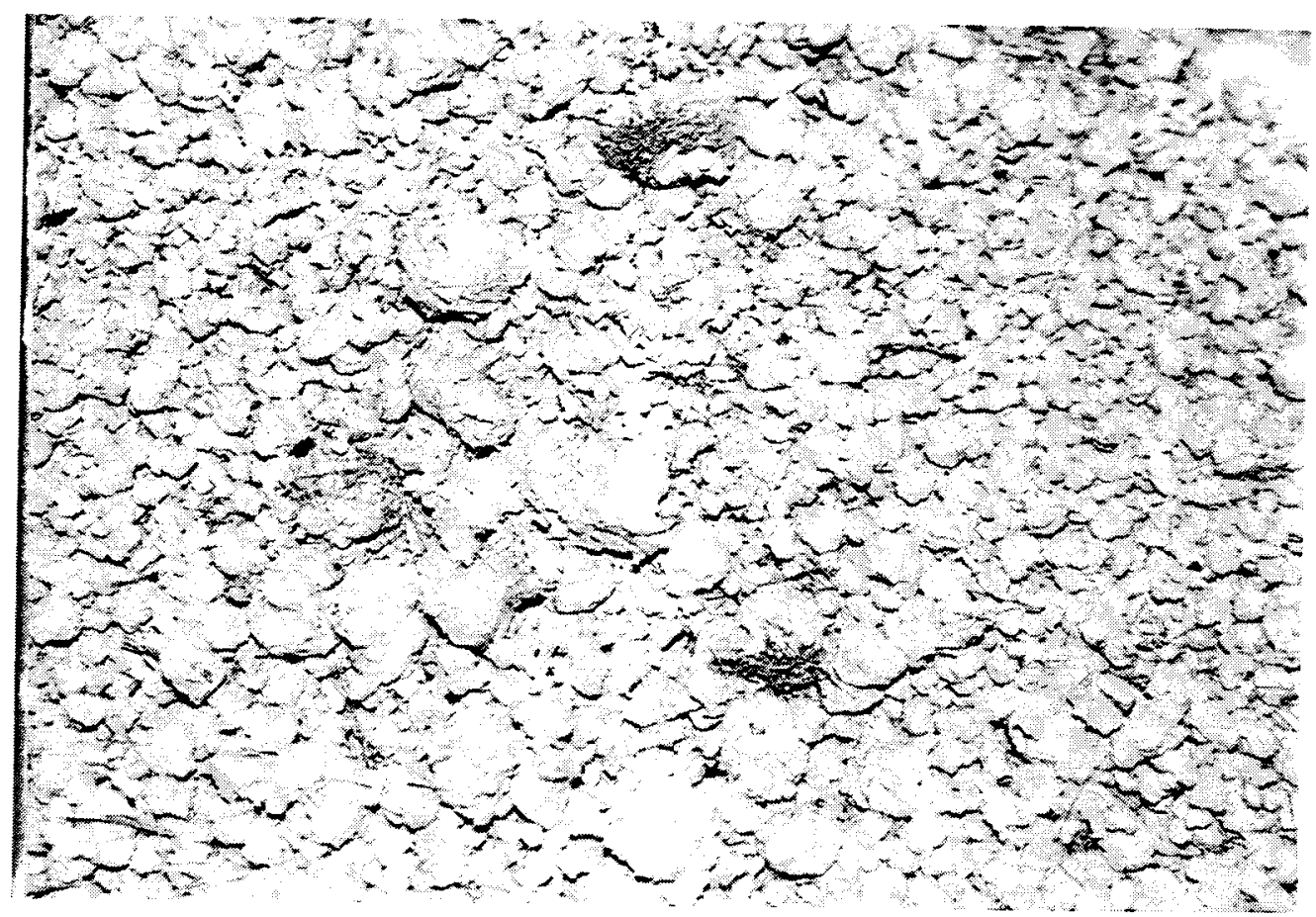

Figure 9. Machine-mixed soil with 0.3 percent fiber content 


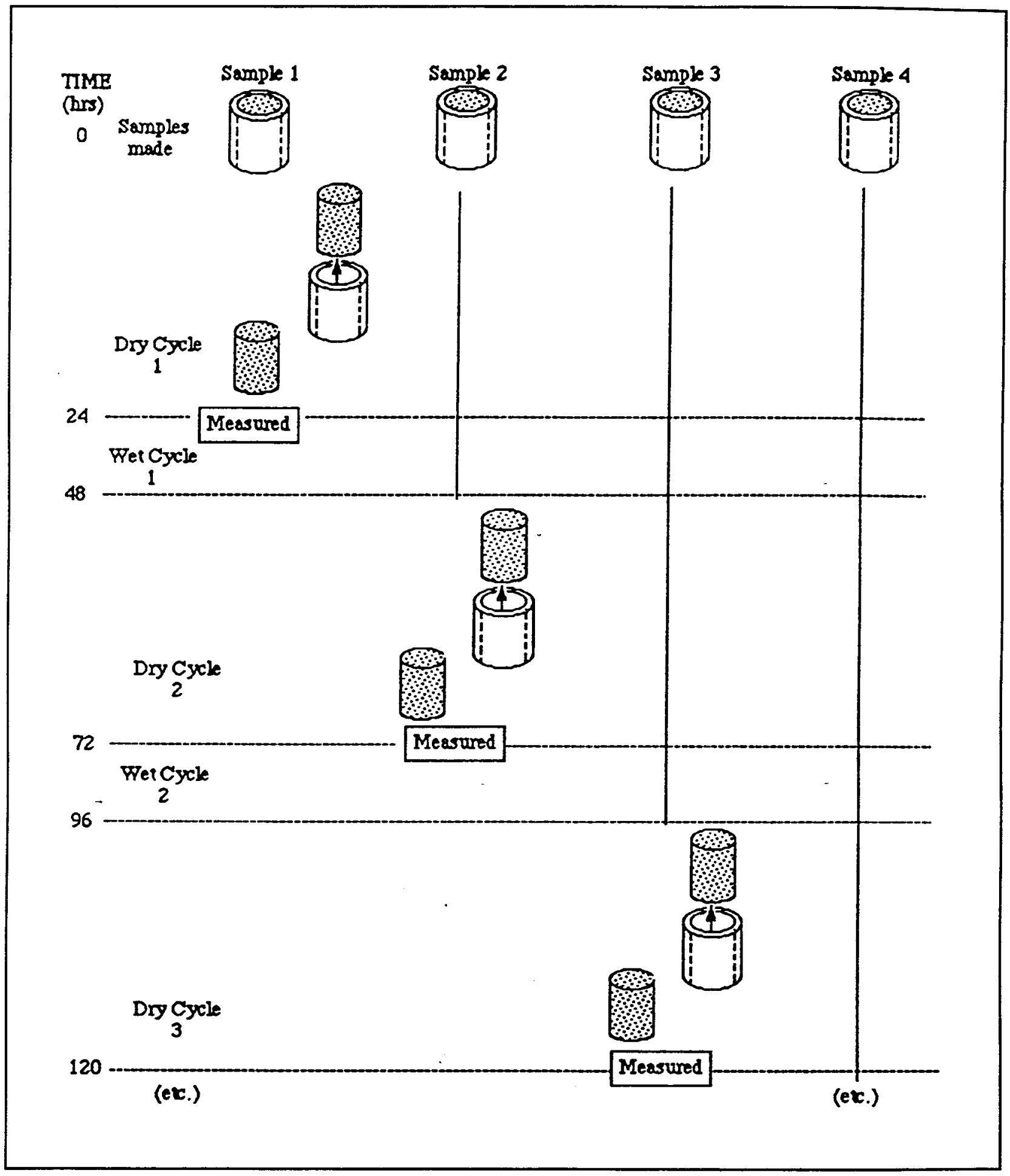

Figure 10. Schematic illustration of volume change/cracking test 


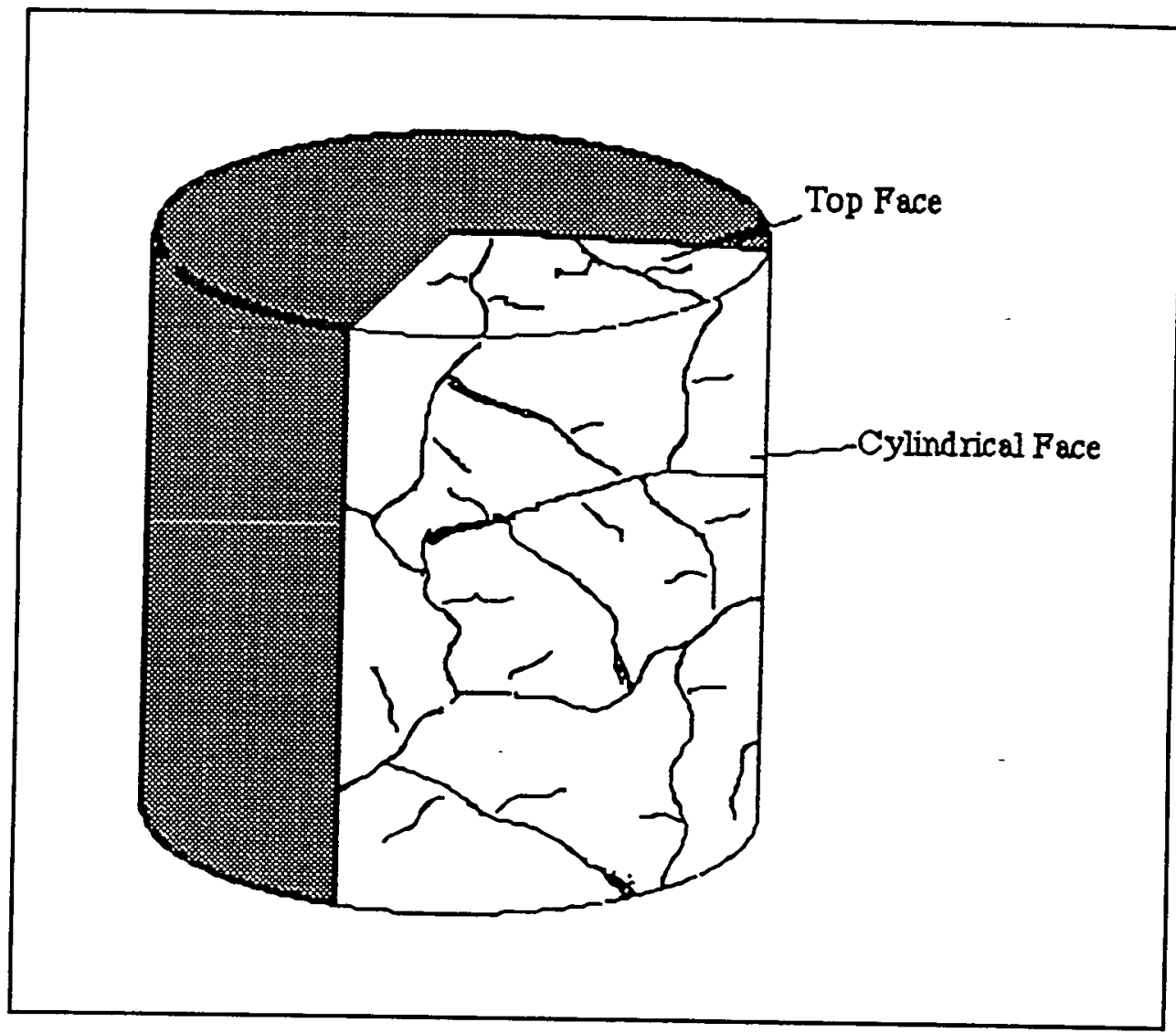

Figure 11. Measurement of cracks on quadrant of specimen 


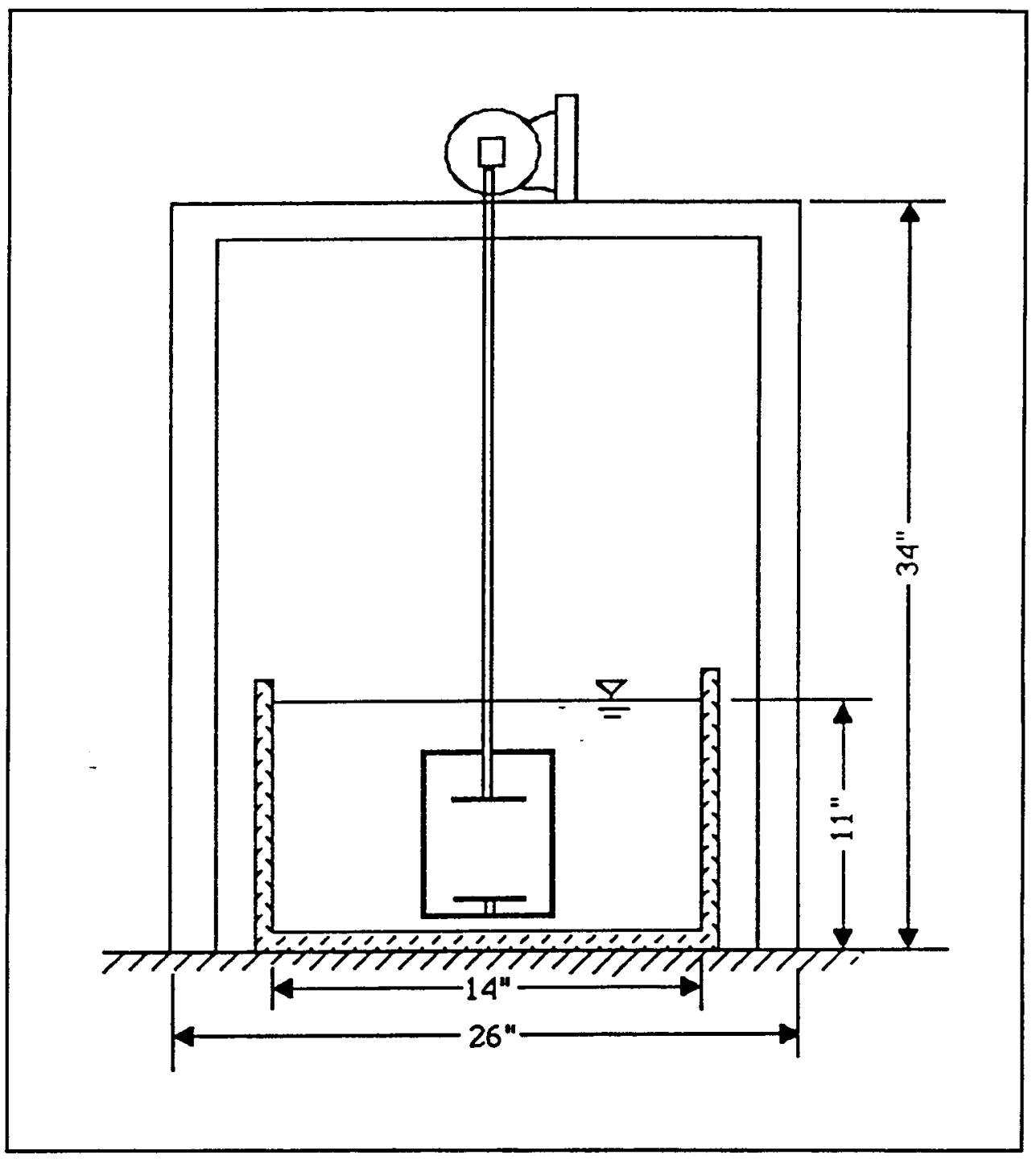

Figure 12. Spin test apparatus 


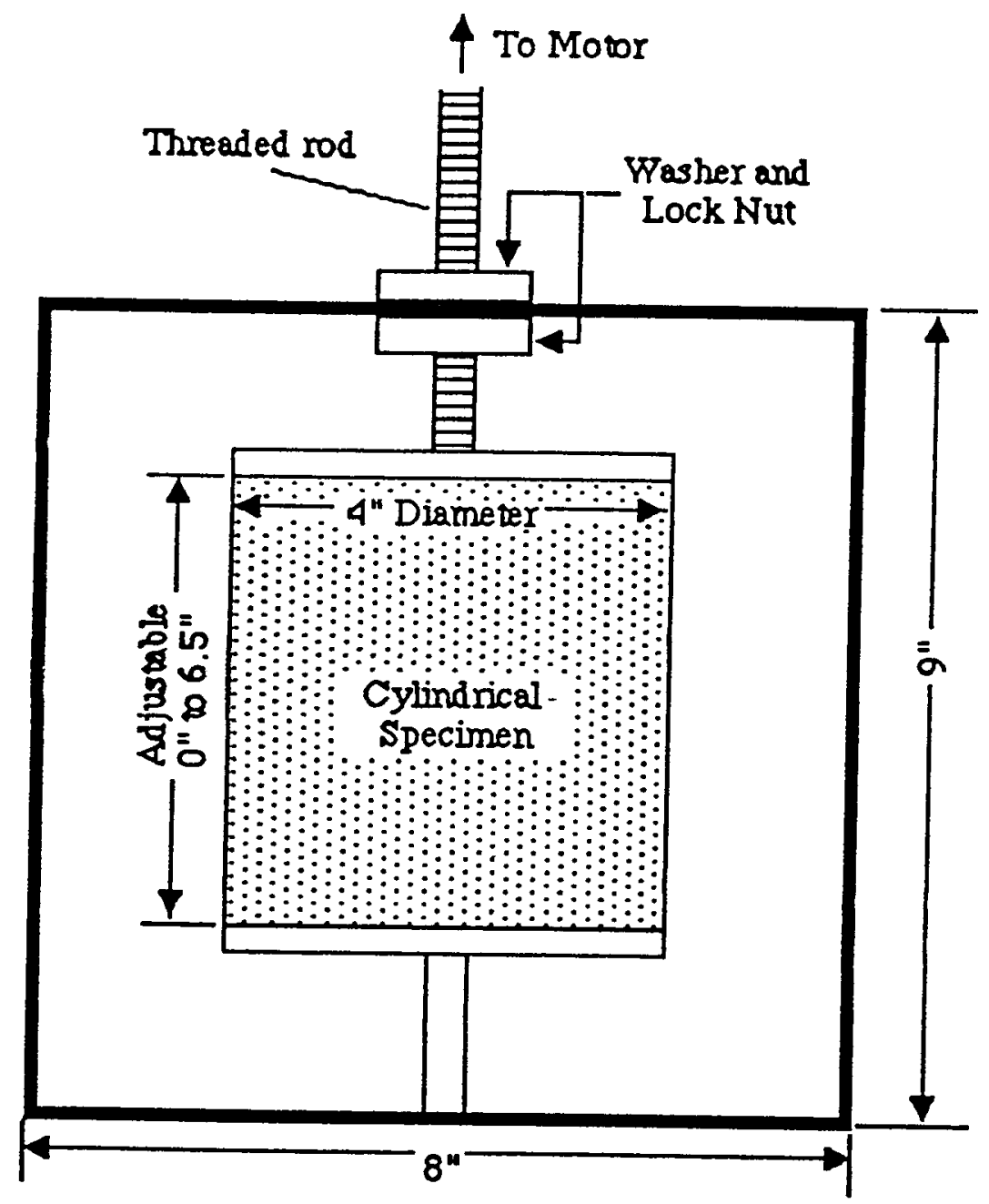

Figure 13. Spin test: specimen clamp 


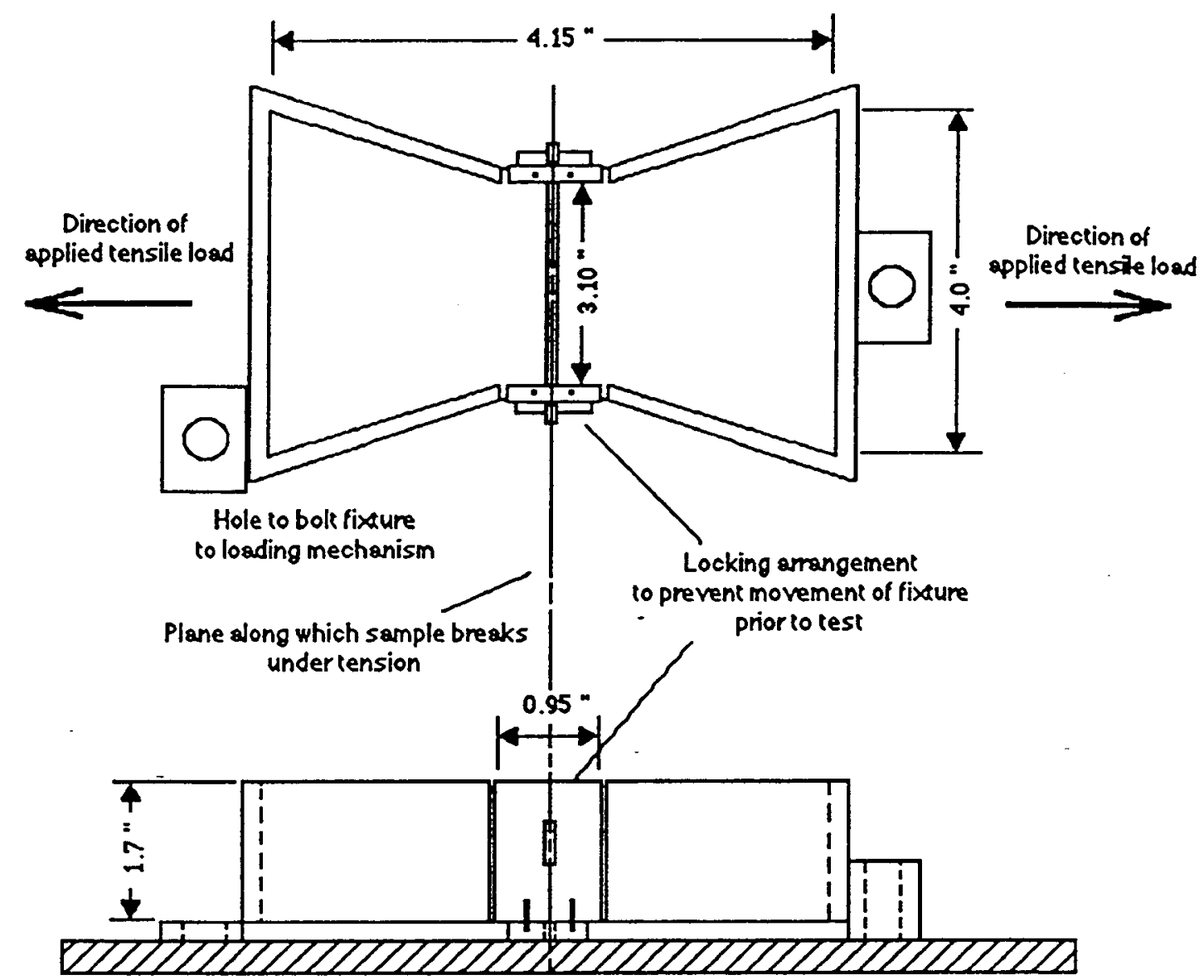

Figure 14. Tension test fixture (To convert inches to millimeters multiply by 25.4.) 


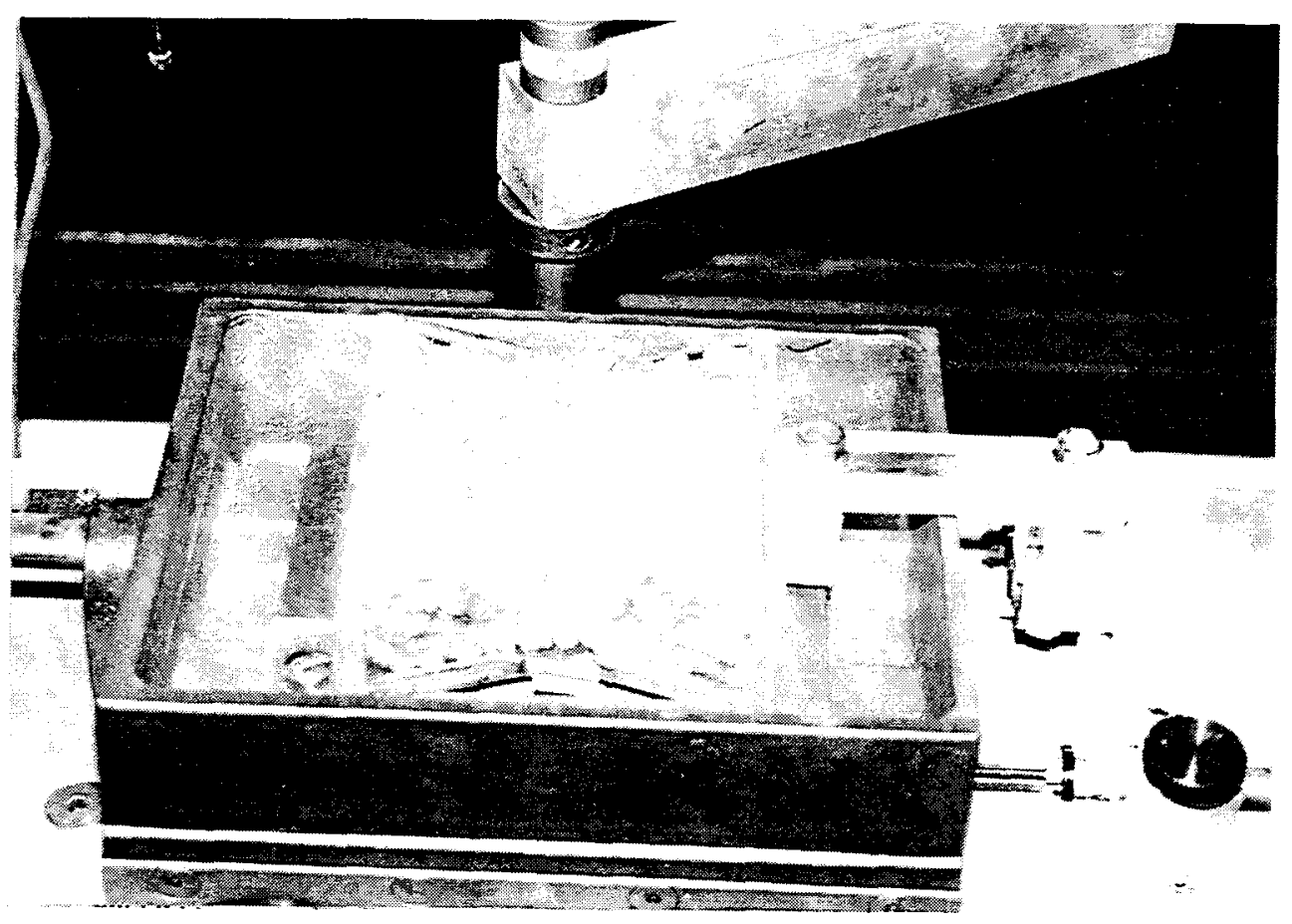

Figure 15. Tension test fixture mounted to direct shear loading mechanism

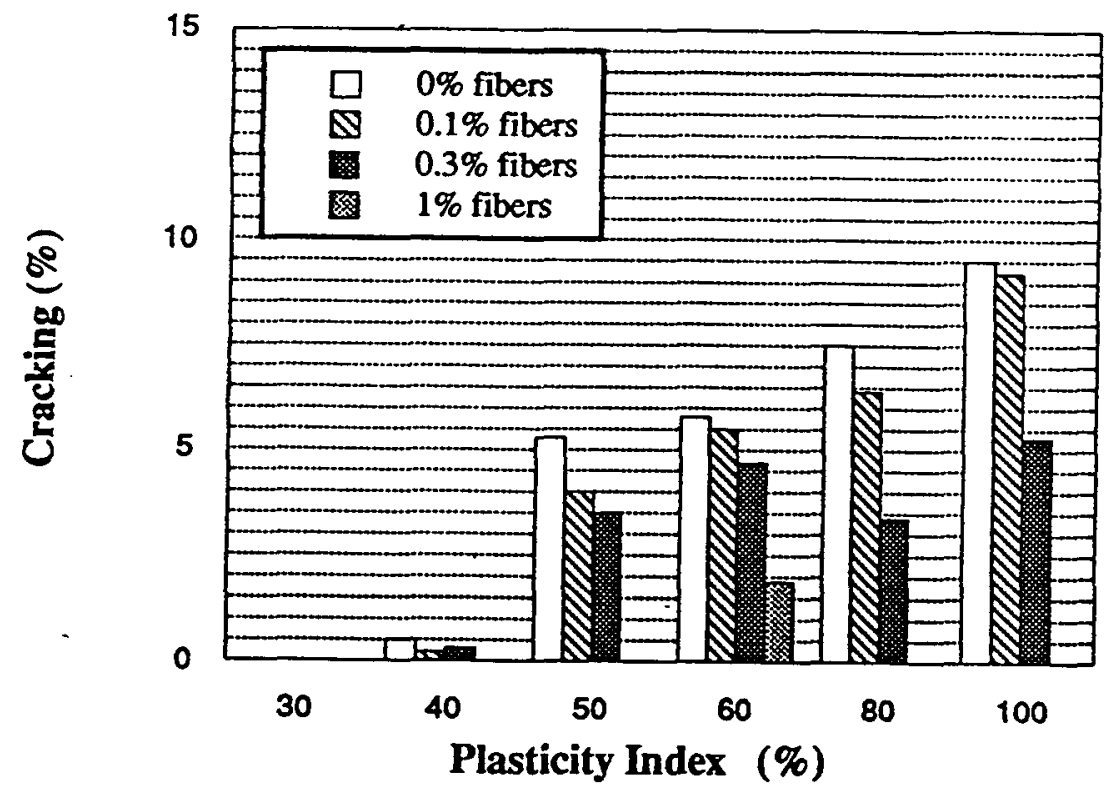

Figure 16. Cracking test results for hand-mixed laboratory-prepared soils: drying cycle 1 (1D) 


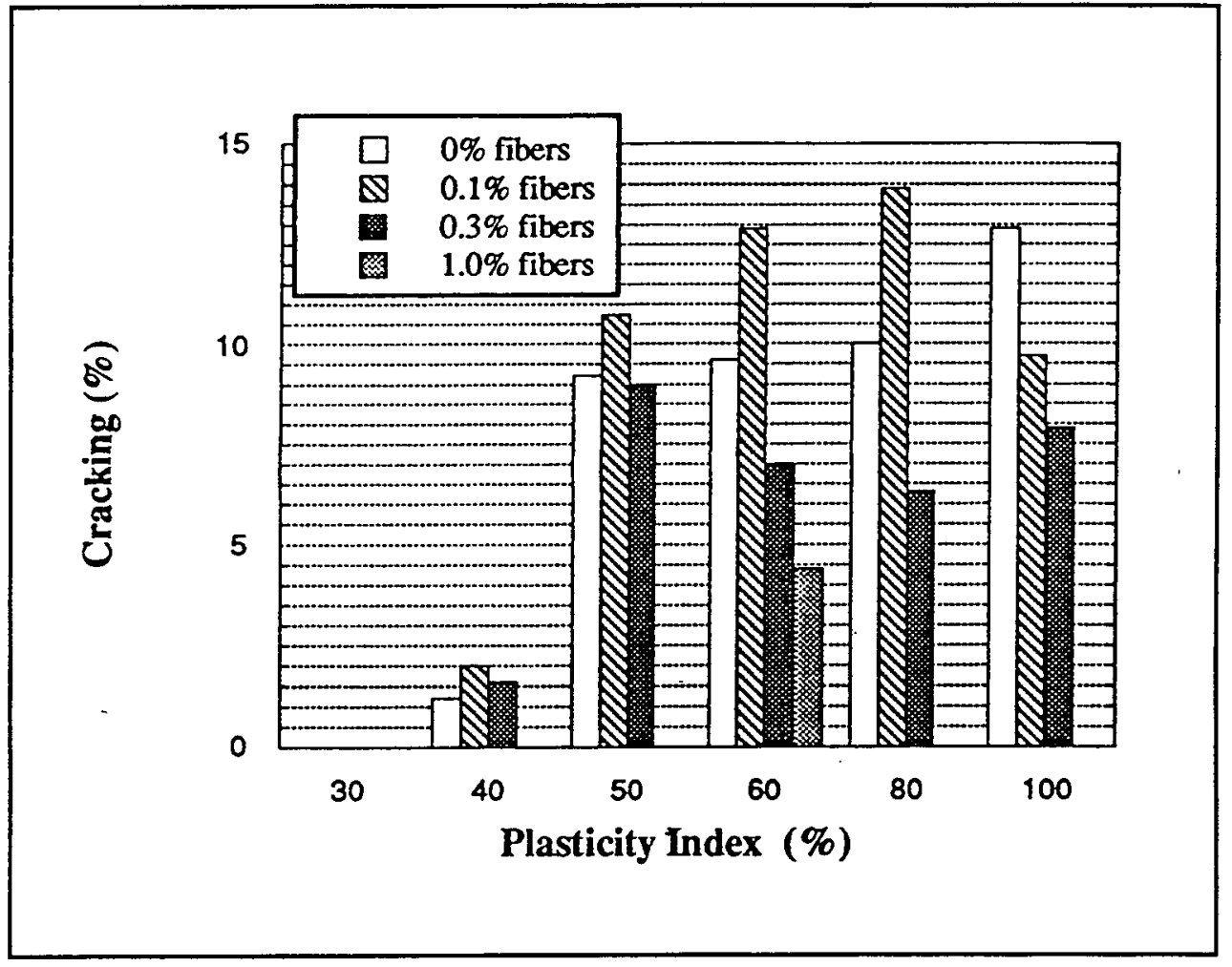

Figure 17. Cracking test results for hand-mixed laboratory-prepared soils: drying cycle 2 (2D) 


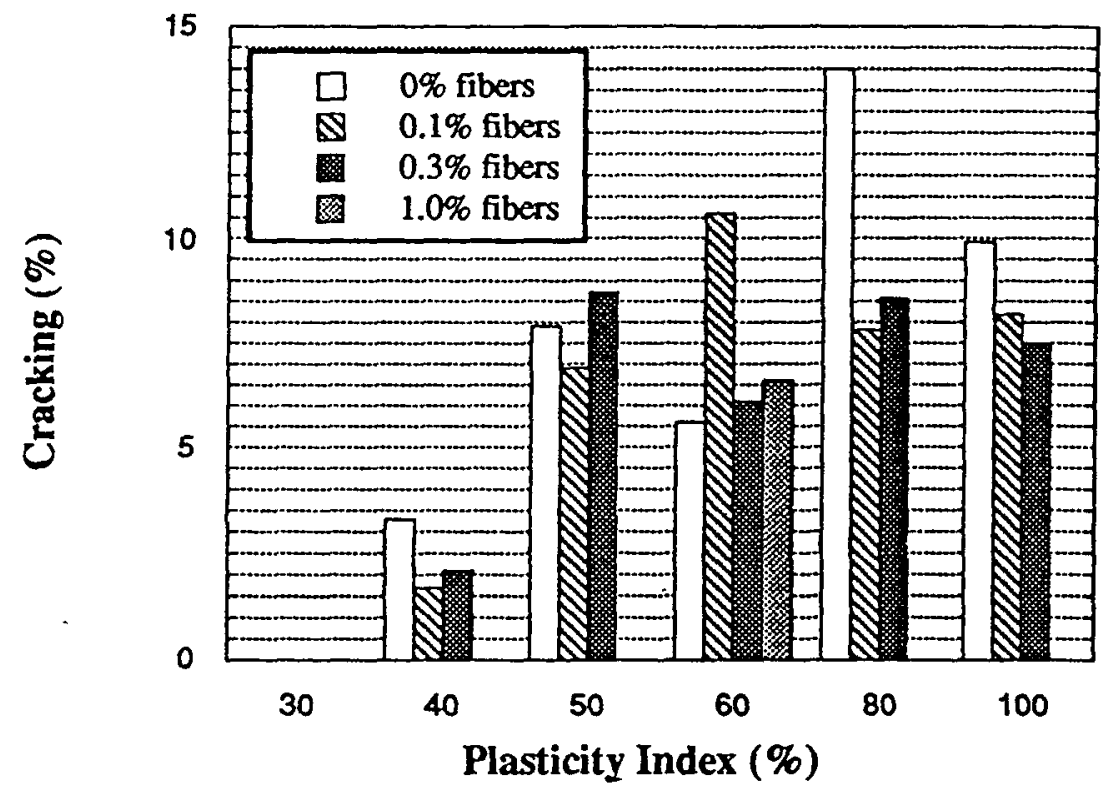

Figure 18. Cracking test results for hand-mixed laboratory-prepared soils: drying cycle $3(3 D)$ 


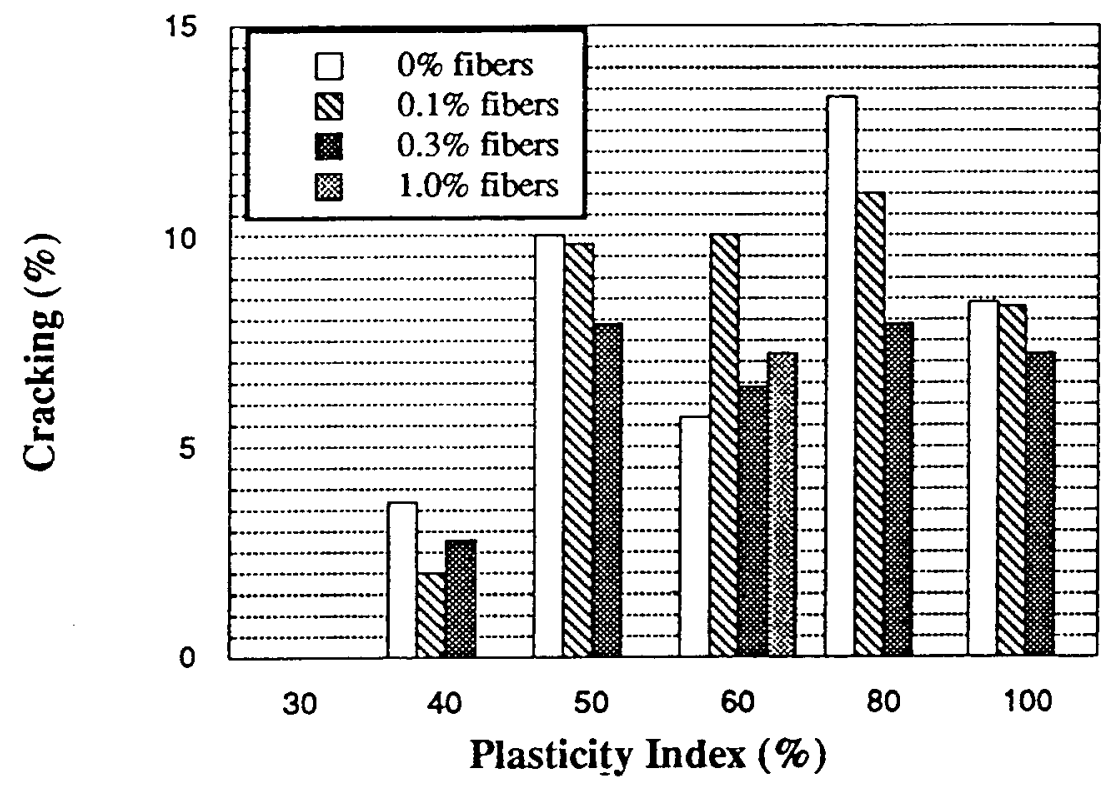

Figure 19. Cracking test results for hand-mixed laboratory-prepared soils: drying cycle 4 (4D) 


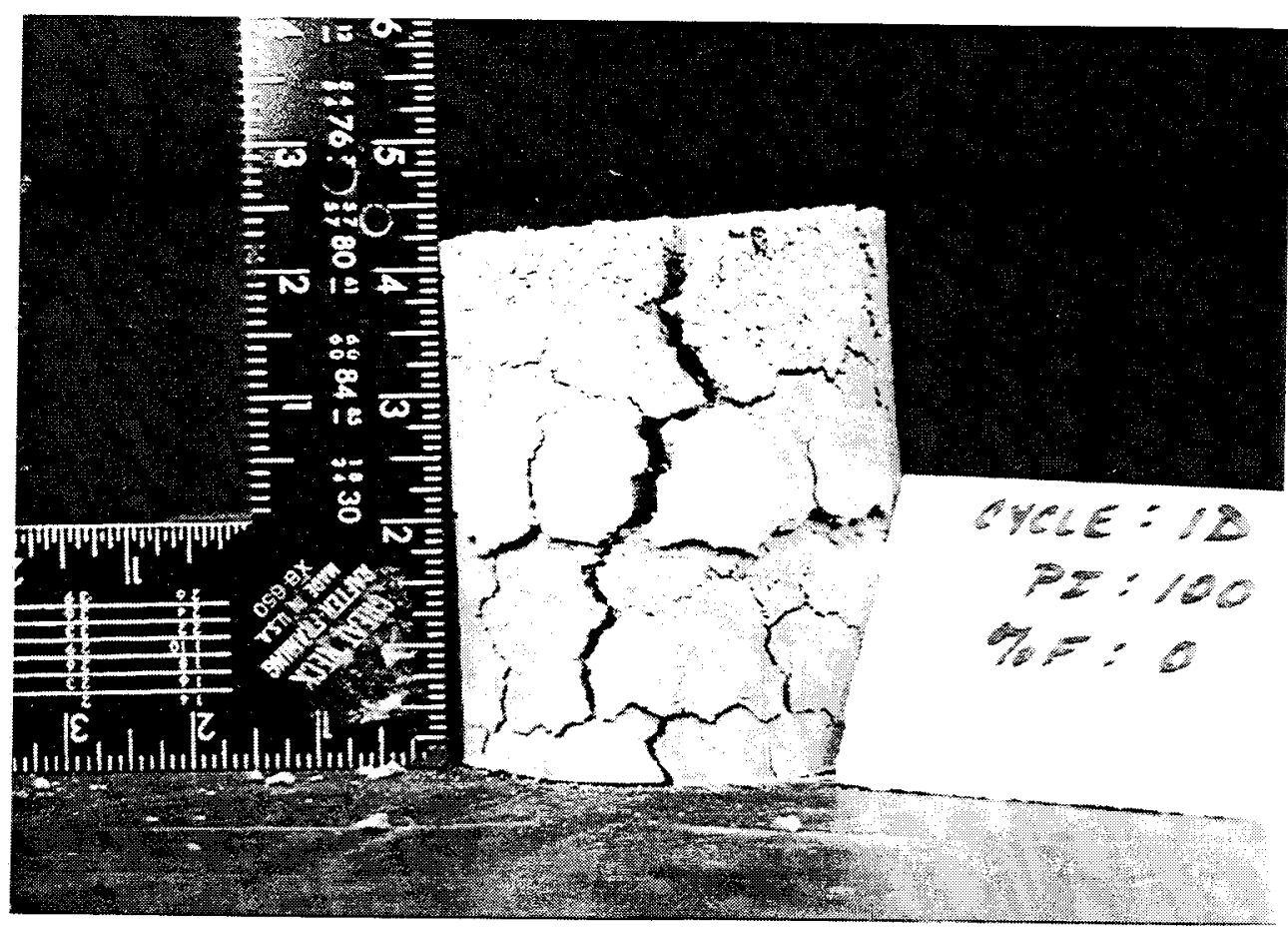

Figure 20. Cracking test sample (hand-mixed) at end of drying cycle $1: \mathrm{PI}=$ 100 , fiber content $=0$ percent 


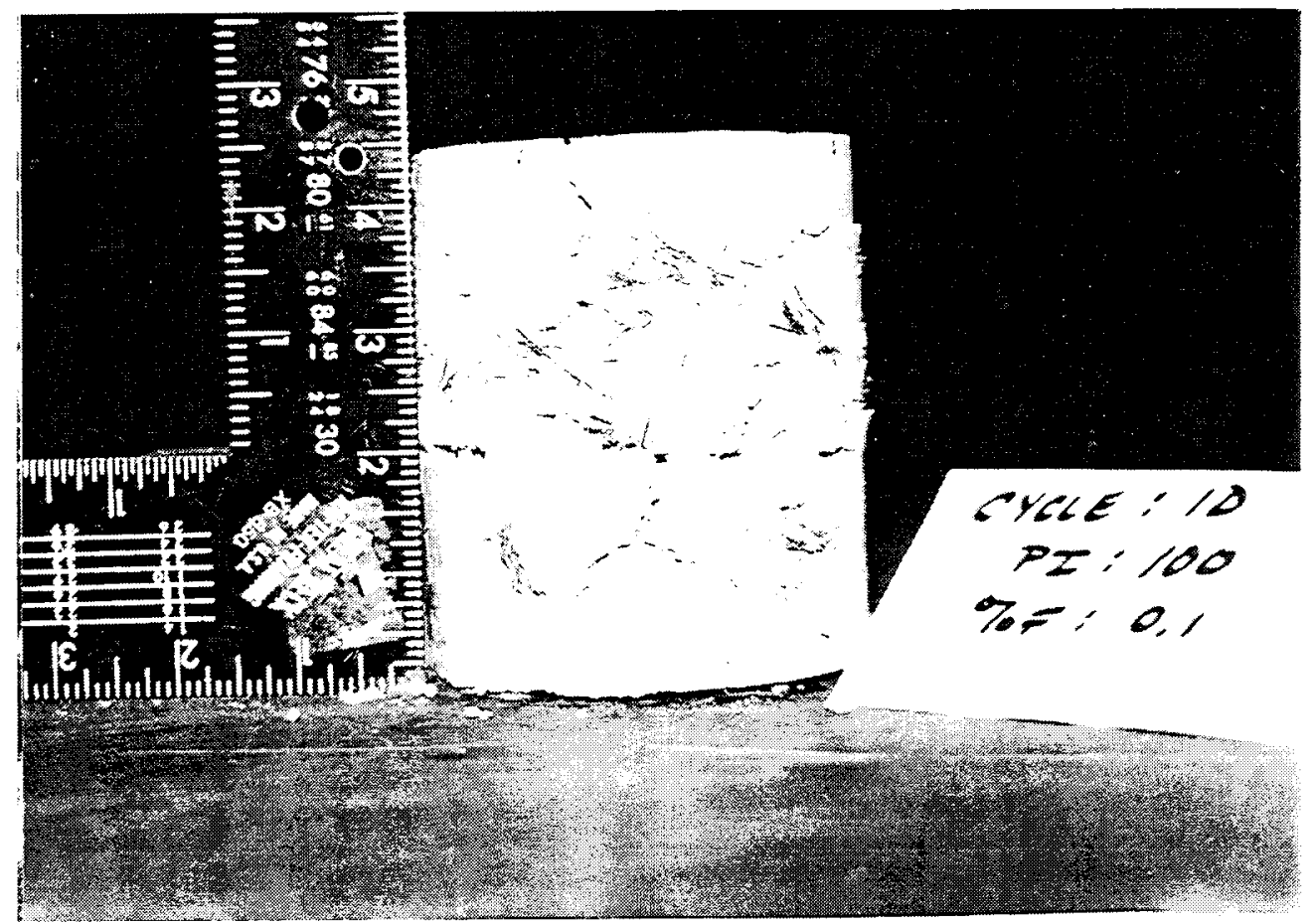

Figure 21. Cracking test sample (hand-mixed) at end of drying cycle 1: $\mathrm{PI}=100$, fiber content $=0.1$ percent 


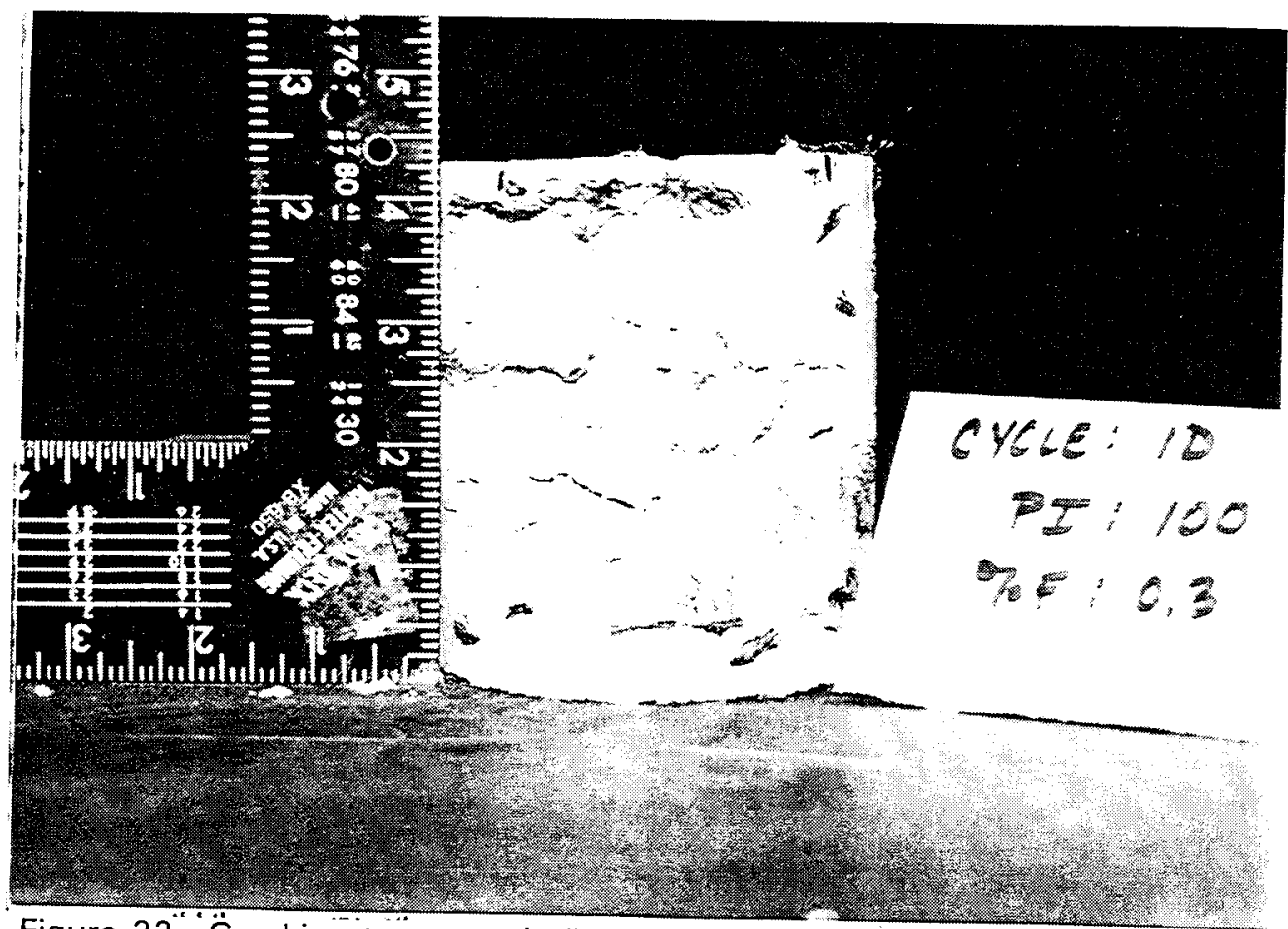

Figure 22. Cracking test sample (hand-mixed) at end of drying cycle 1: $\mathrm{PI}=100$, fiber content $=0.3$ percent 


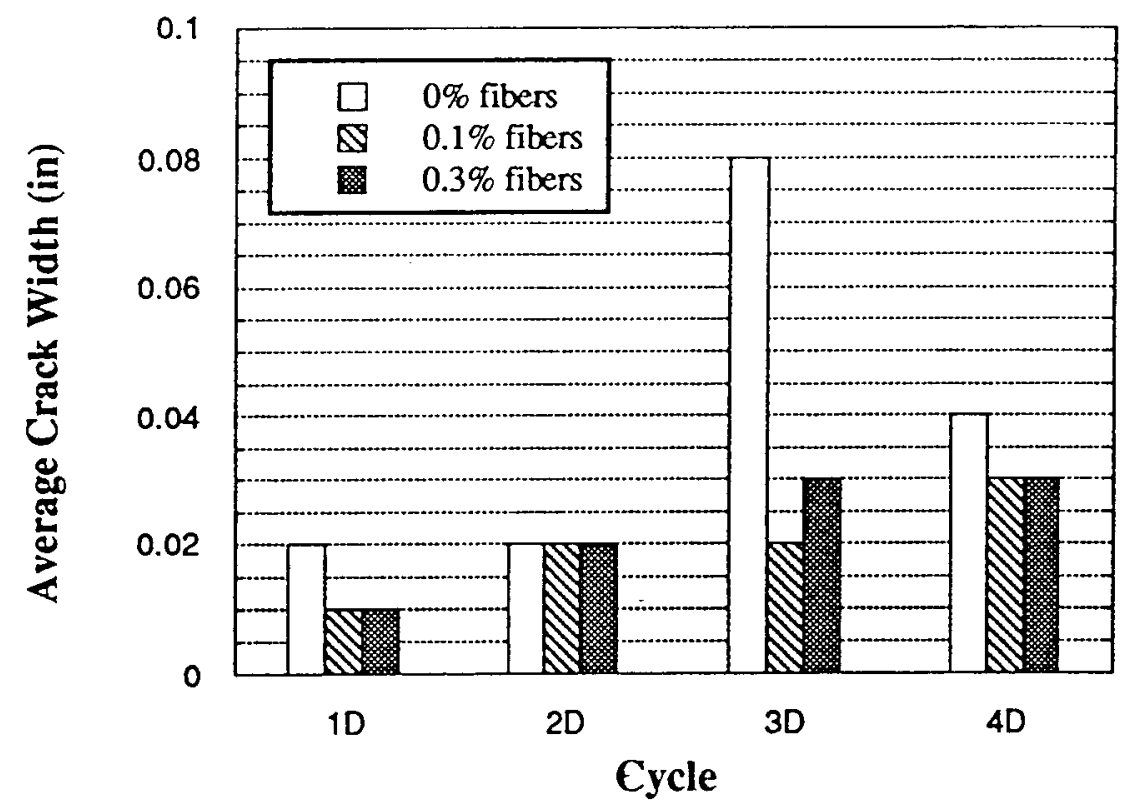

Figure 23. Average crack width for hand-mixed laboratory-prepared soil: $\mathrm{PI}=40$ (To convert inches to millimeters multiply by 25.4 .) 


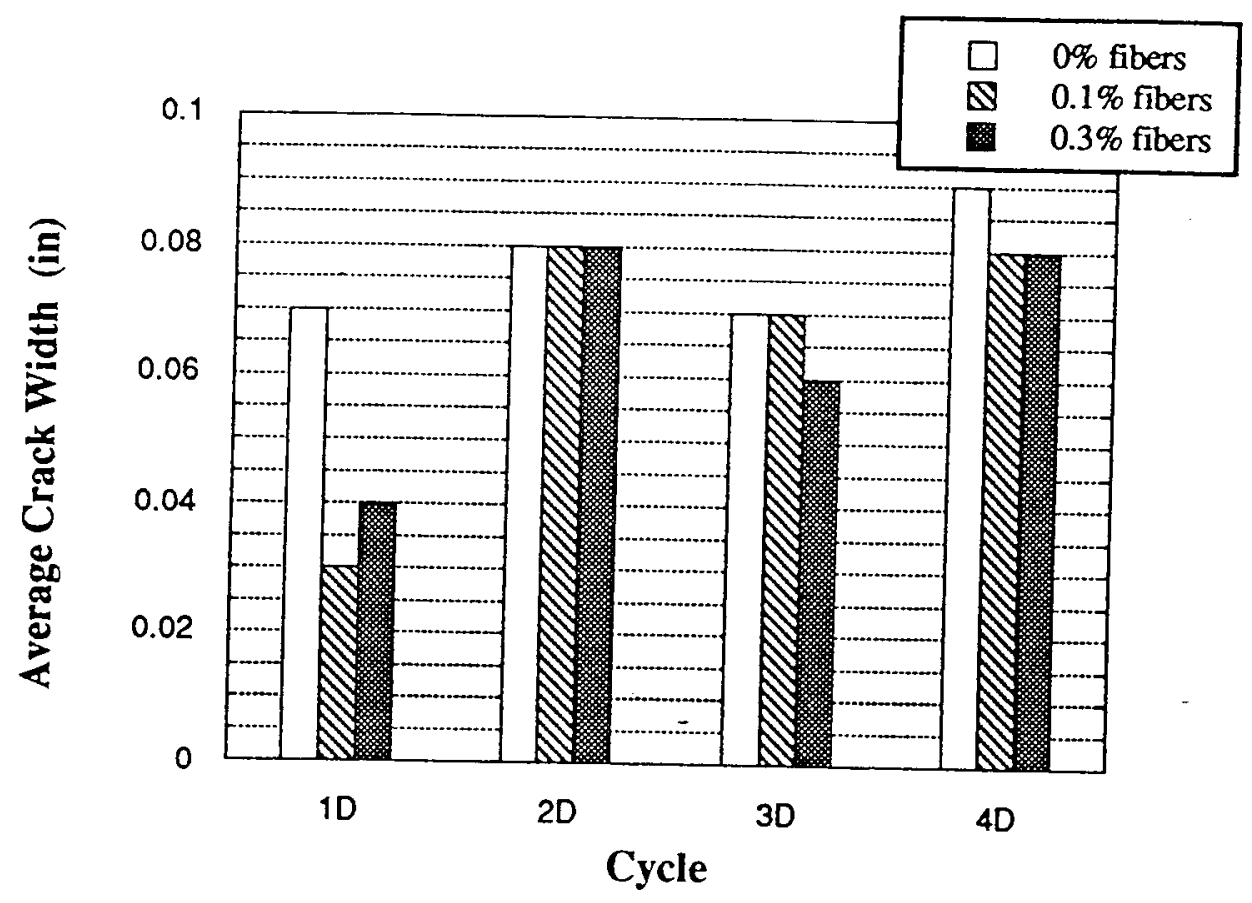

Figure 24. Average crack width for hand-mixed laboratory-prepared soil: $\mathrm{PI}=50$ (To convert inches to millimeters multiply by 25.4 .) 


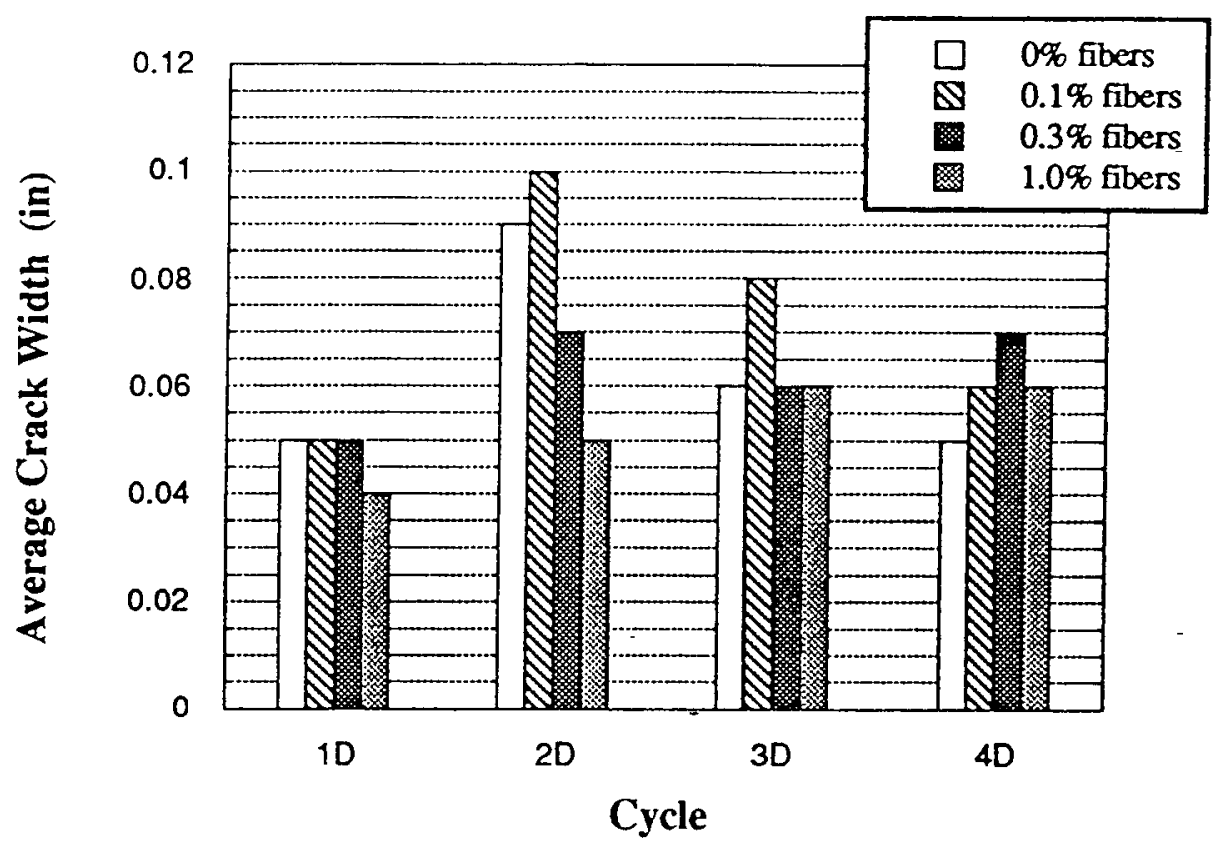

Figure 25. Average crack width for hand-mixed laboratory-prepared soil: $P I=60$ (To convert inches to millimeters multiply by 25.4 .) 


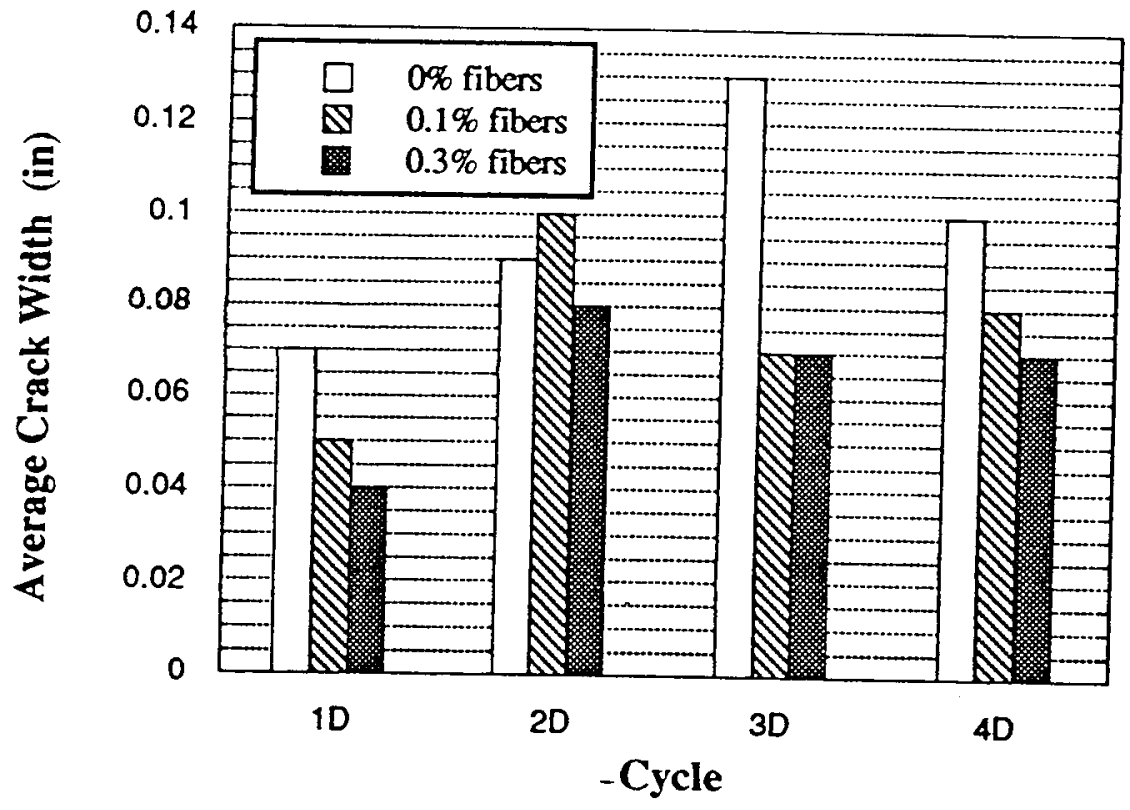

Figure 26. Average crack width for hand-mixed laboratory-prepared soils: $\mathrm{PI}=80$ (To convert inches to millimeters multiply by 25.4 .) 


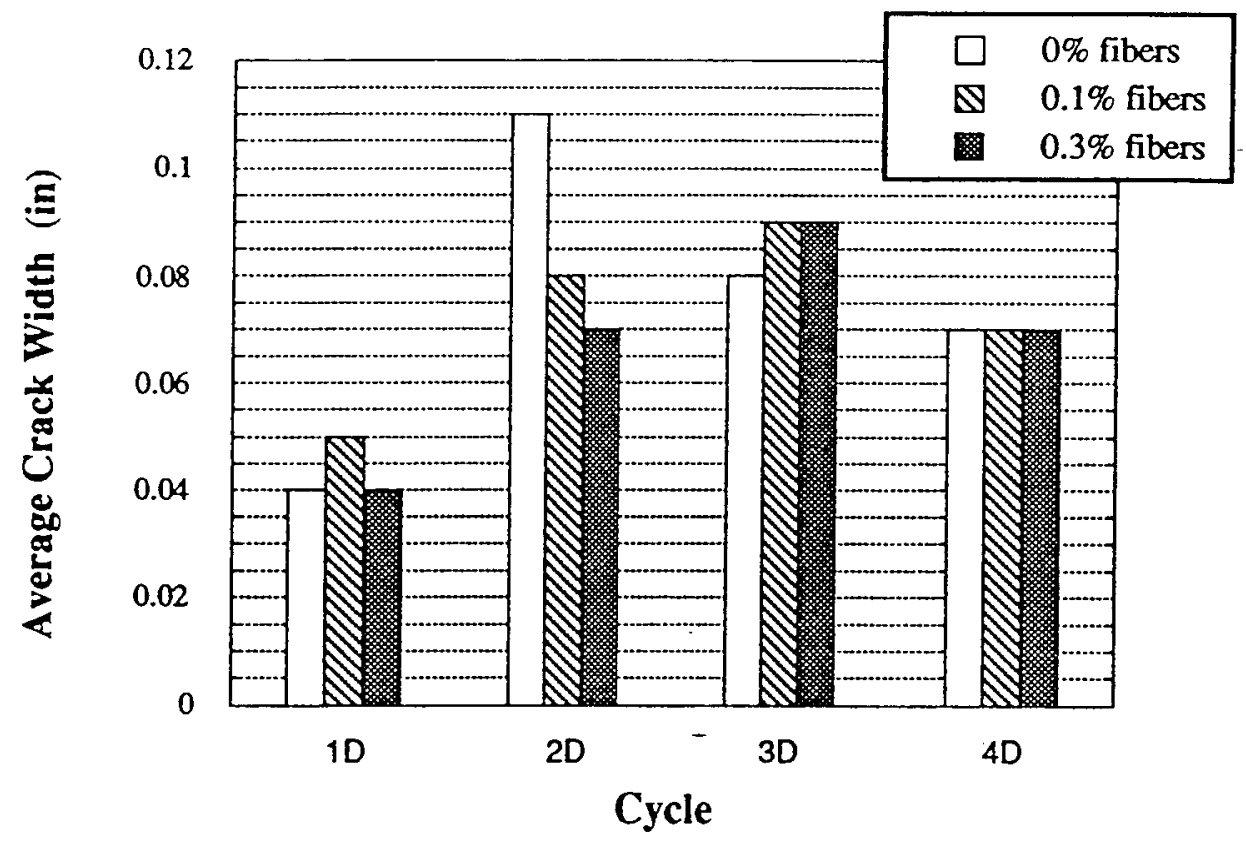

Figure 27. Average crack width for hand-mixed laboratory-prepared soil: $\mathrm{Pl}=100$ (To convert inches to millimeters multiply by 25.4 .) 


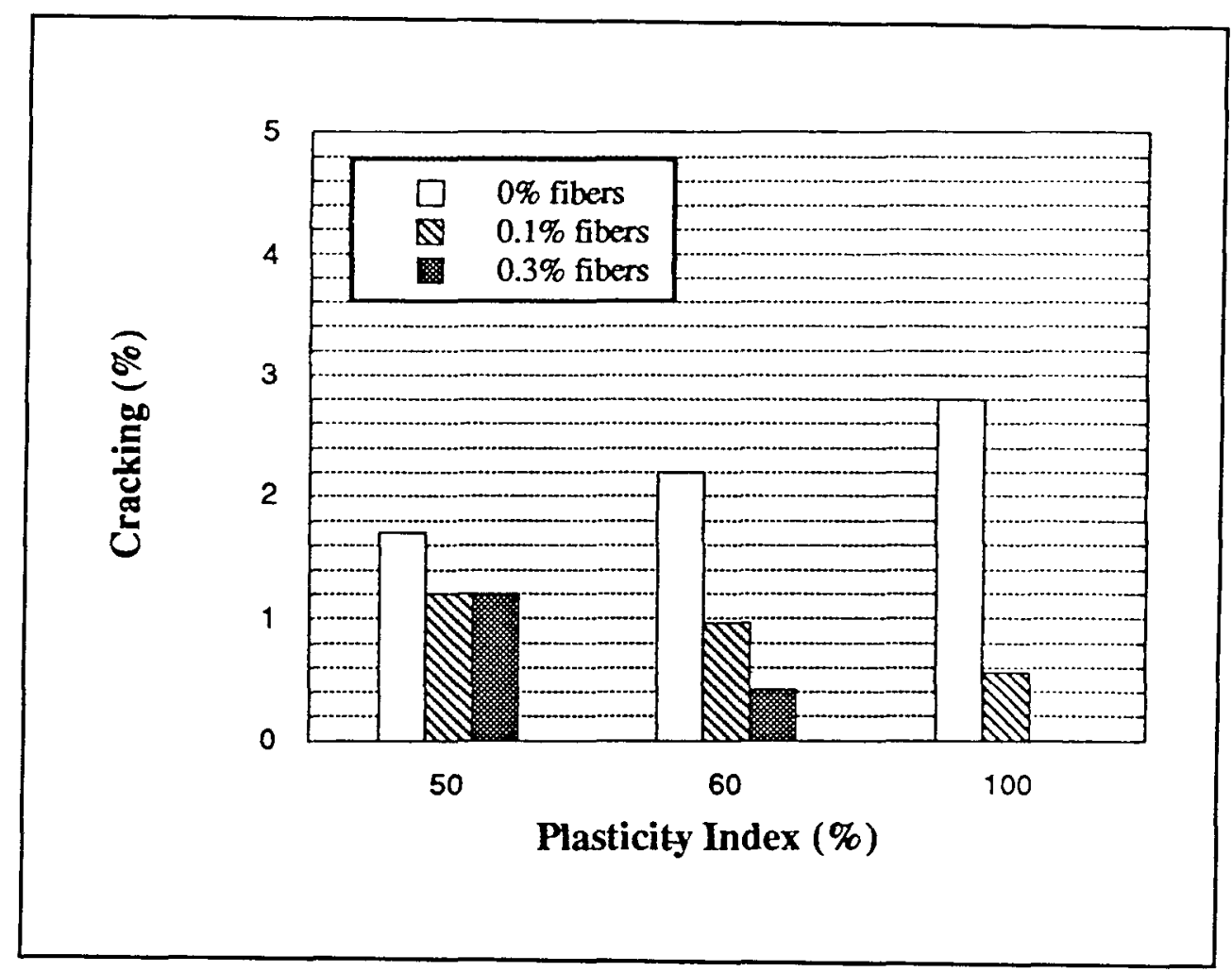

Figure 28. Cracking test results for machine-mixed laboratory-prepared soils: drying cycle 1 


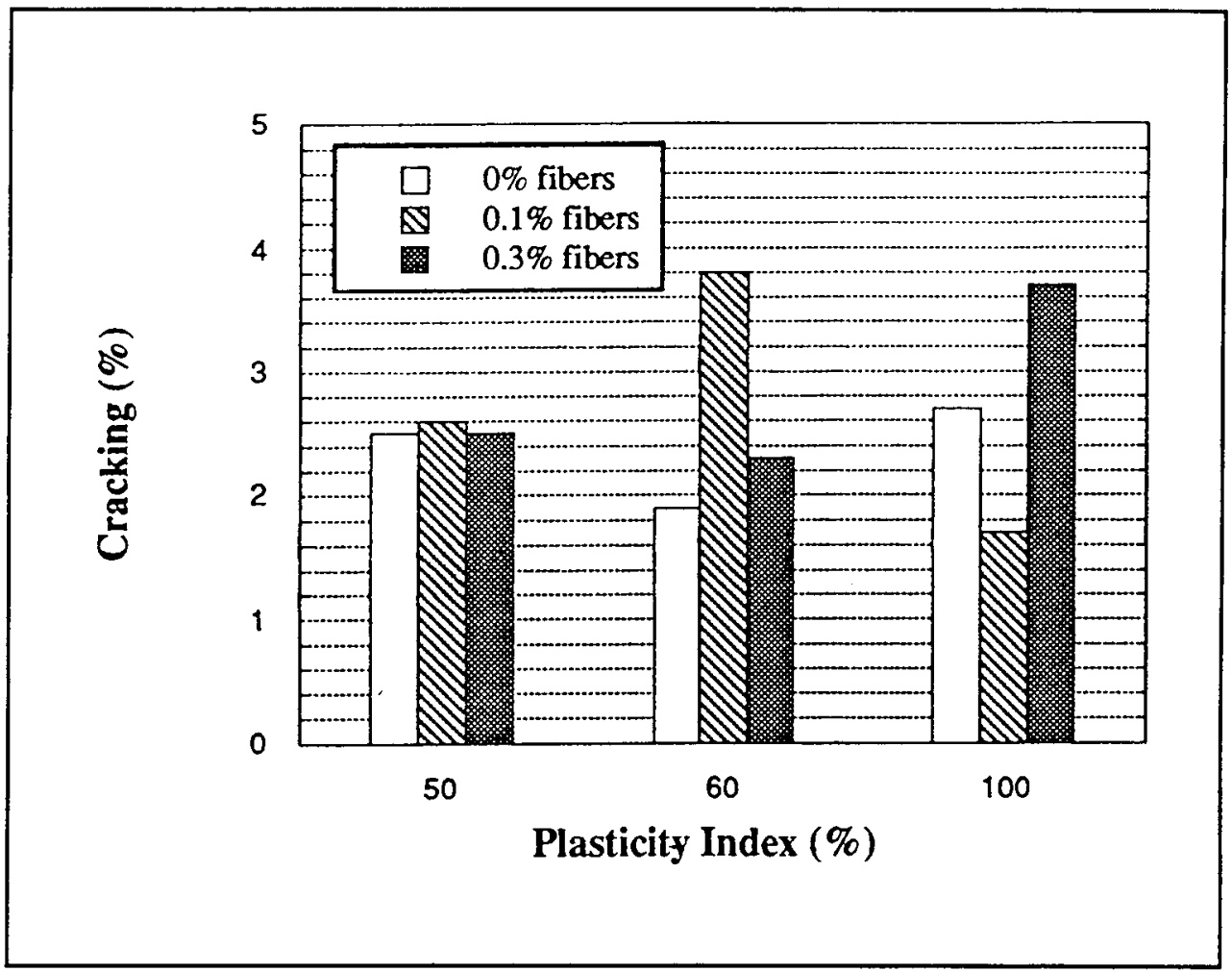

Figure 29. Cracking test results for machine-mixed laboratory-prepared soils: drying cycle 2 


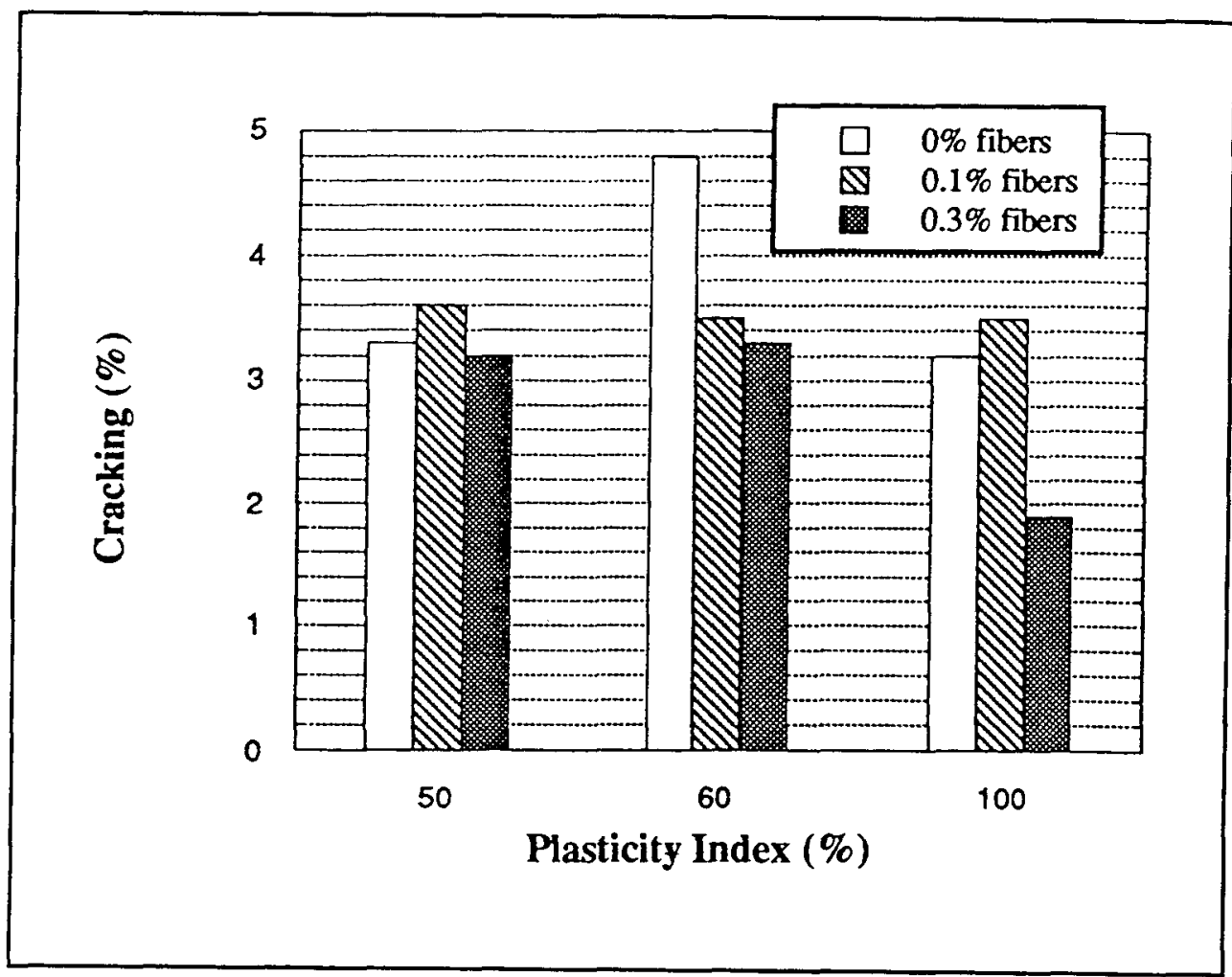

Figure 30. Cracking test results for machine-mixed laboratory-prepared soils: drying cycle 3 


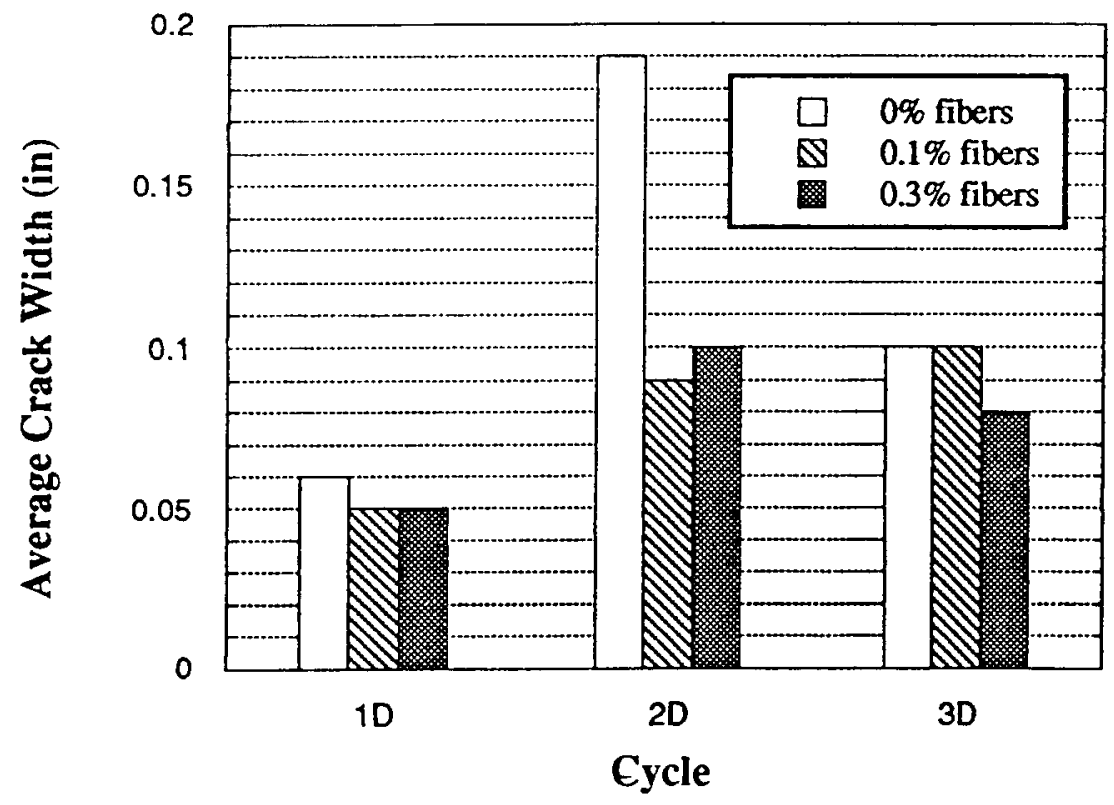

Figure 31. Average crack width for machine-mixed laboratory-prepared soil: $\mathrm{PI}=50$ (To convert inches to millimeters multiply by 25.4 .) 


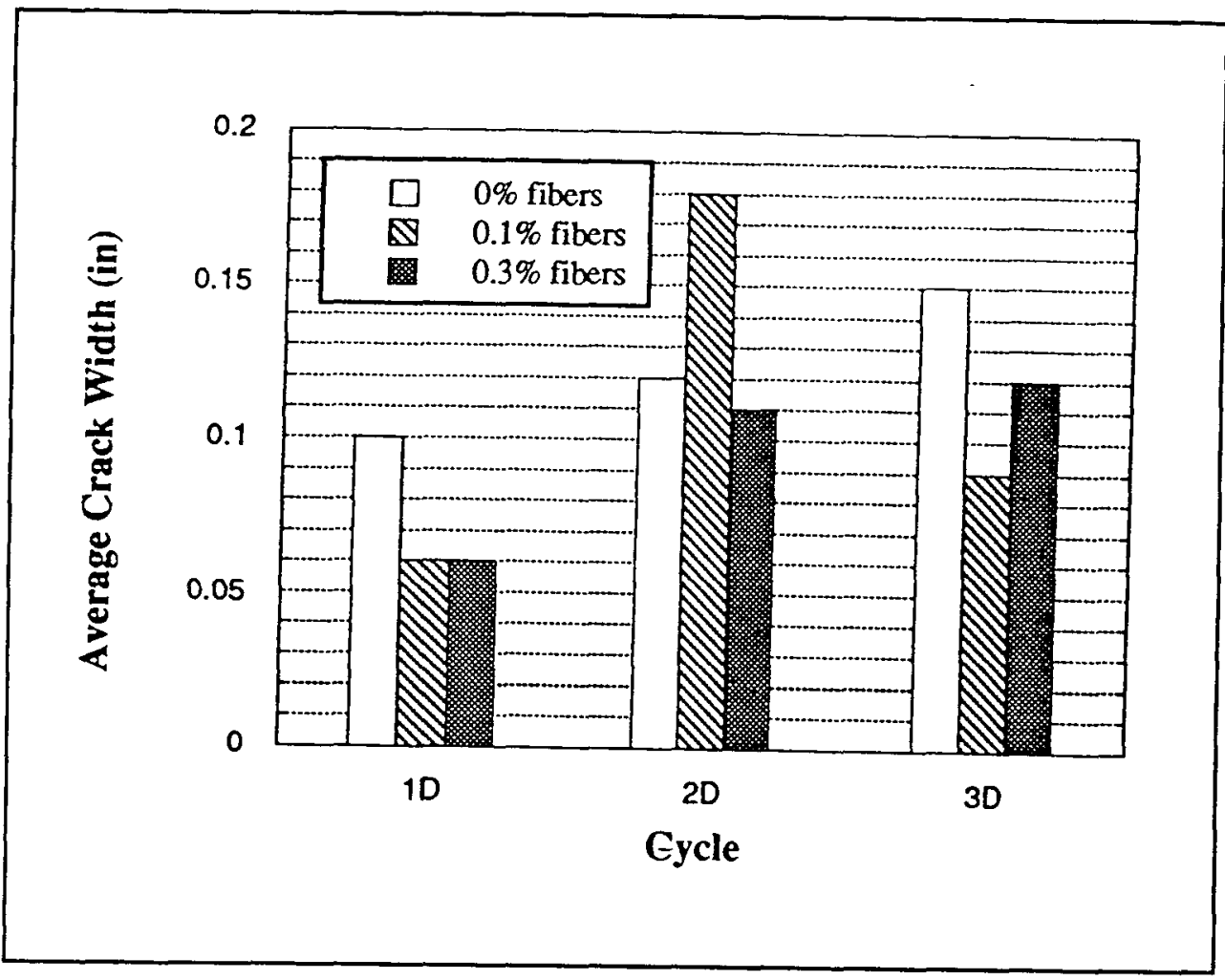

Figure 32. Average crack width for machine-mixed laboratory-prepared soil: $\mathrm{PI}=60$ (To convert inches to millimeters multiply by 25.4 .) 


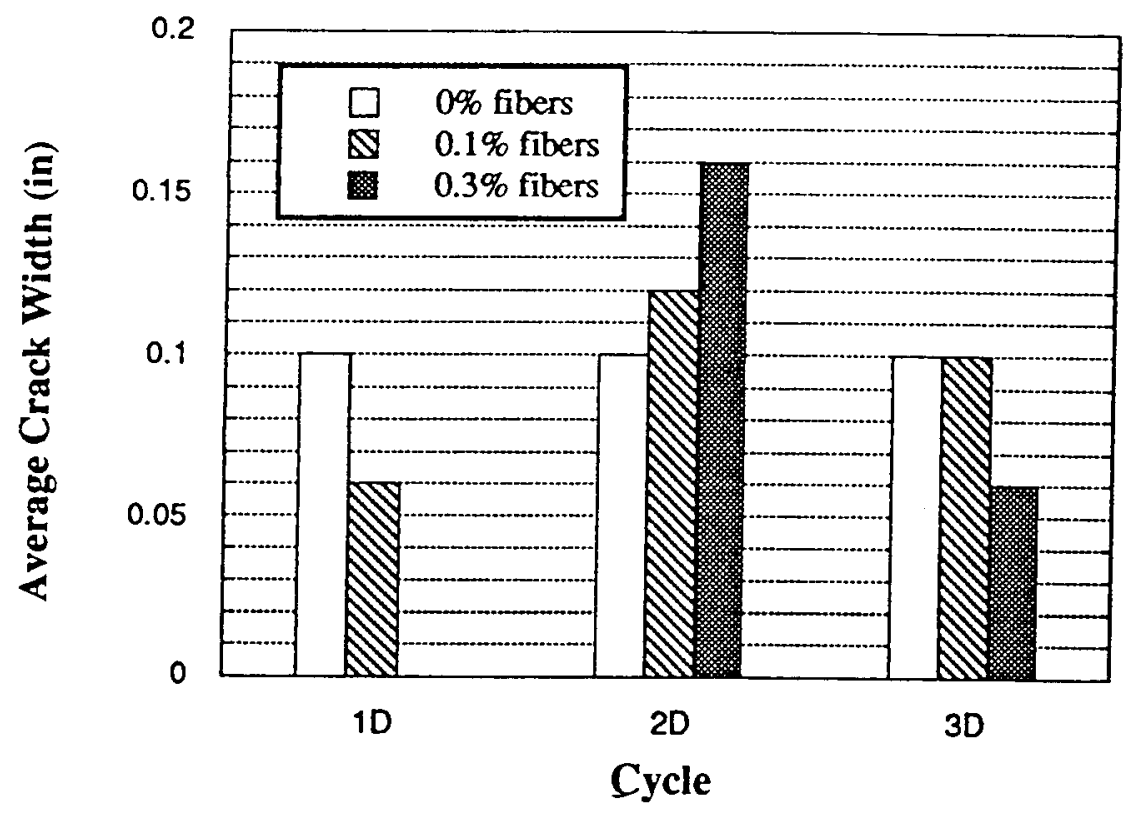

Figure 33. Average crack width for machine-mixed laboratory-prepared soil: $\mathrm{PI}=100$ (To convert inches to millimeters multiply by 25.4 .) 


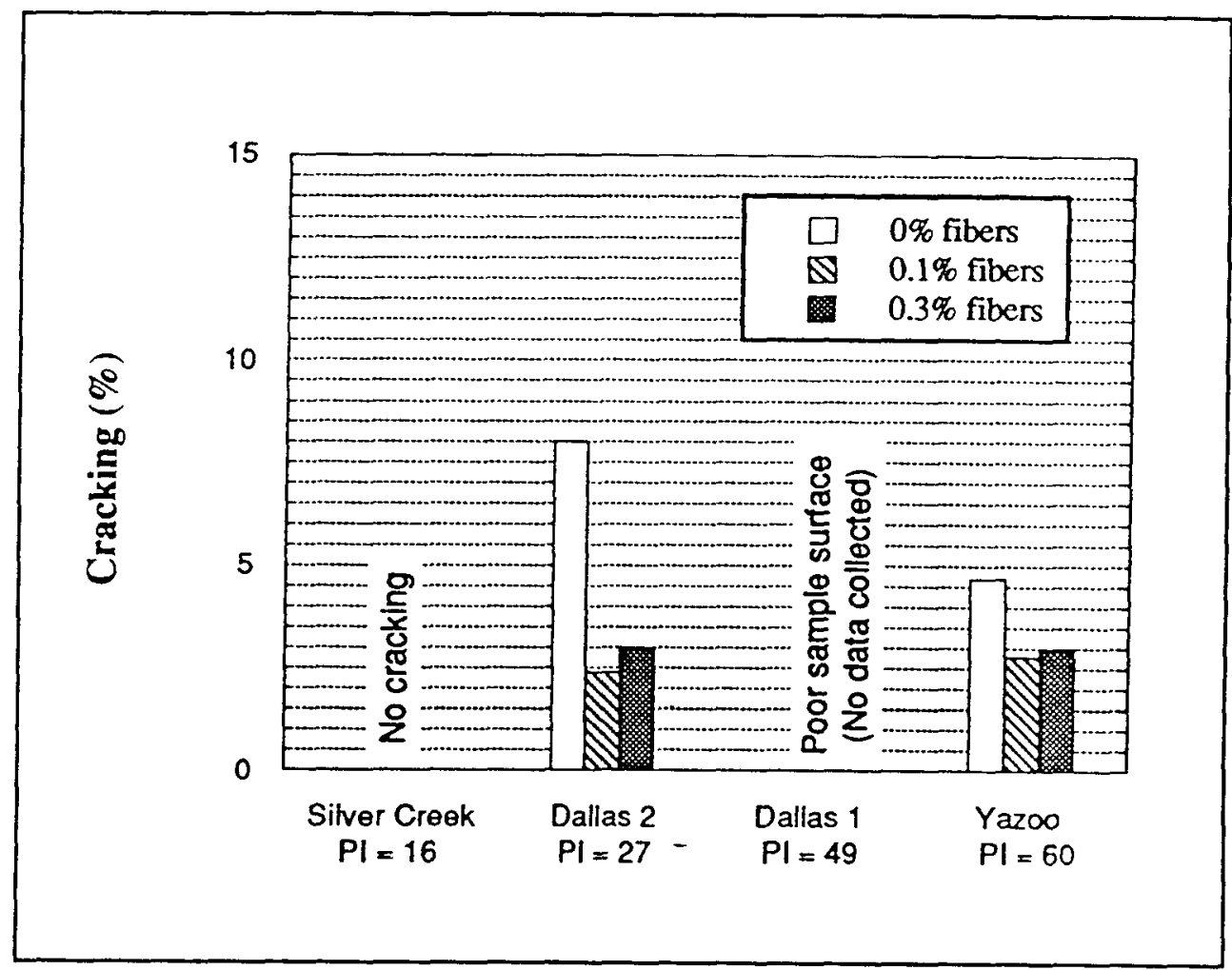

Figure 34. Cracking test results for hand-mixed natural soils: drying cycle 1 (1D) 


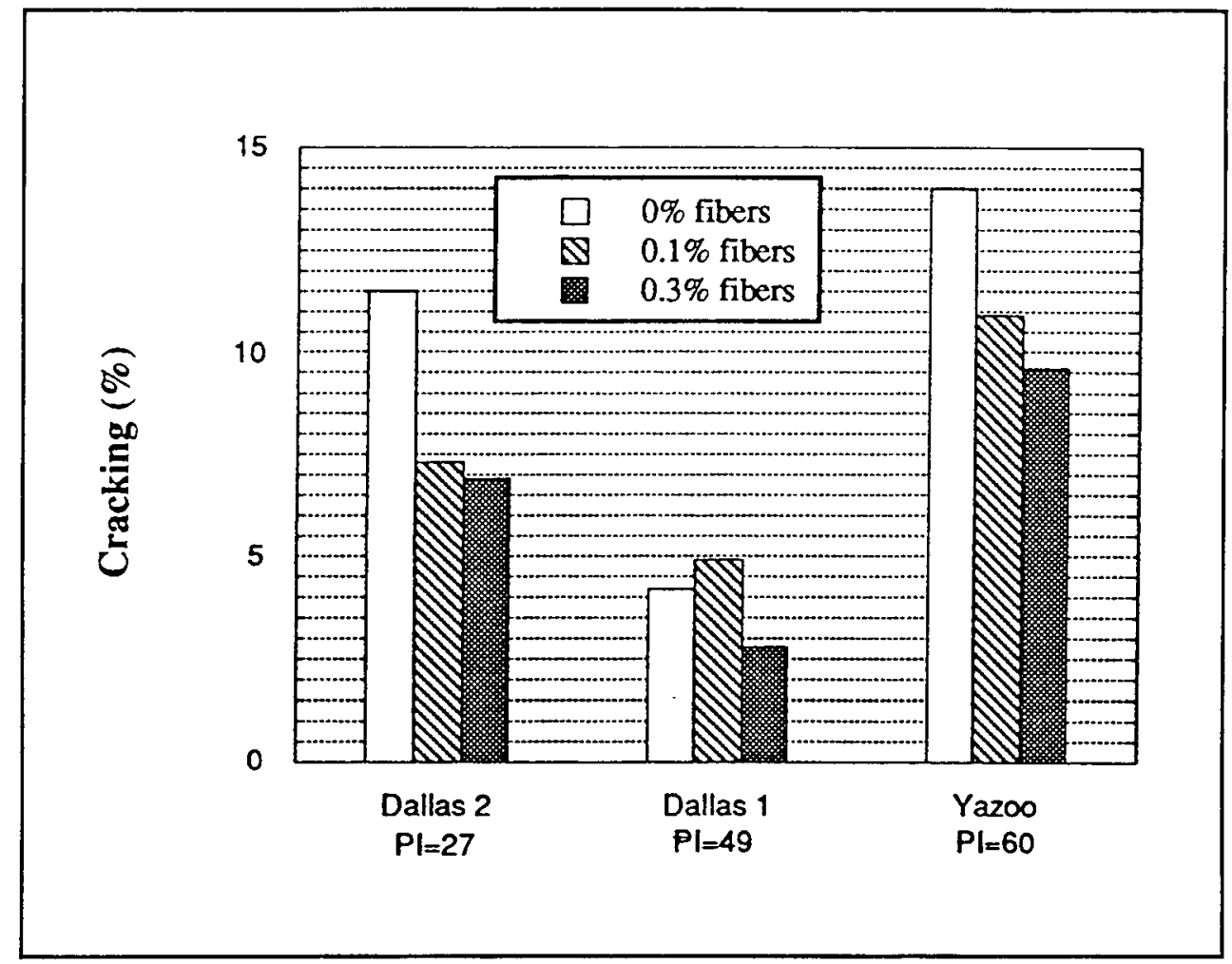

Figure 35. Cracking test results for hand-mixed natural soils: drying cycle 2 (2D) 


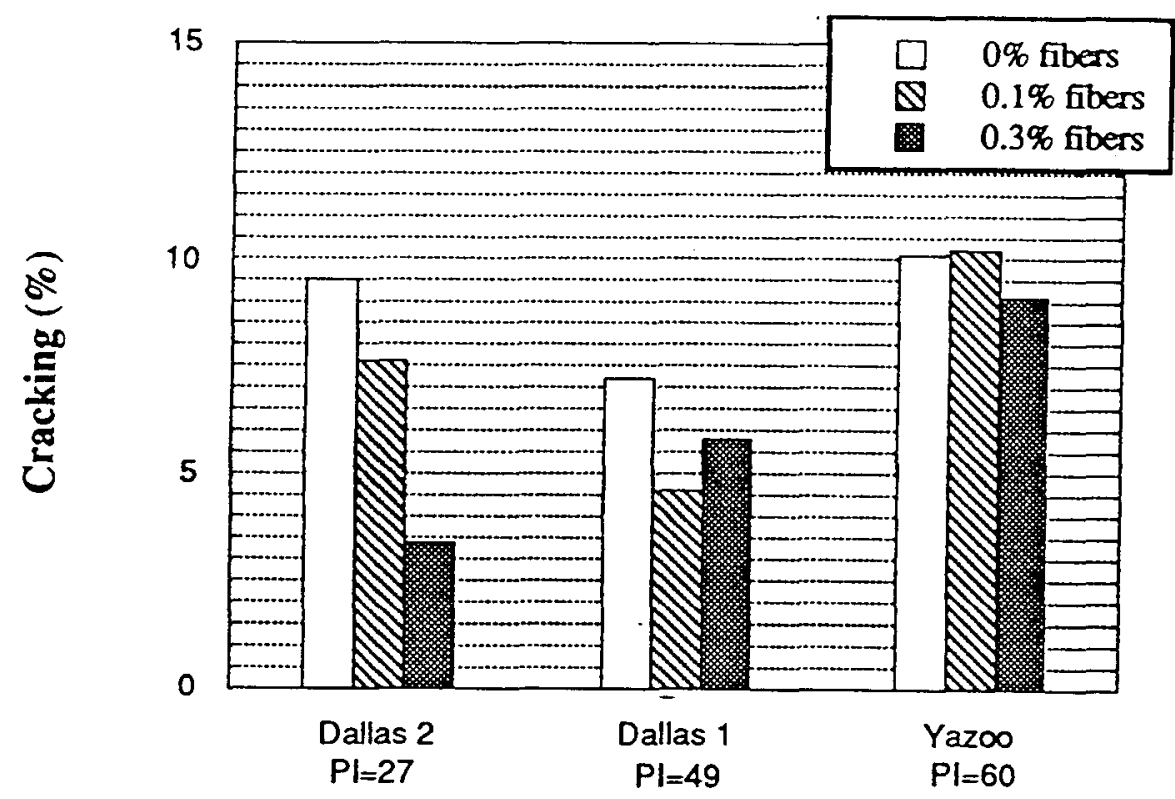

Figure 36. Cracking test results for hand-mixed natural soils: drying cycle 3 (3D) 


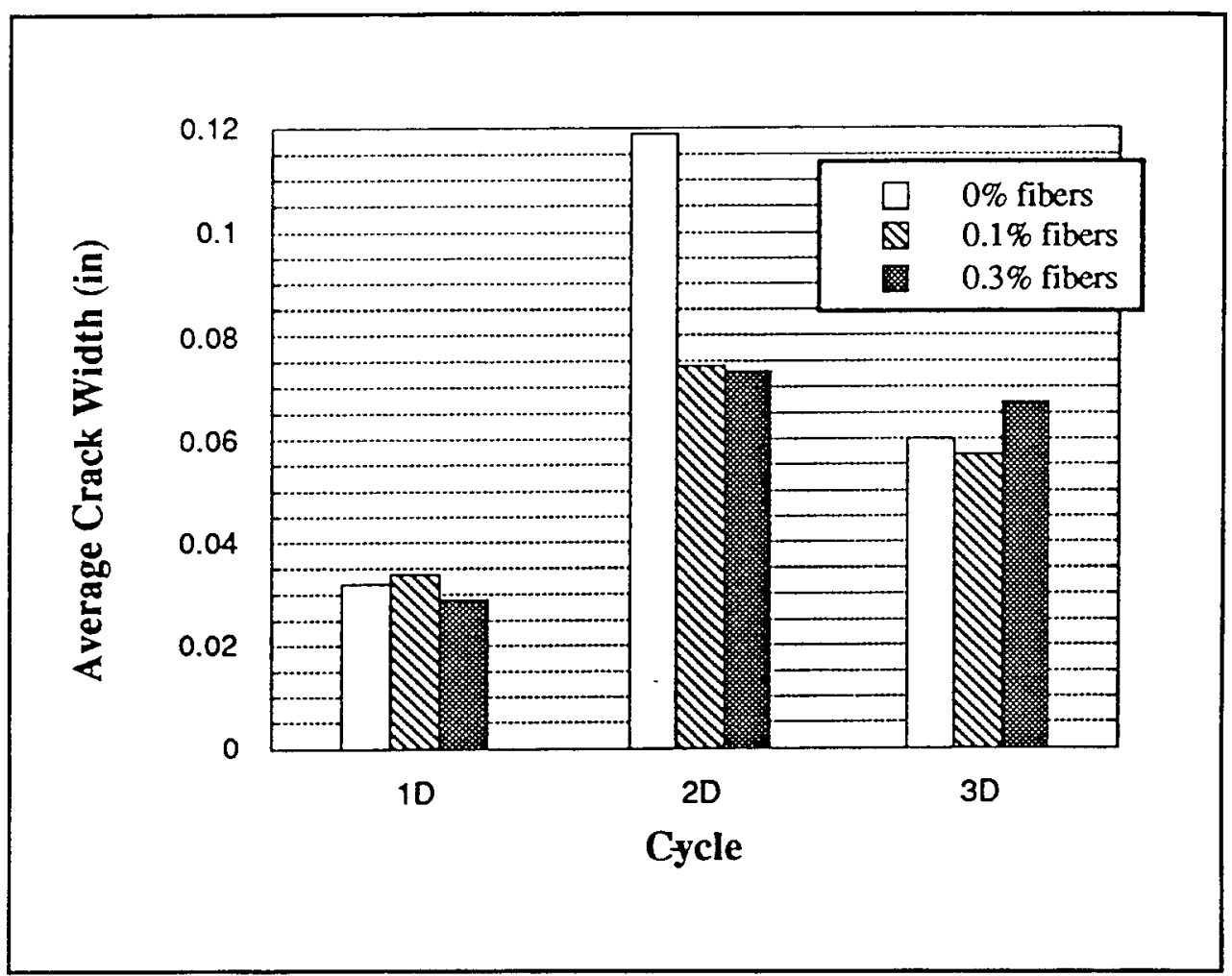

Figure 37. Average crack width for hand-mixed Yazoo Clay: PI $=60$ (To convert inches to millimeters multiply by 25.4 .) 


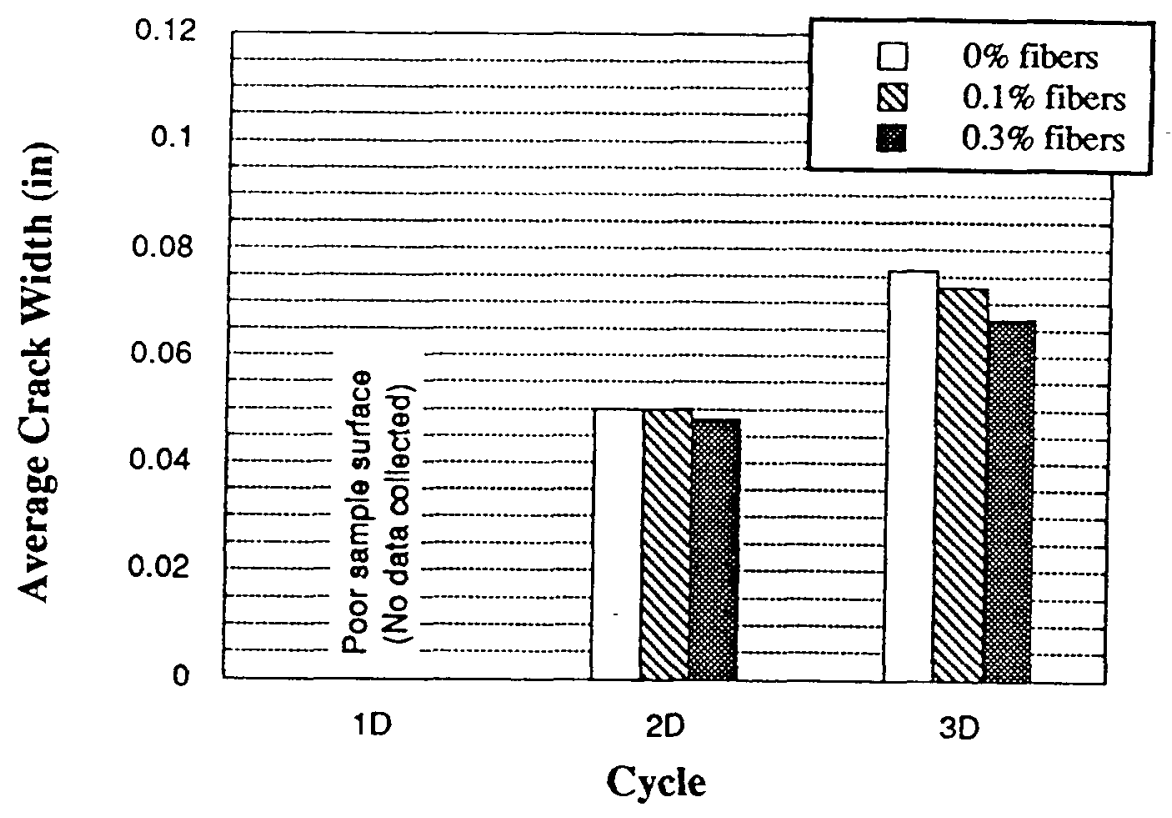

Figure 38. Average crack width for hand-mixed Dallas 1 Clay: PI $=49$ (To convert inches to millimeters multiply by 25.4 .) 


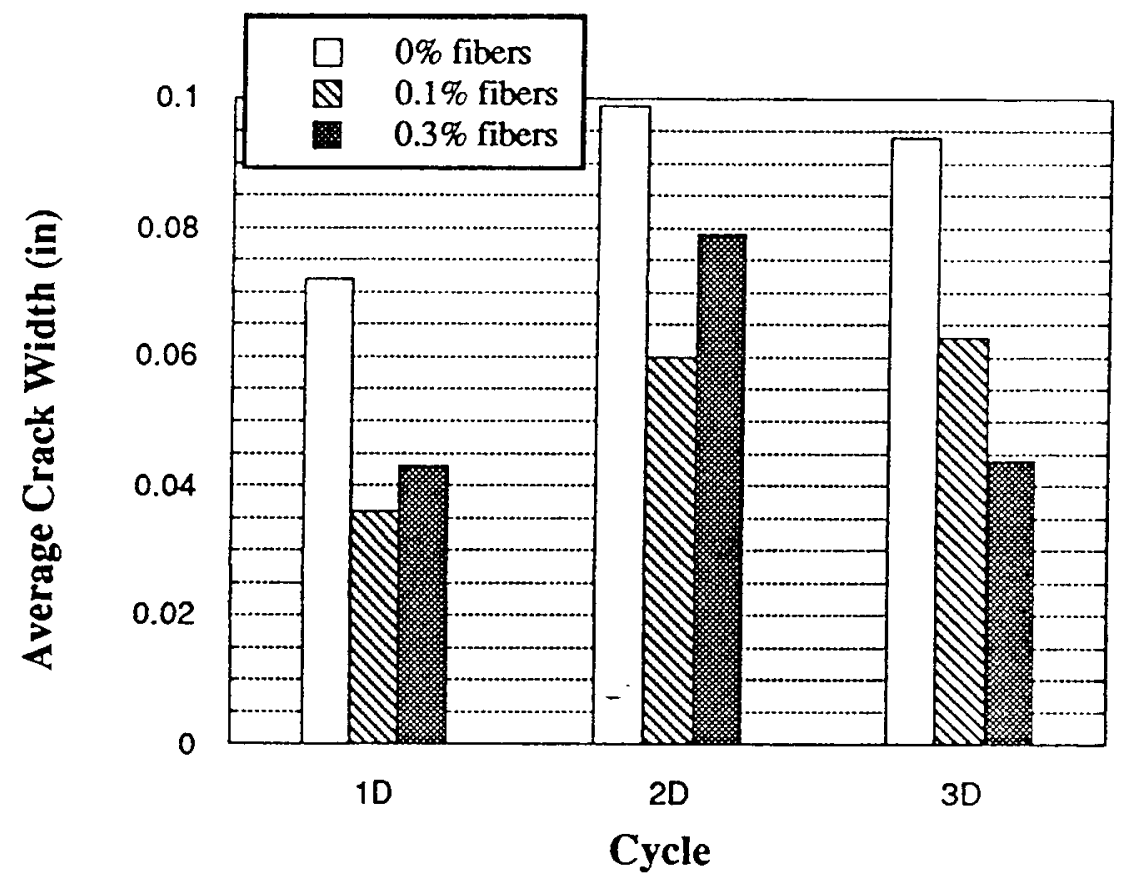

Figure 39. Average crack width for hand-mixed Dallas 2 Clay: $\mathrm{PI}=27$ (To convert inches to millimeters multiply by 25.4 .) 


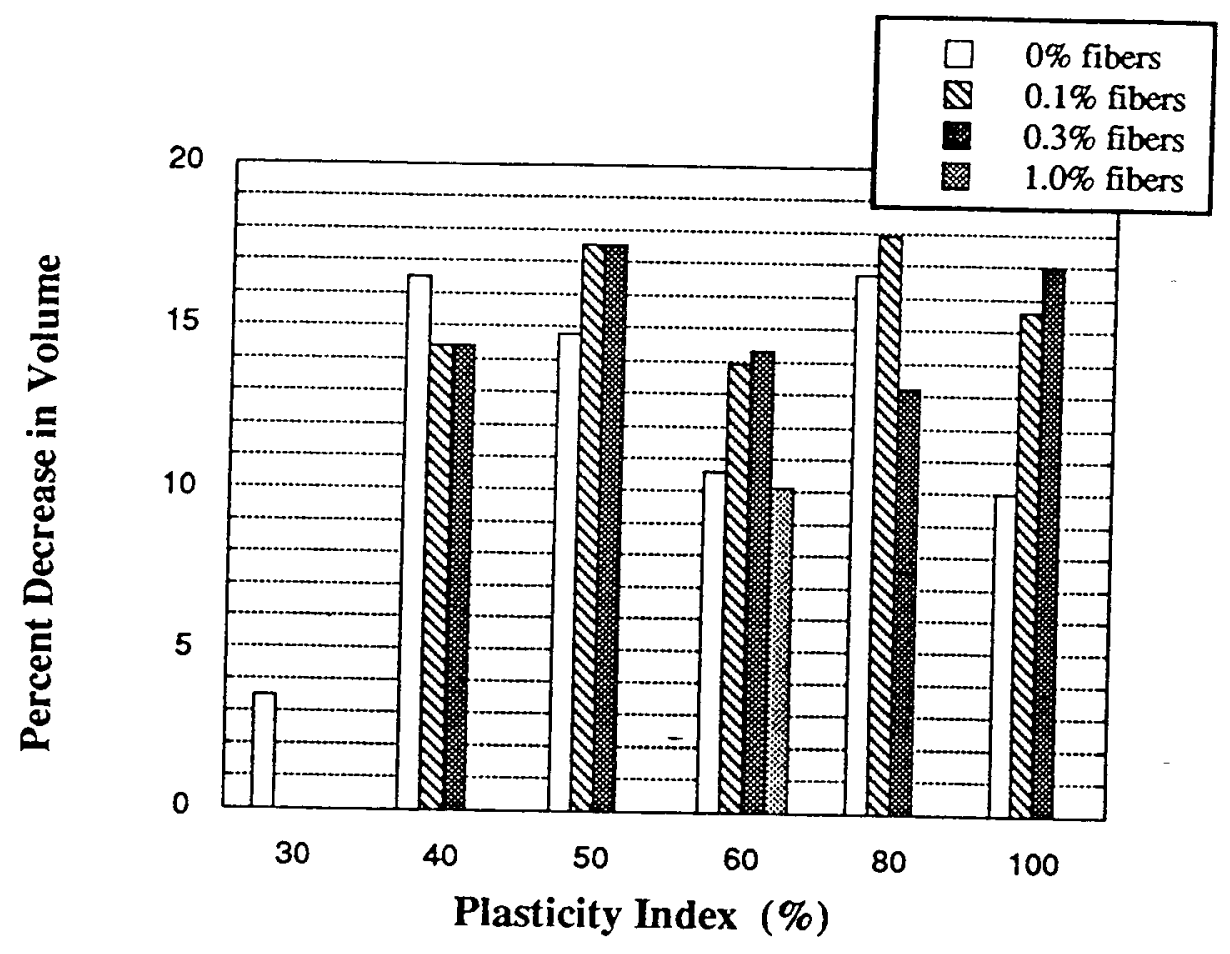

Figure 40. Volume change results for hand-mixed laboratory-prepared soil: drying cycle 1 (1D) 


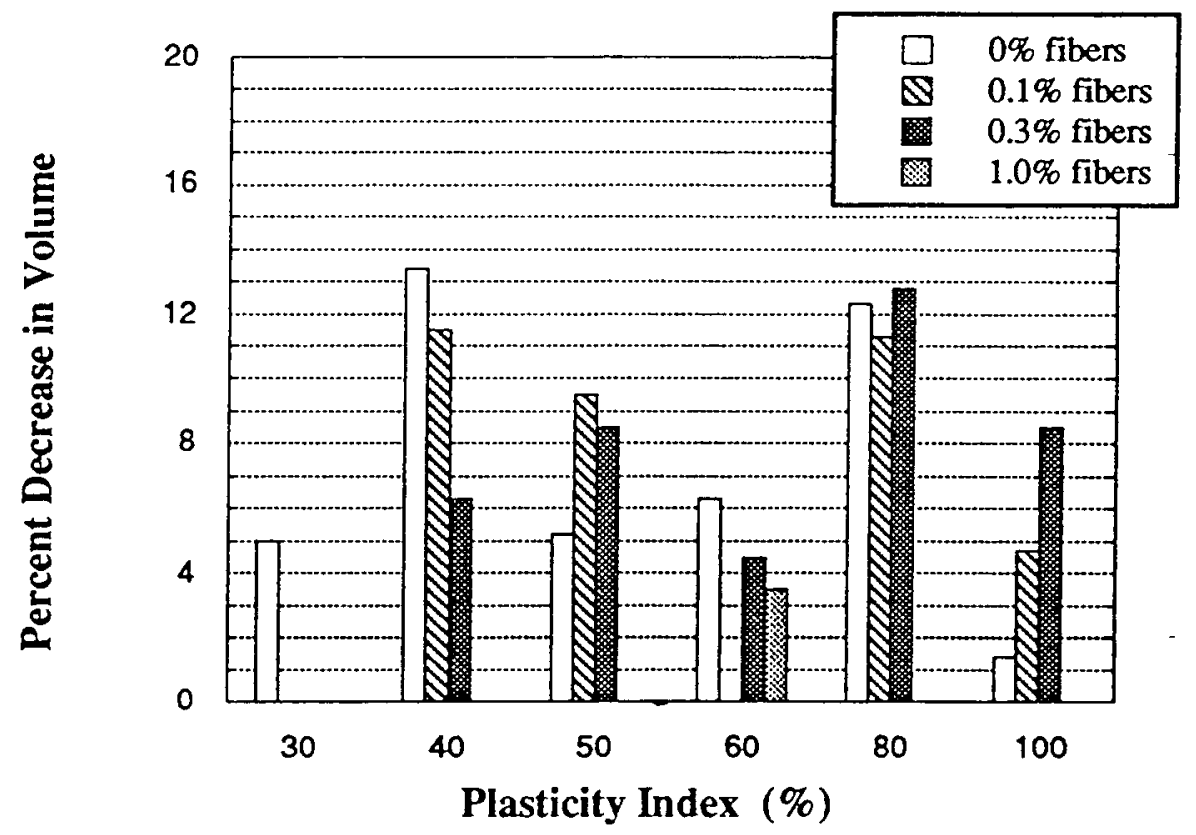

Figure 41. Volume change results for hand-mixed laboratory-prepared soil: drying cycle 2 (2D) 


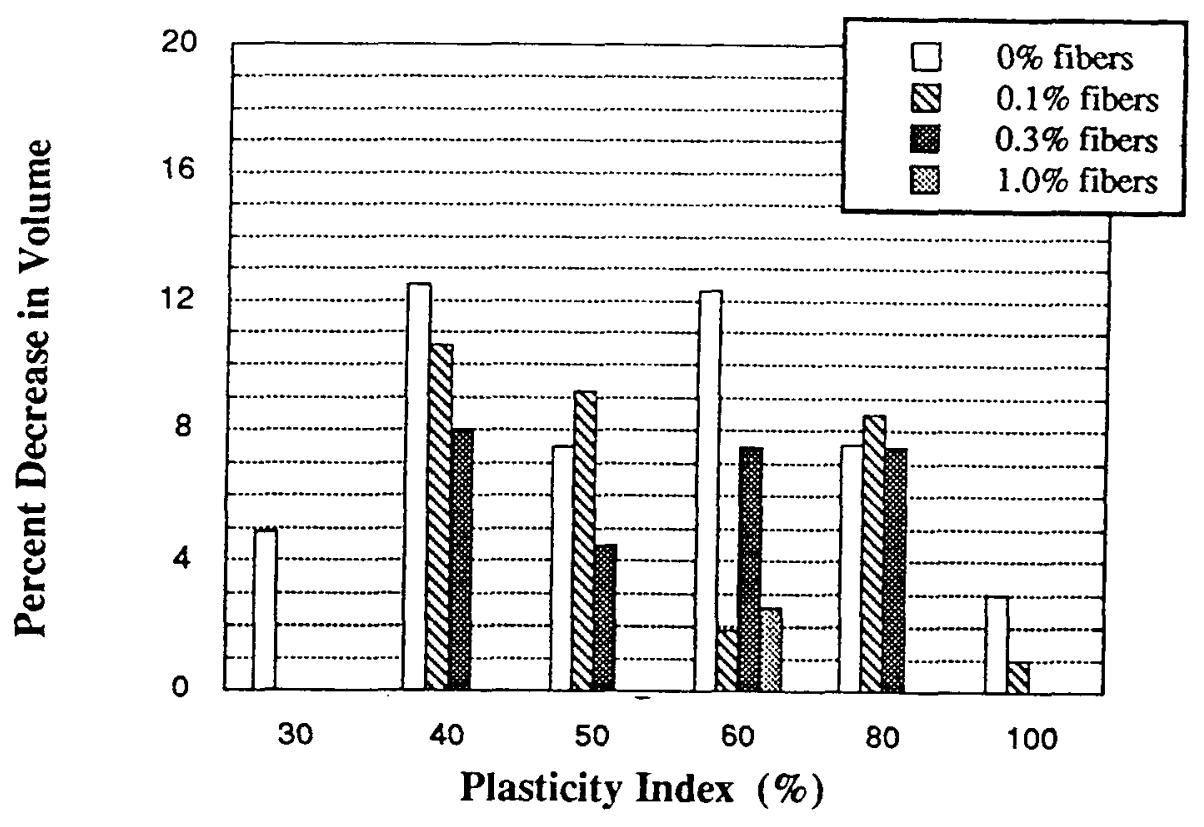

Figure 42. Volume change results for hand-mixed laboratory-prepared soils: drying cycle 3 (3D) 


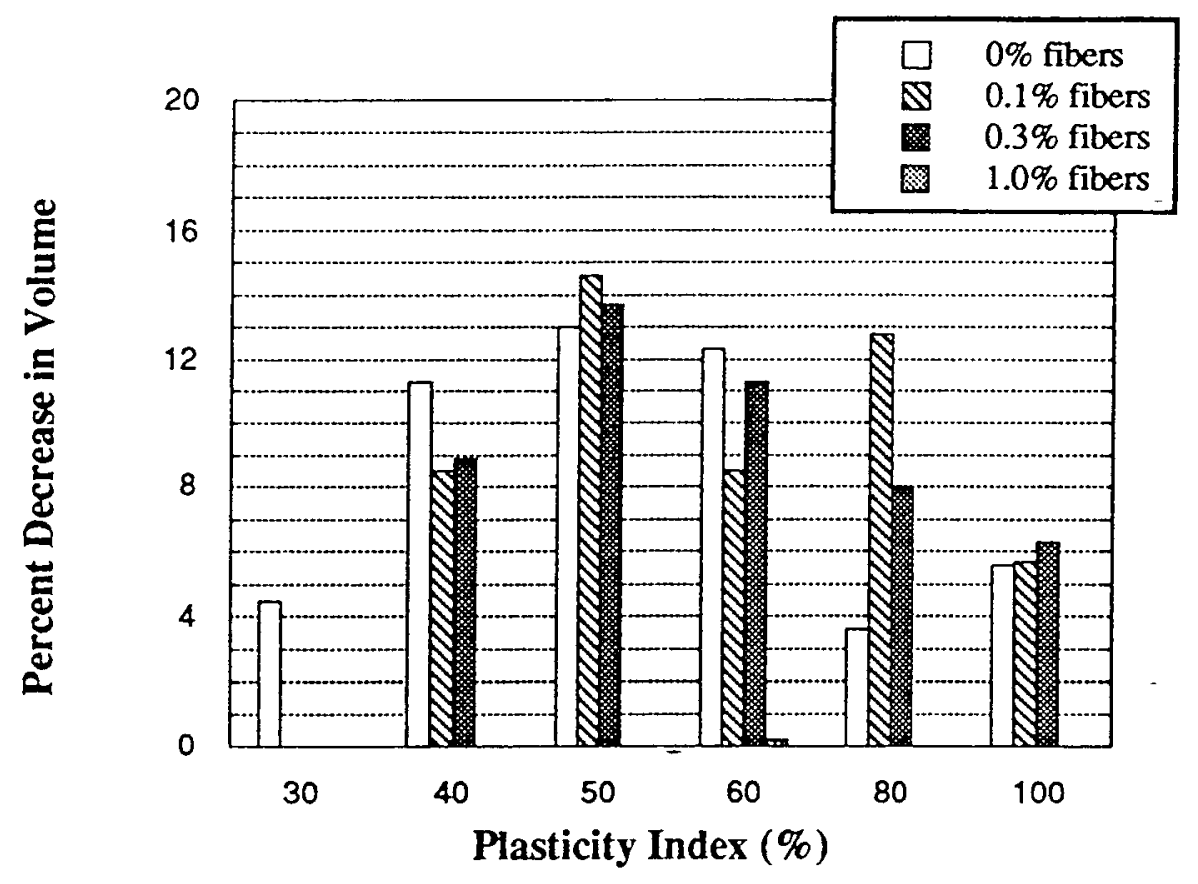

Figure 43. Volume change results for hand-mixed laboratory-prepared soil: drying cycle 4 (4D) 


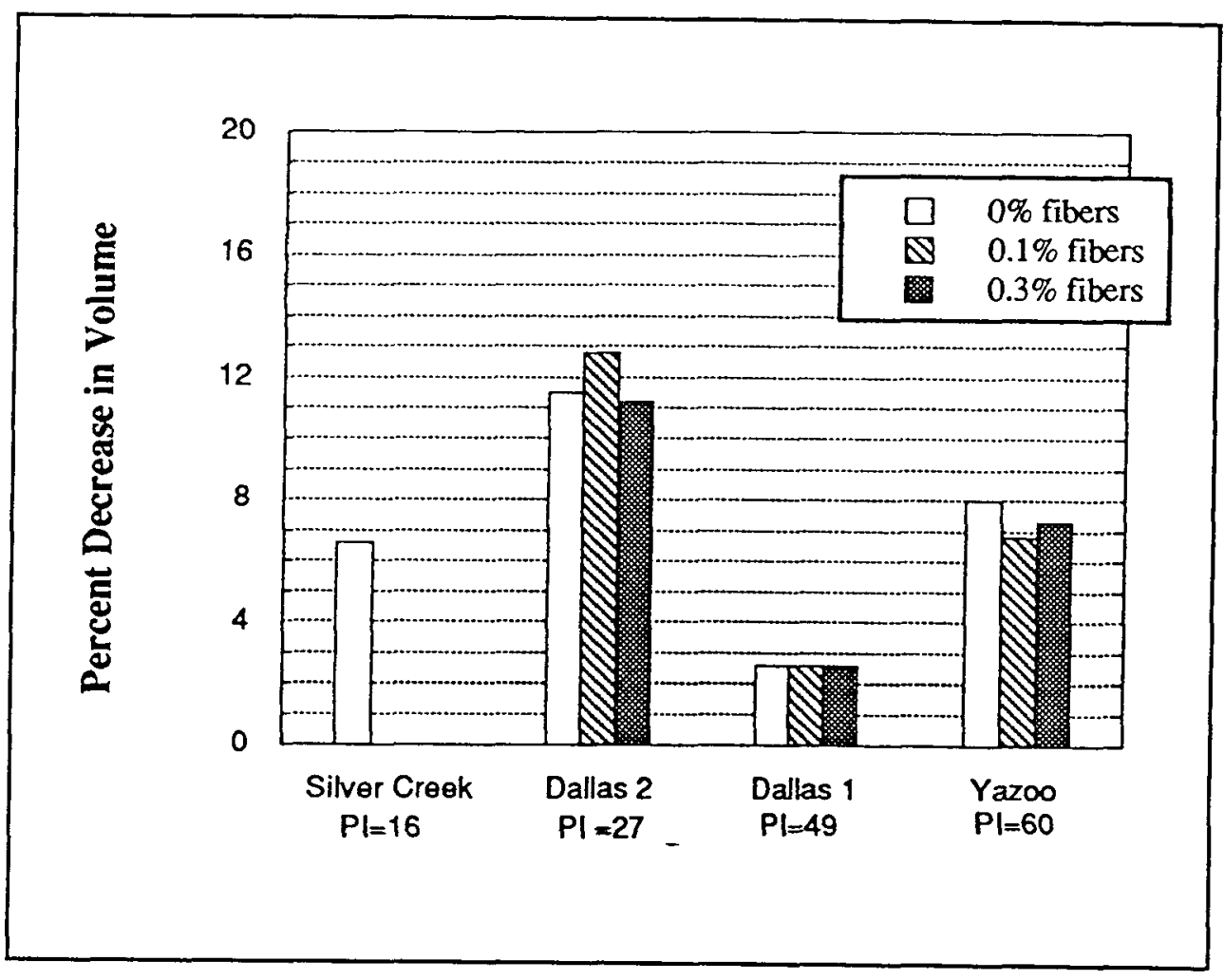

Figure 44. Volume change results for hand-mixed natural soils: drying cycle 1 (1D) 


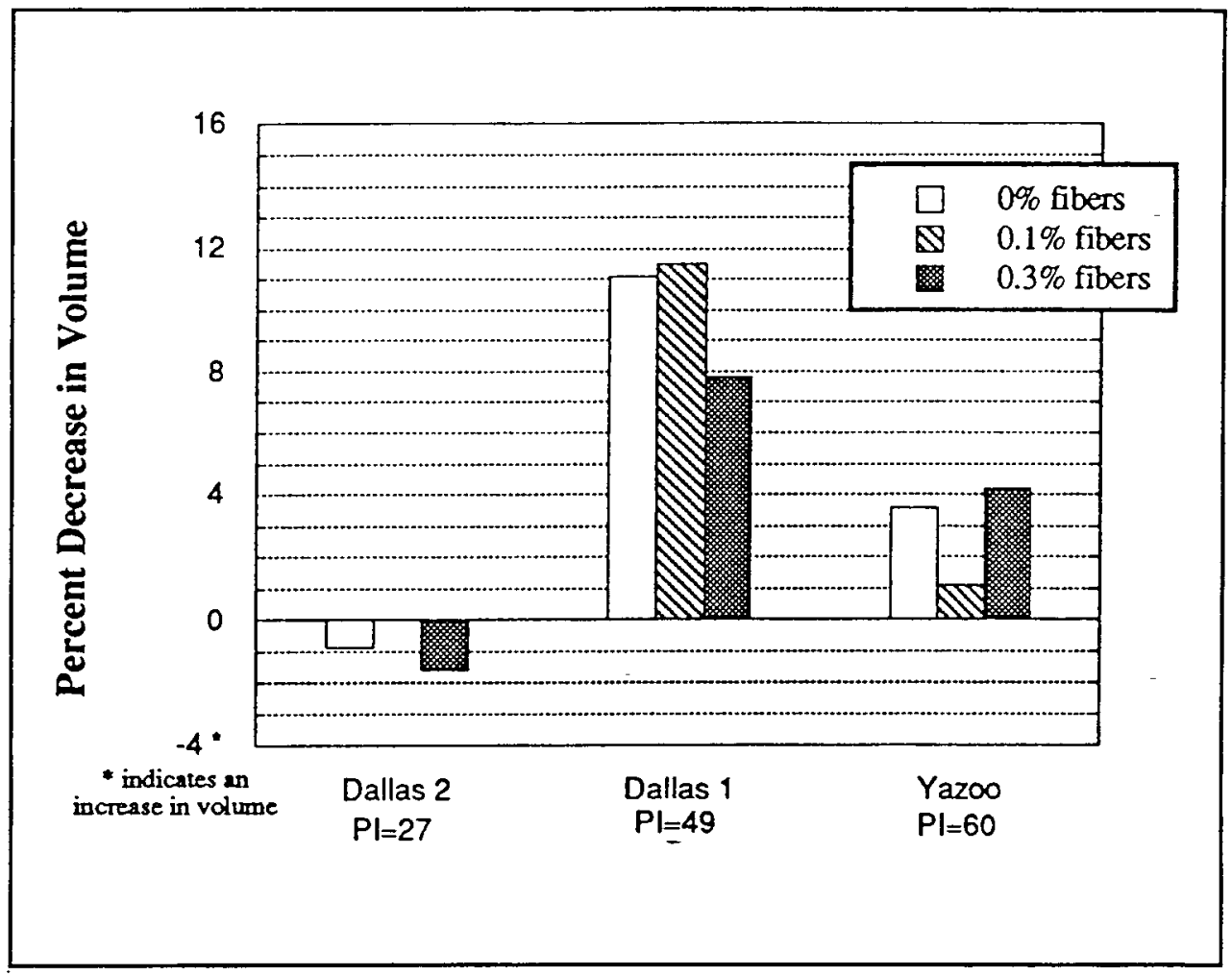

Figure 45. Volume change results for hand-mixed natural soils: drying cycle 2 (2D) 


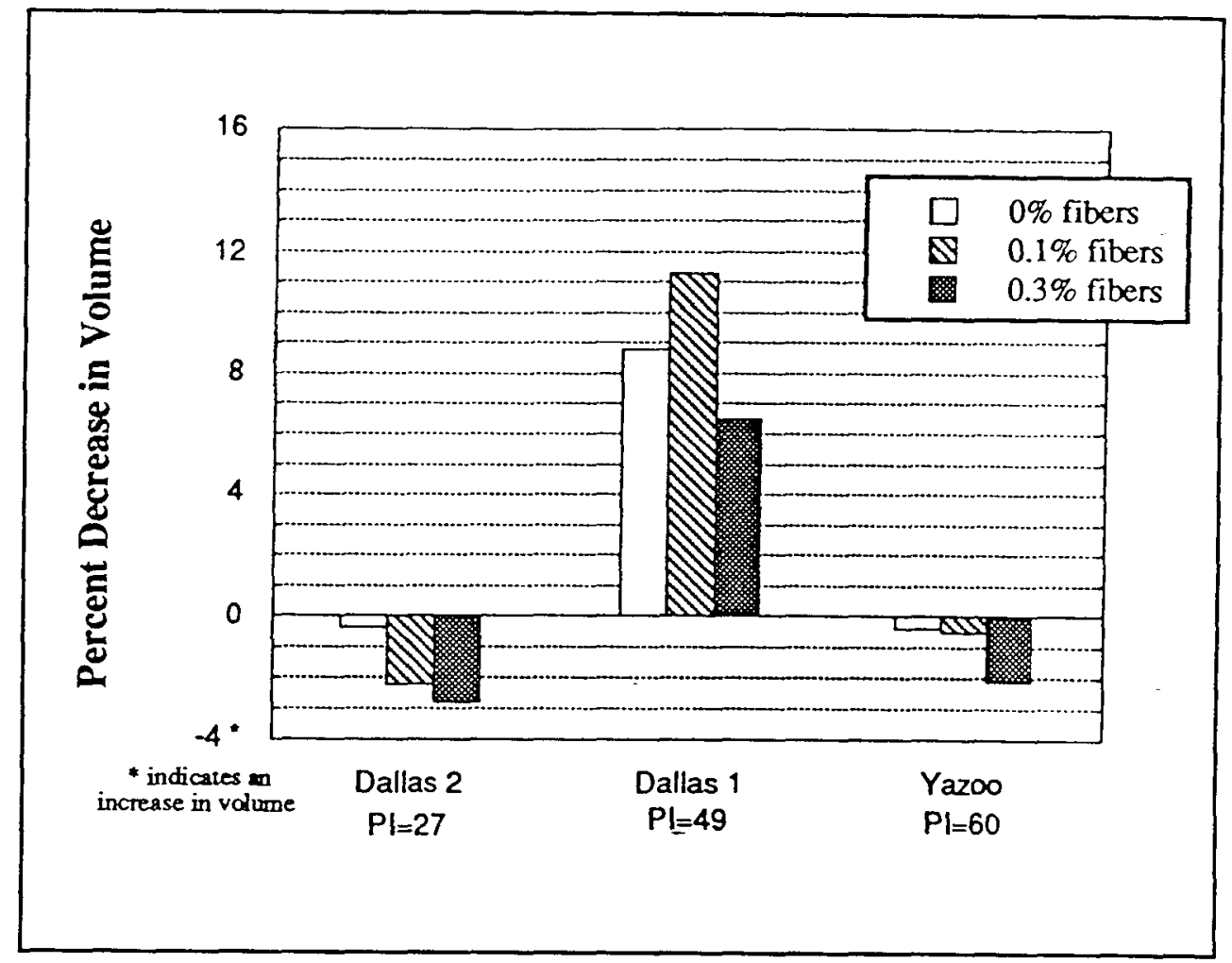

Figure 46. Volume change results for hand-mixed natural soils: drying cycle 3 (3D) 


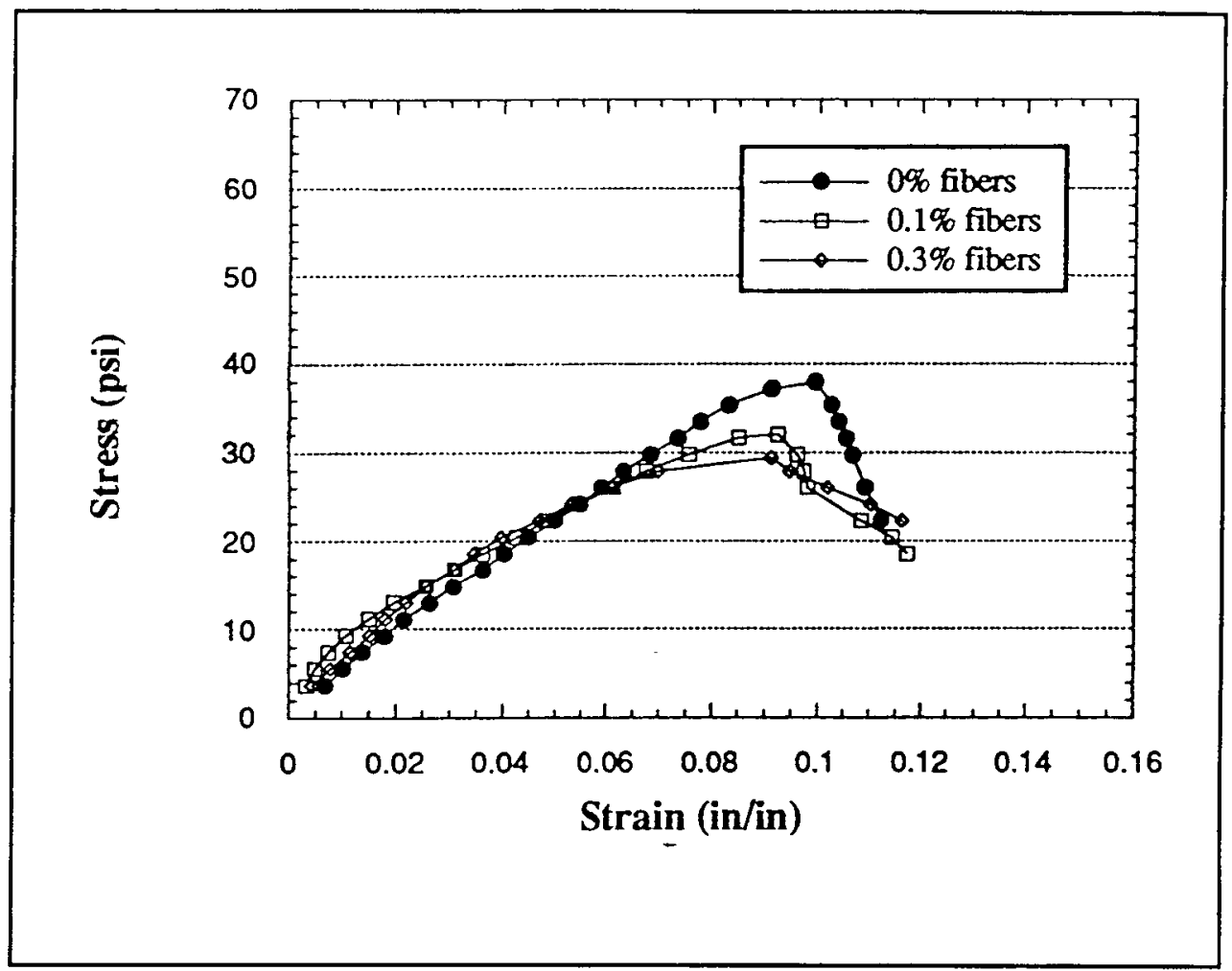

Figure 47. Unconfined compression test results for hand-mixed laboratoryprepared soil: $\mathrm{PI}=30$ (To convert inches to millimeters multiply by 25.4 ; psi to kilopascals multiply by 6.8947579. .) 


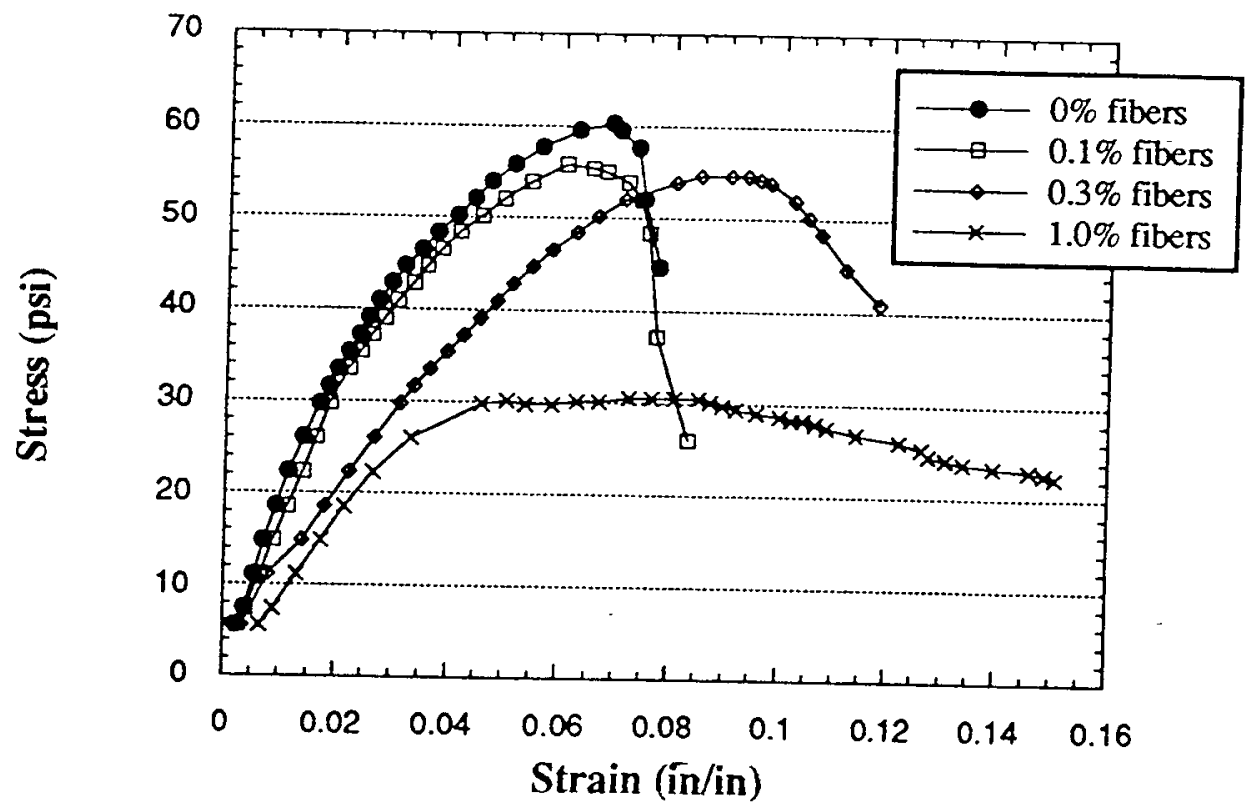

Figure 48. Unconfined compression test results for hand-mixed laboratory-prepared soil: $\mathrm{PI}=60$ (To convert inches to millimeters multiply by 25.4 ; psi to kilopascals multiply by 6.8947579 .) 


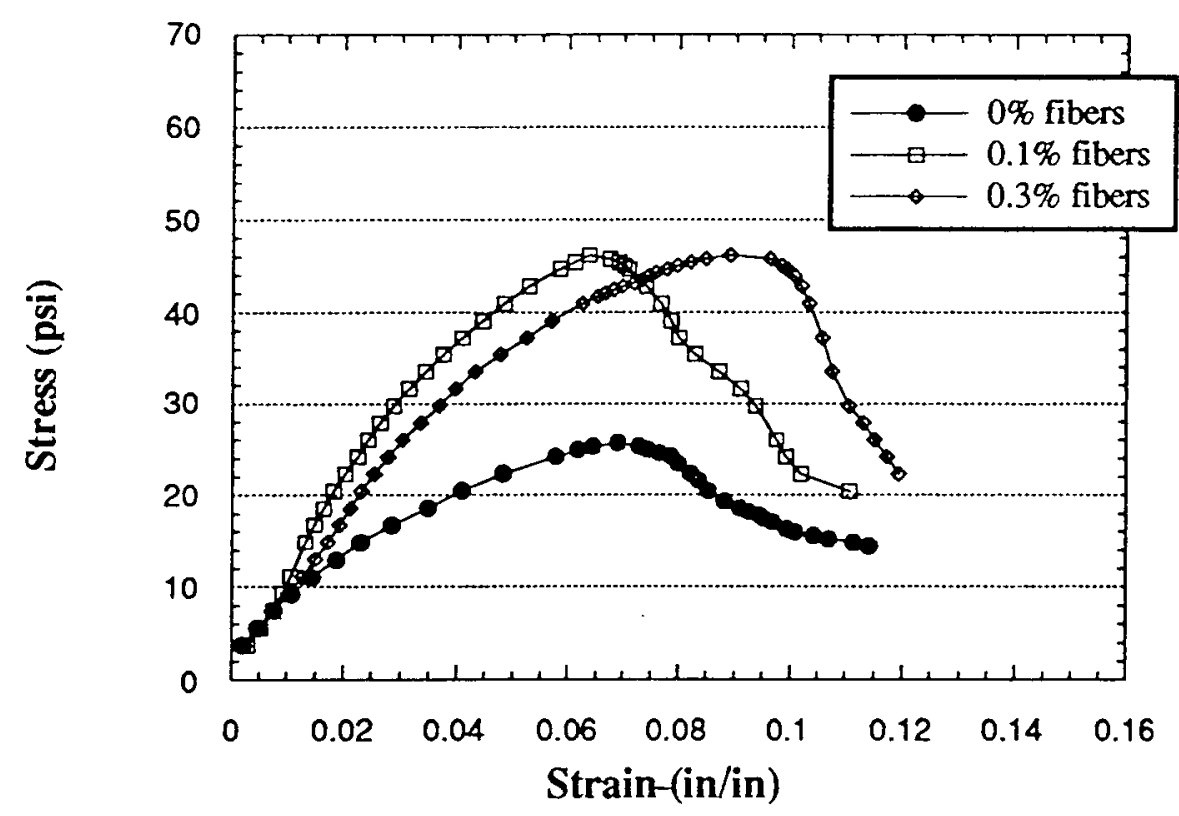

Figure 49. Unconfined compression test results for hand-mixed laboratoryprepared soil: $\mathrm{PI}=100$ (To convert inches to millimeters multiply by 25.4 ; psi to kilopascals multiply by 6.8947579 .) 


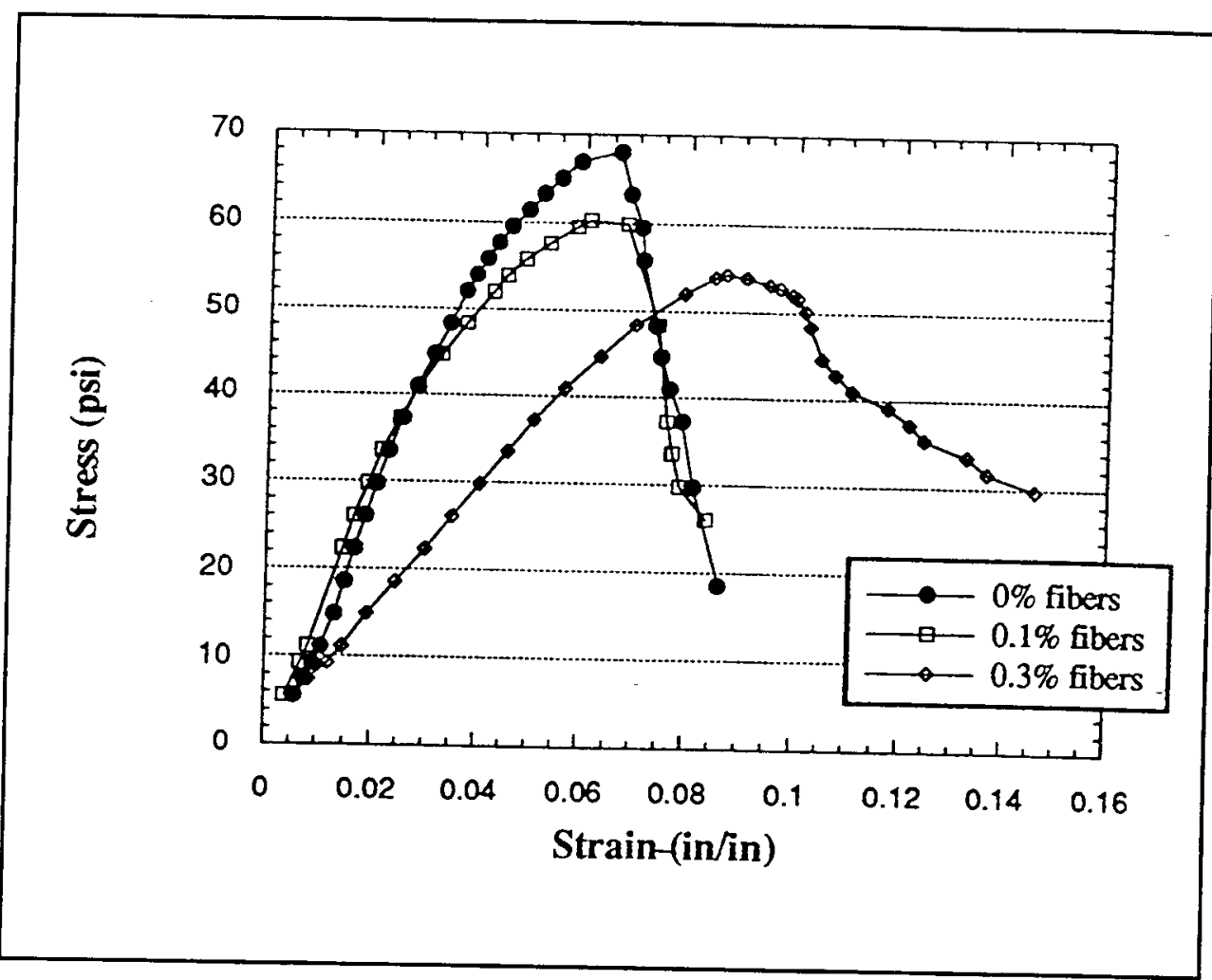

Figure 50. Unconfined compression test results for hand-mixed laboratoryprepared soil: $\mathrm{PI}=60+10$ percent sand (To convert inches to millimeters multiply by 25.4 ; psi to kilopascals multiply by 6.8947579.) 


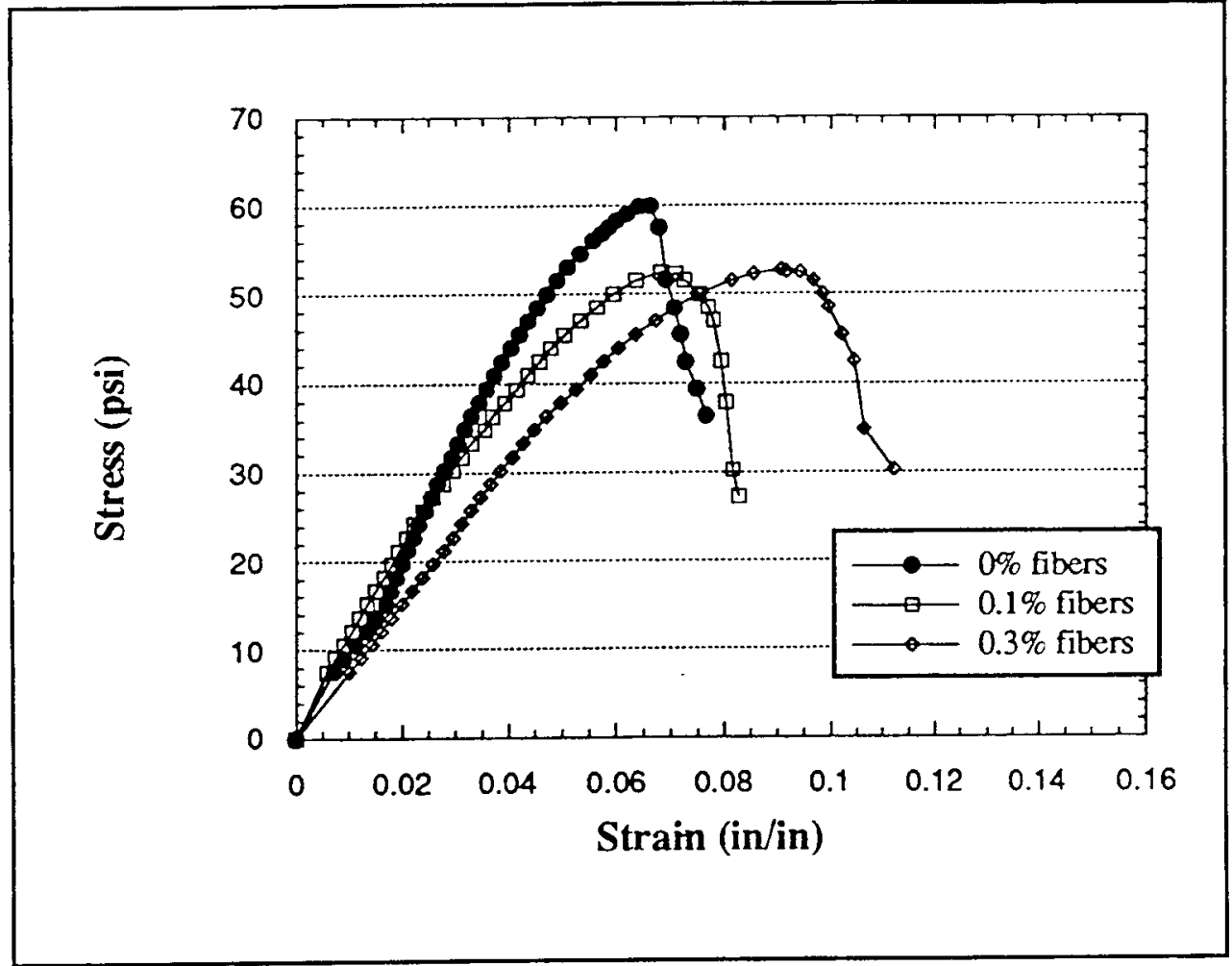

Figure 51. Unconfined compression test results for hand-mixed laboratoryprepared soil, 3-in.-diam sample: $\mathrm{PI}=60$ (To convert inches to millimeters multiply by 25.4 ; psi to kilopascals multiply by 6.8947579.) 


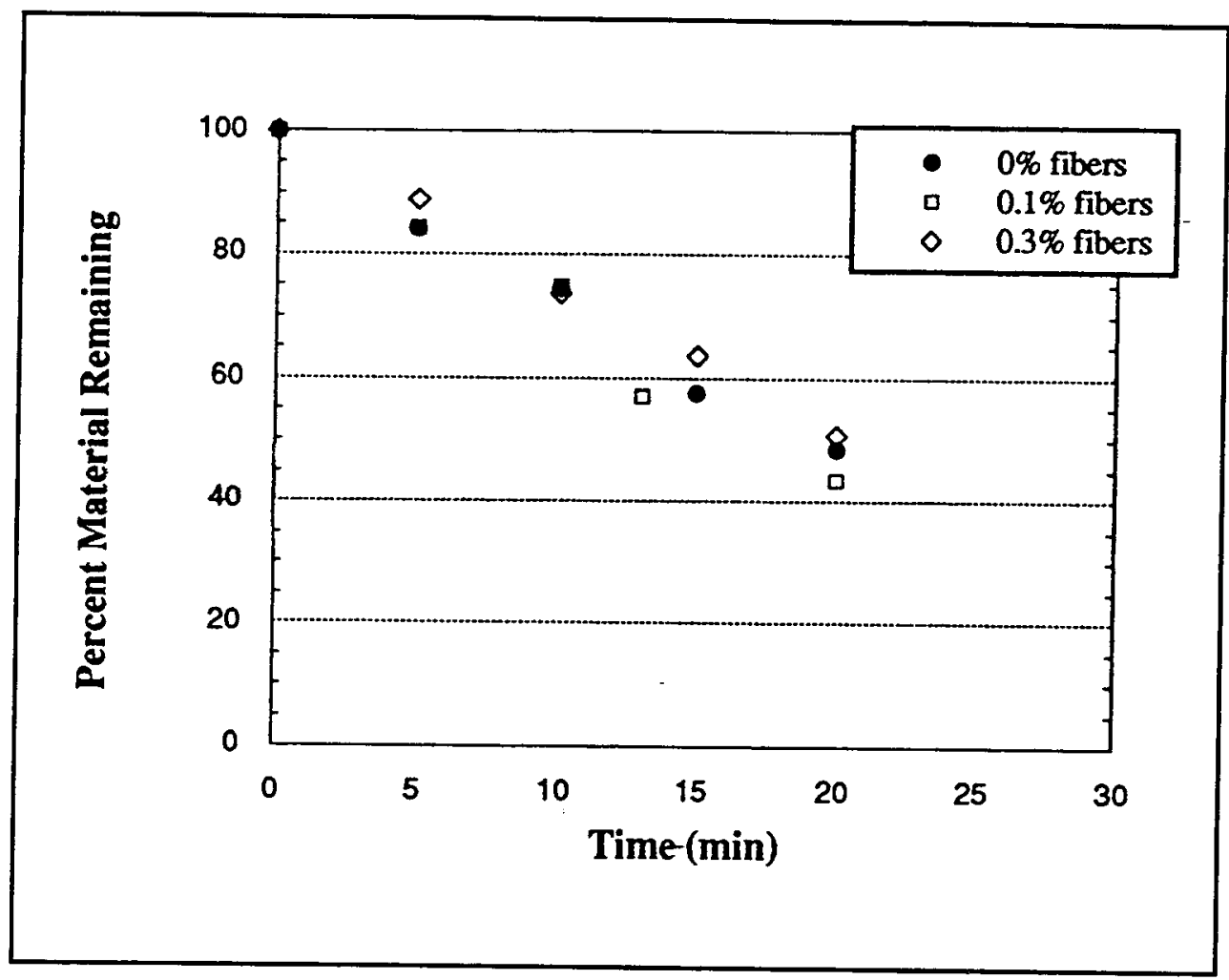

Figure 52. Spin test results for hand-mixed laboratory-prepared soil: $\mathrm{PI}=30$ 


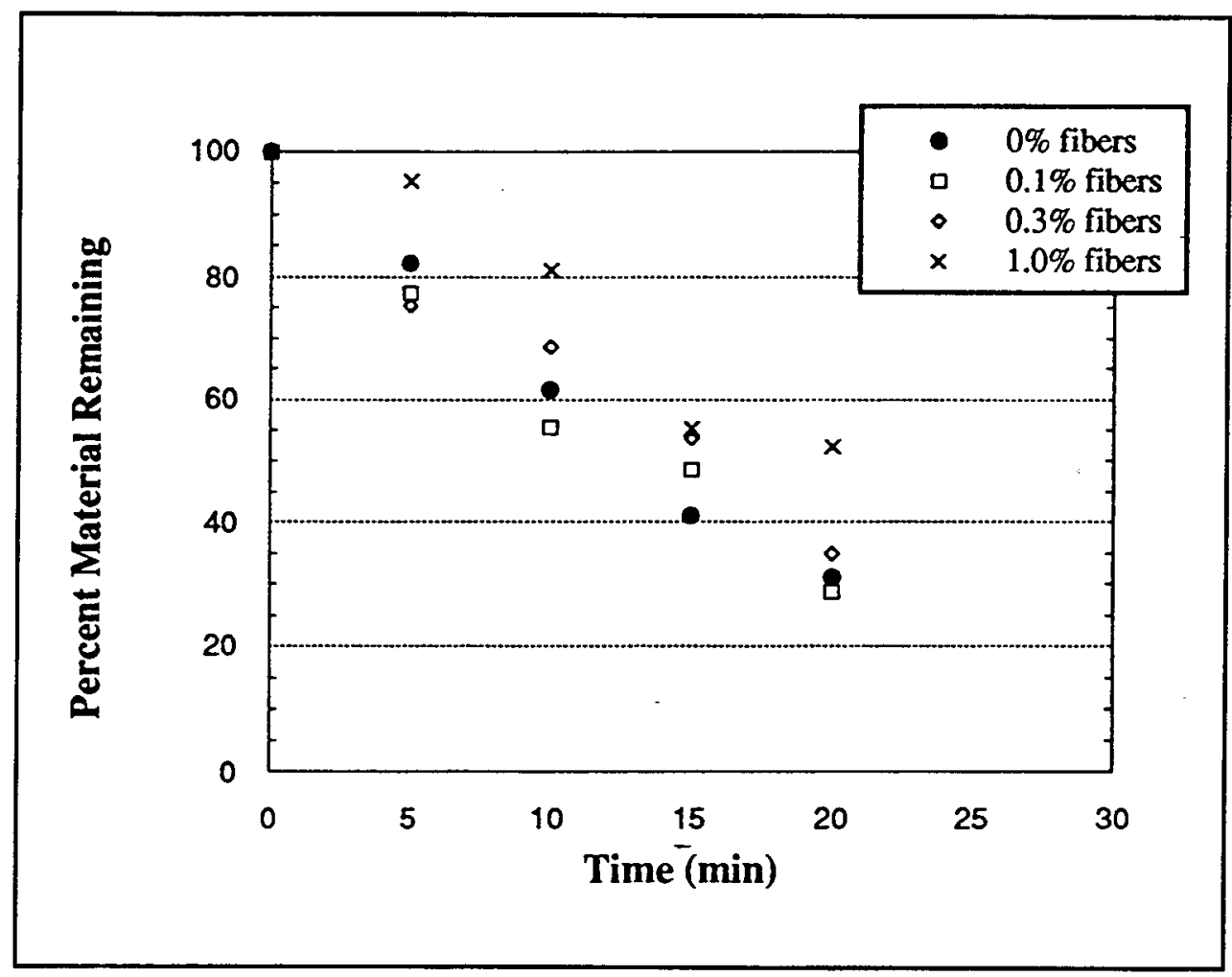

Figure 53. Spin test results for hand-mixed laboratory-prepared soil: $\mathrm{PI}=60$ 


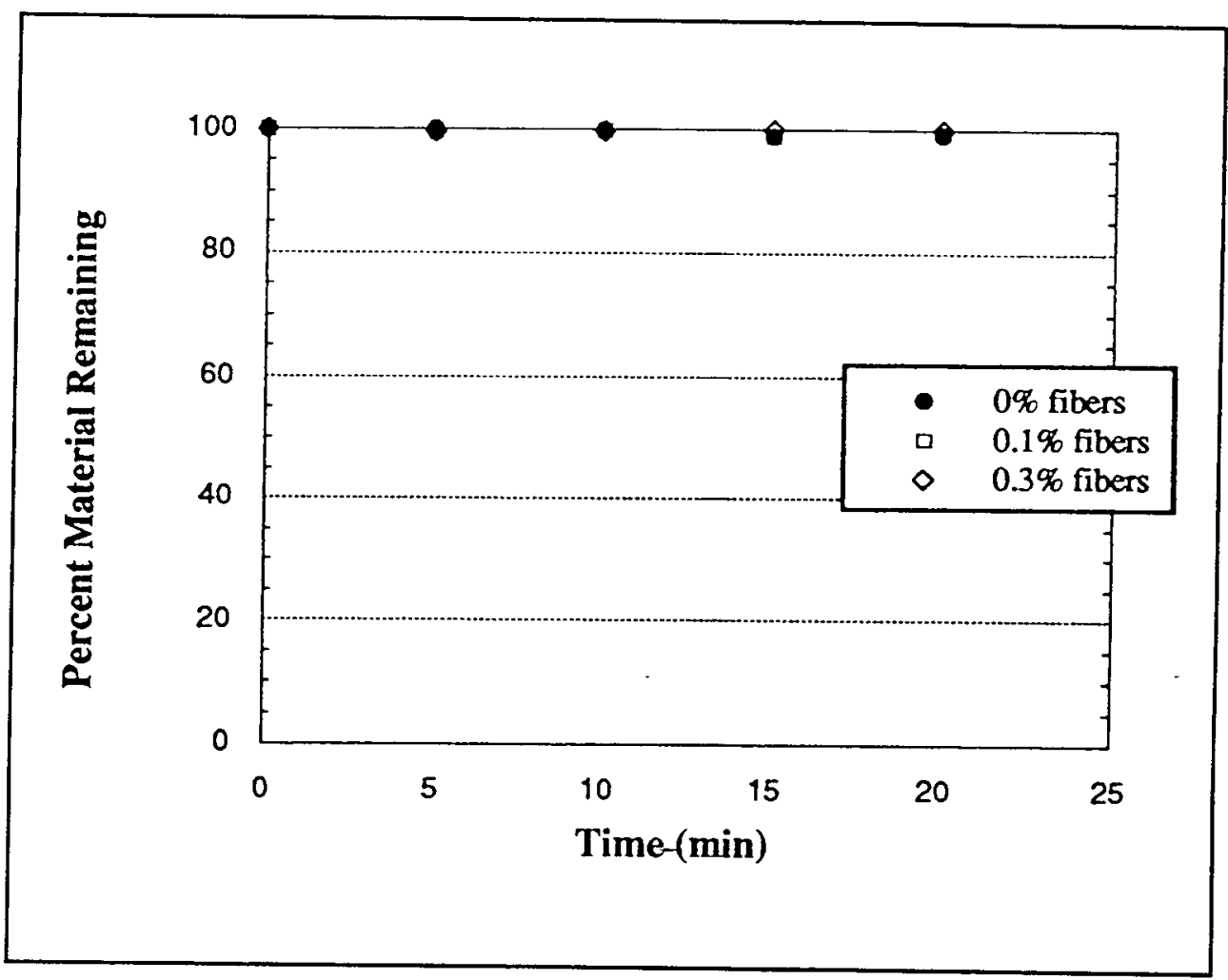

Figure 54. Spin test results for hand-mixed laboratory-prepared soil: $\mathrm{PI}=100$ 


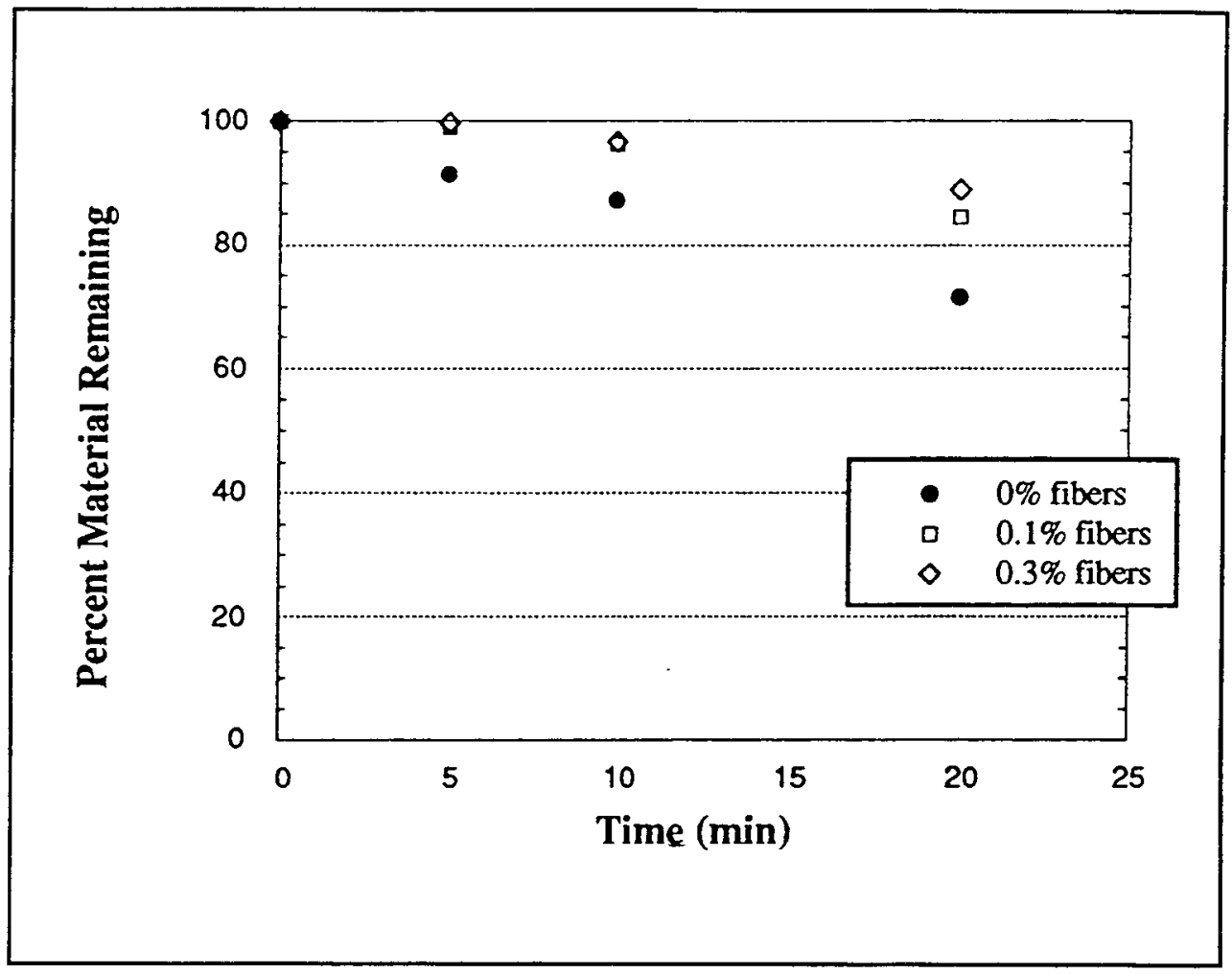

Figure 55. Spin test results for hand-mixed natural soil: Silver Creek $(P I=16)$ 


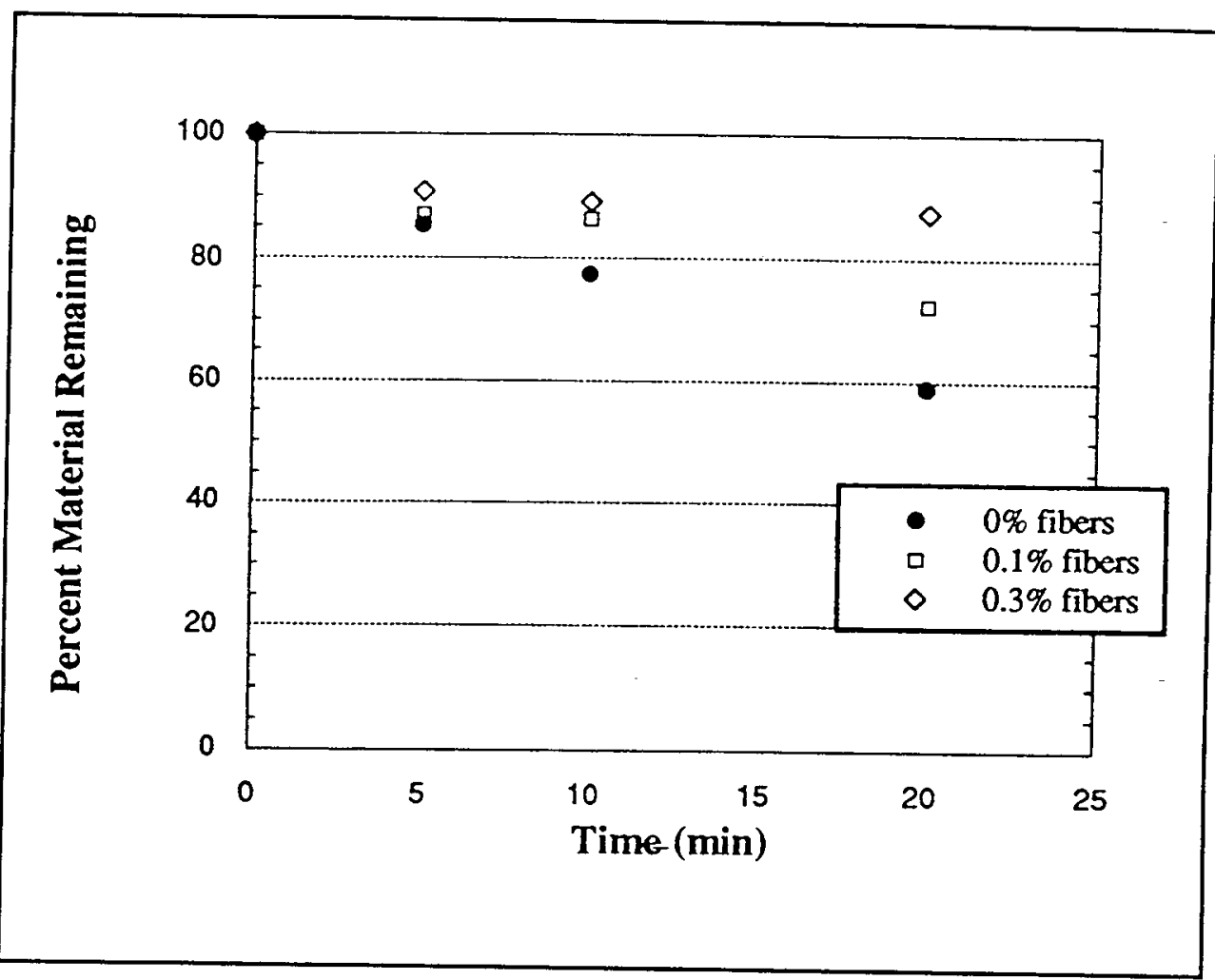

Figure 56. Spin test results for hand-mixed natural soil: Dallas $1(P \mid=49)$ 


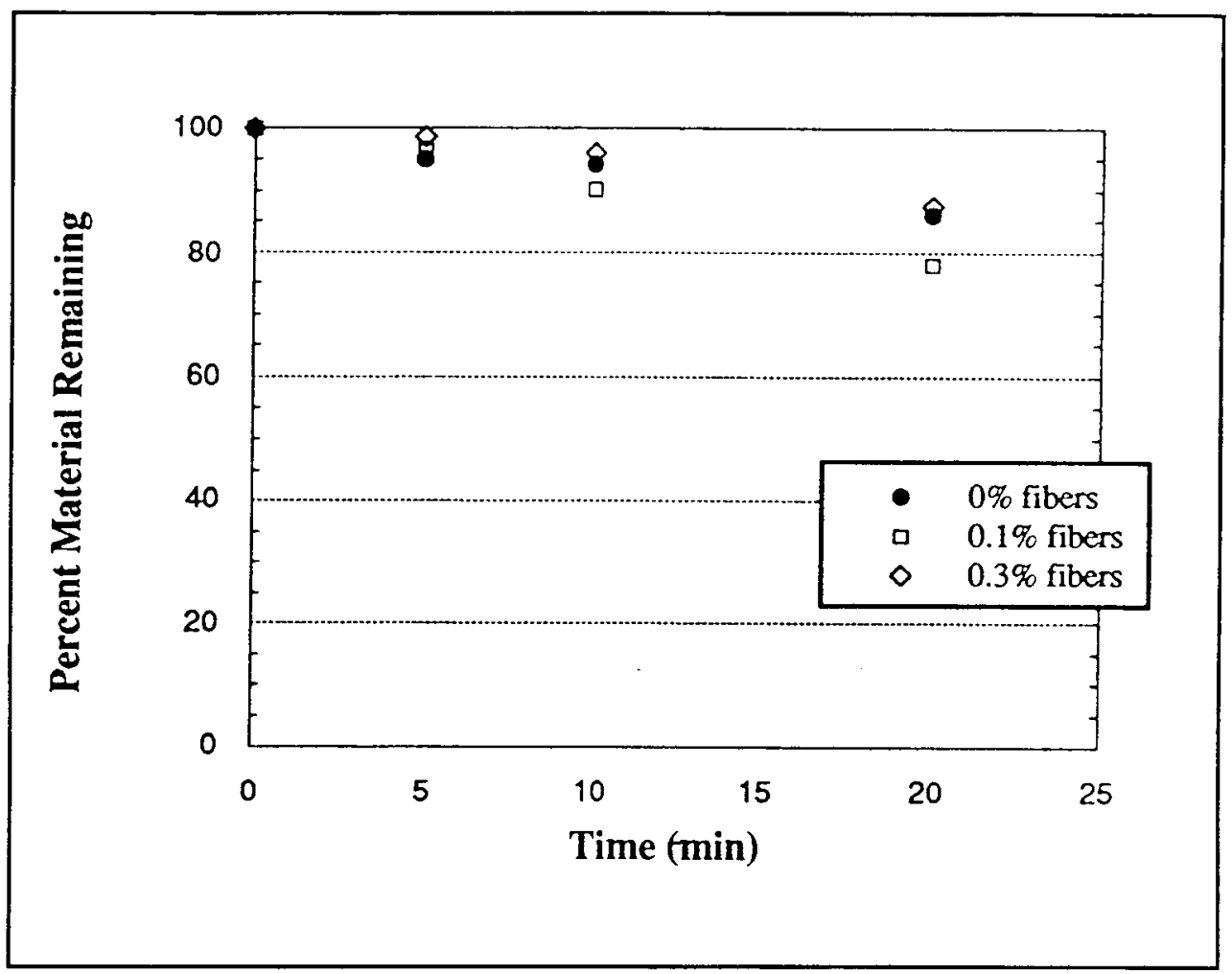

Figure 57. Spin test results for hand-mixed natural soil: Dallas $2(P \mid=27)$ 


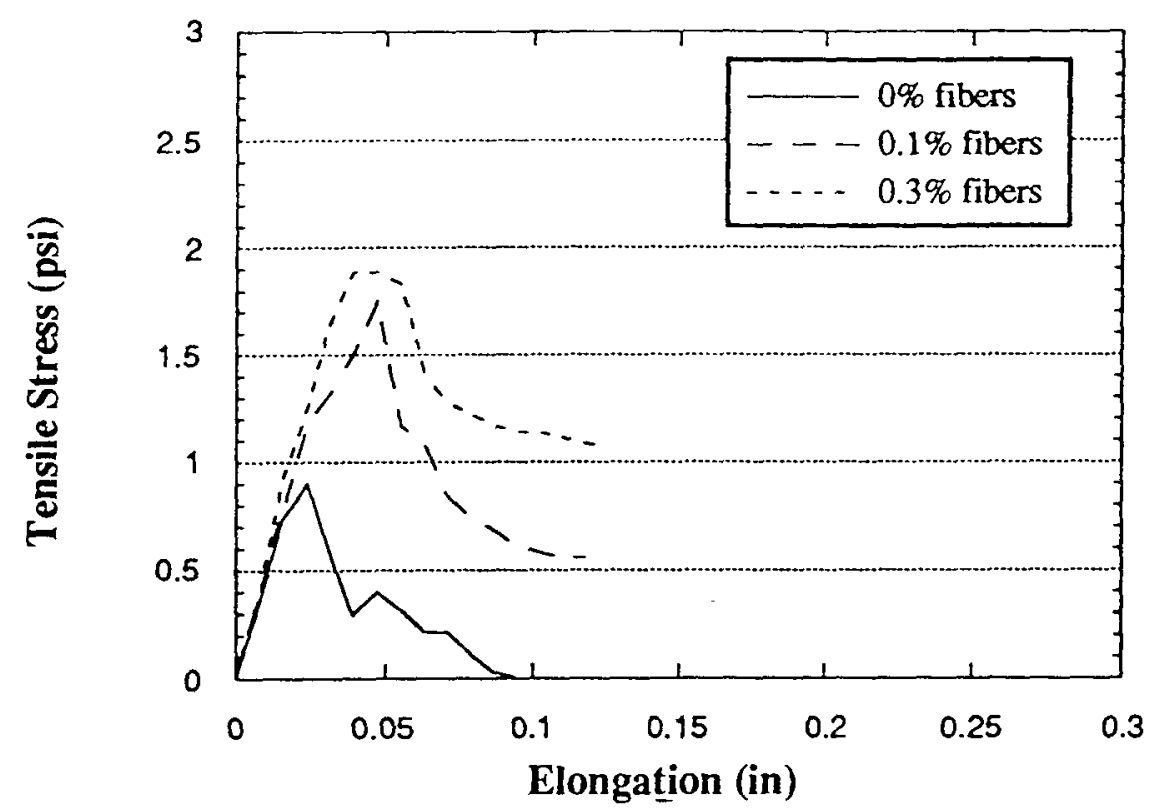

Figure 58. Tension test results for hand-mixed laboratory-prepared soil: $\mathrm{PI}=30$ (To convert inches to millimeters multiply by 25.4 ; psi to kilopascals multiply by 6.8947579.$)$ 


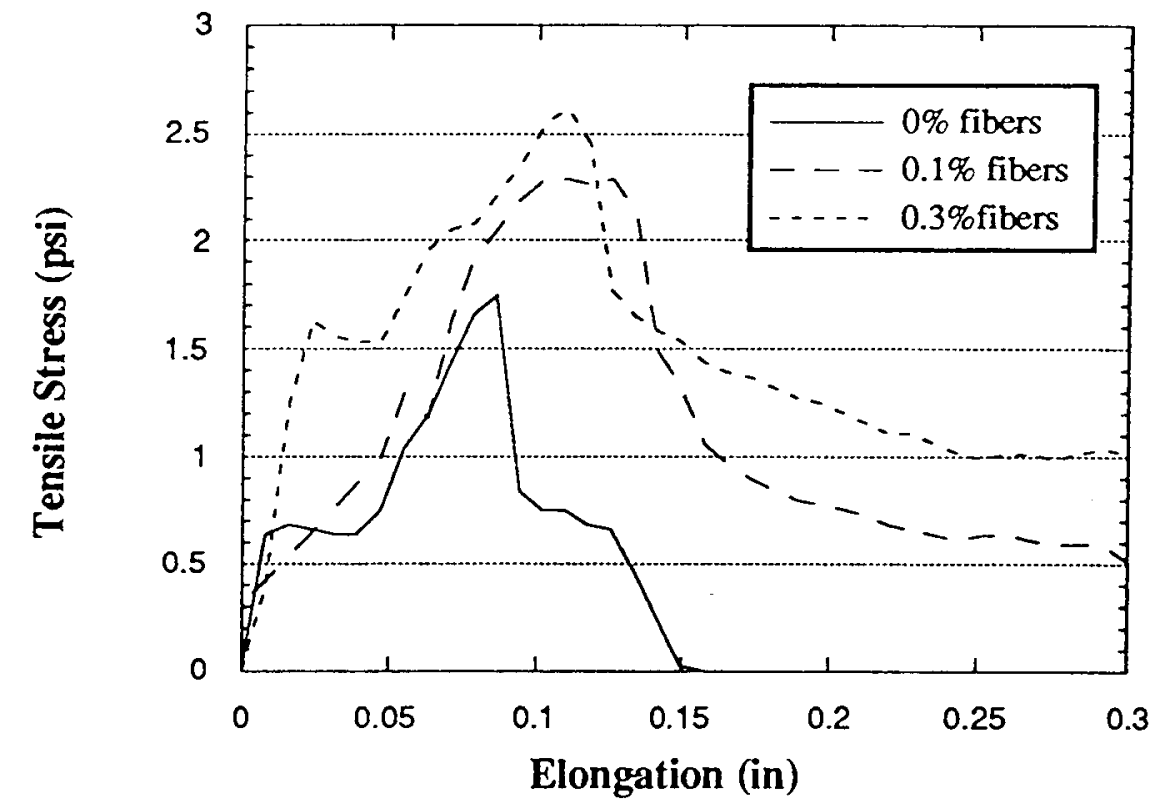

Figure 59. Tension test results for machine-mixed laboratory-prepared soil: $\mathrm{PI}=30$ (To convert inches to millimeters multiply by 25.4 ; psi to kilopascals multiply by 6.8947579 .) 


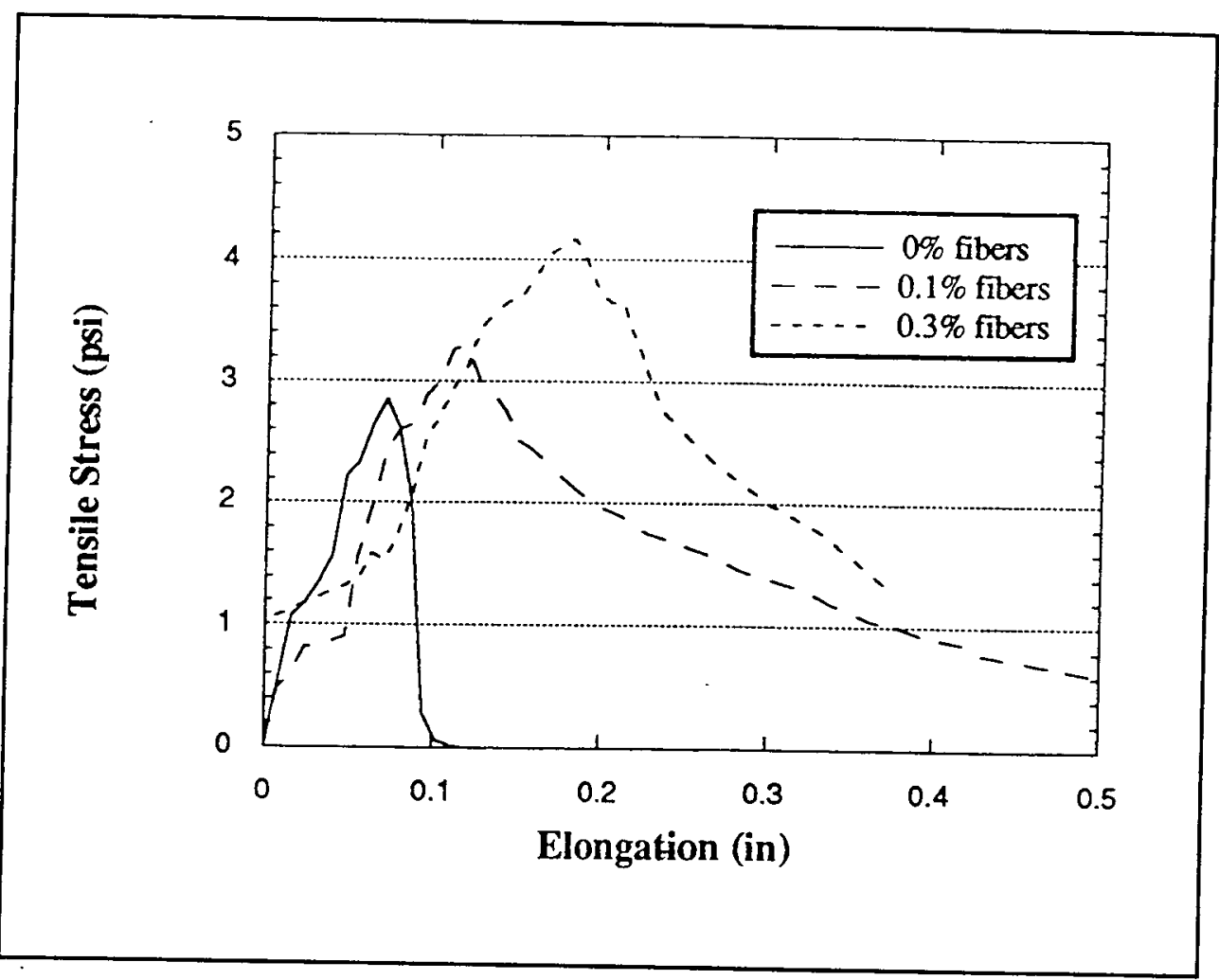

Figure 60. Tension test results for hand-mixed laboratory-prepared soil: $\mathrm{PI}=60$ (To convert inches to millimeters multiply by 25.4 ; psi to kilopascals multiply by 6.8947579 .) 


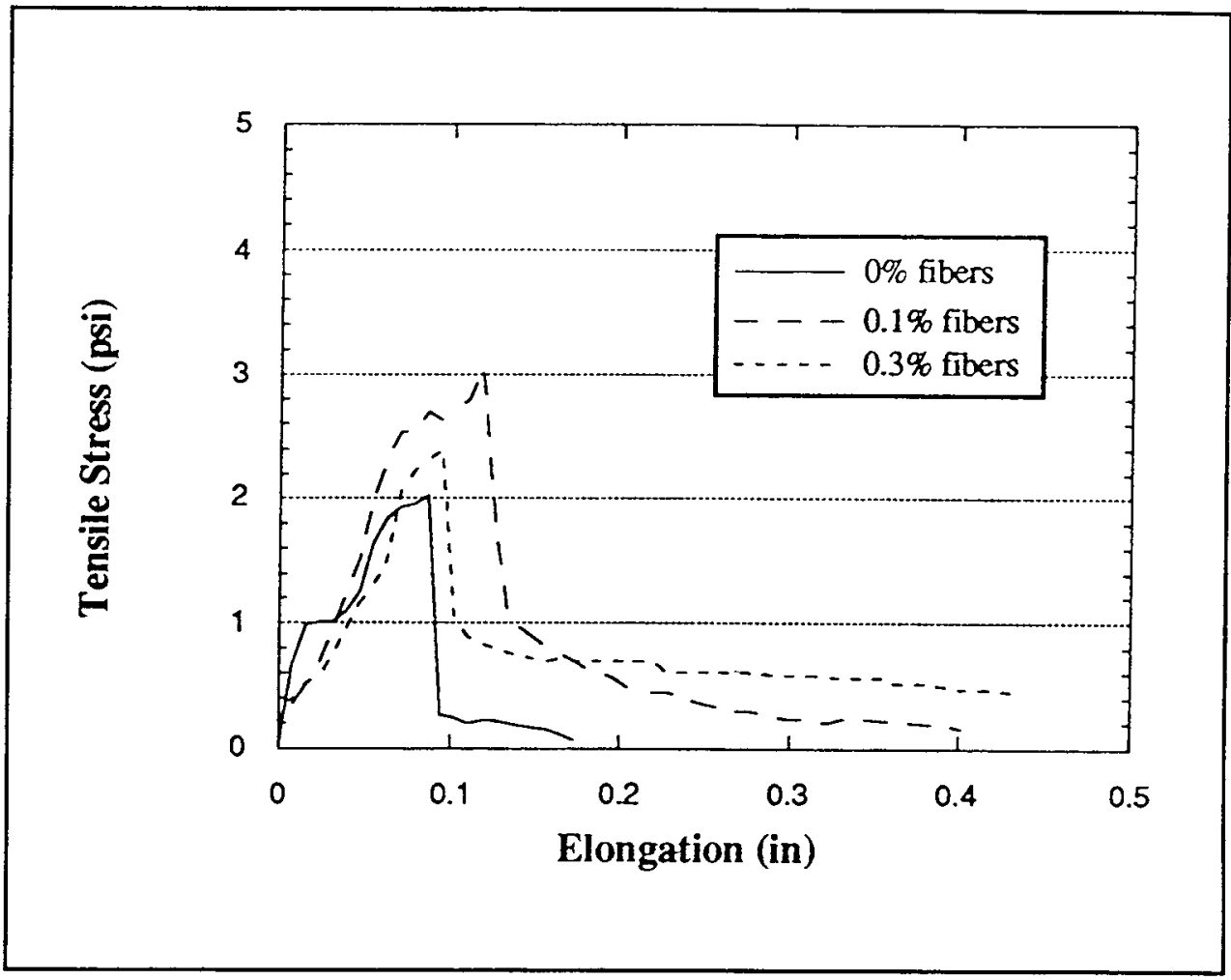

Figure 61. Tension test results for machine-mixed laboratory-prepared soil: $\mathrm{PI}=60$ (To convert inches to millimeters multiply by 25.4 ; psi to kilopascals multiply by 6.8947579 .) 


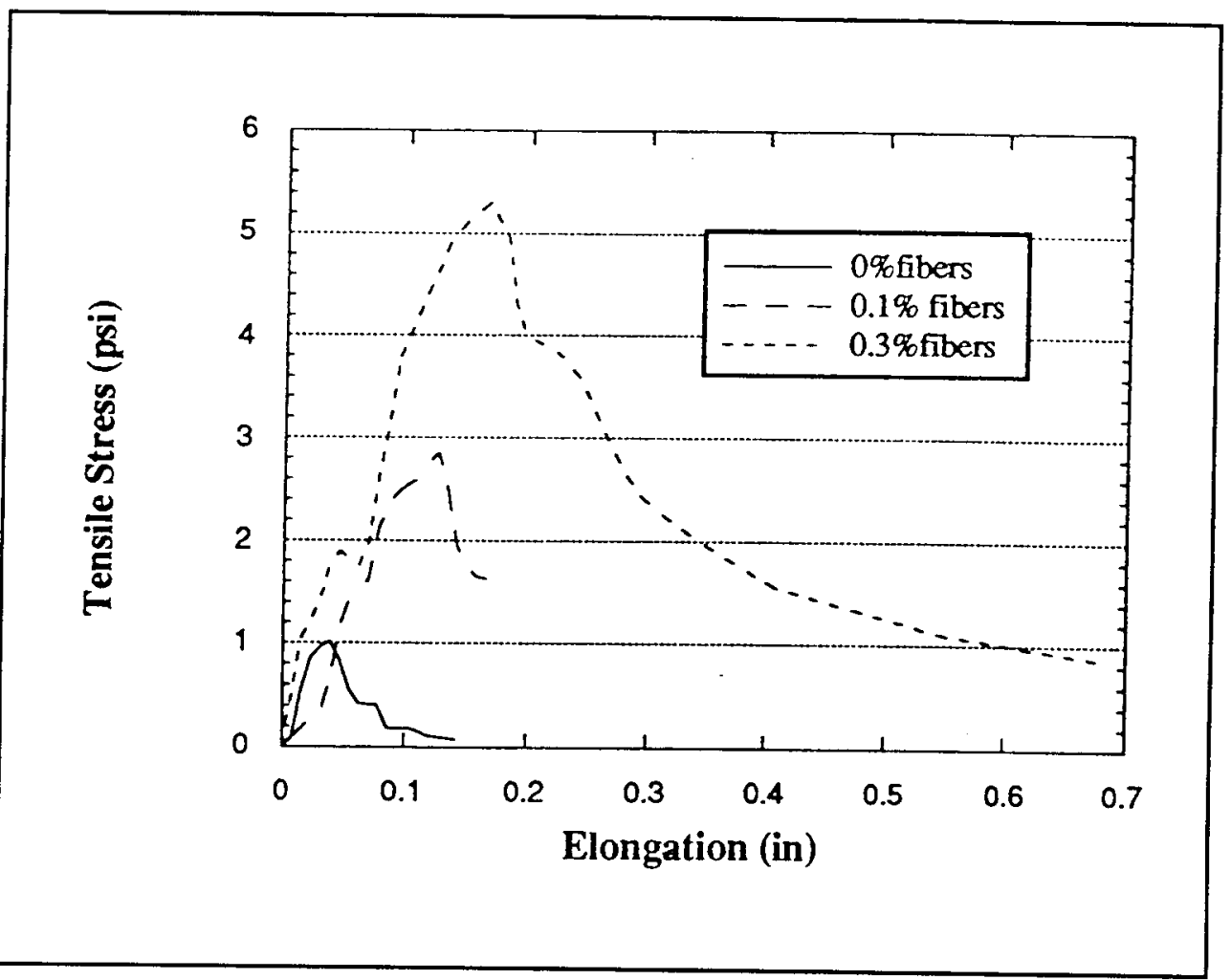

Figure 62. Tension test results for hand-mixed laboratory-prepared soil: $\mathrm{Pl}=100$ (To convert inches to millimeters multiply by 25.4 ; psi to kilopascals multiply by 6.8947579 .) 


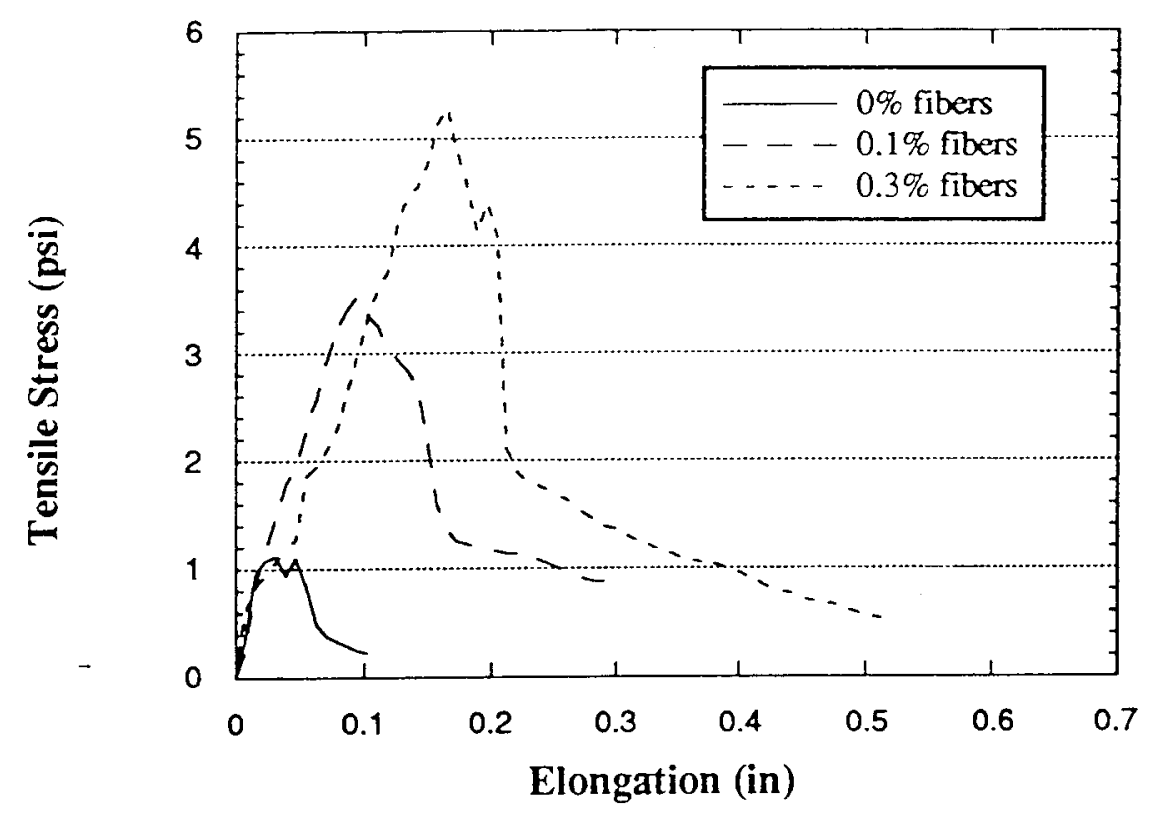

Figure 63. Tension test results for machine-mixed laboratory-prepared soil: $\mathrm{PI}=100$ (To convert inches to millimeters multiply by $25.4 ; \mathrm{psi}$ to kilopascals multiply by 6.8947579 .)

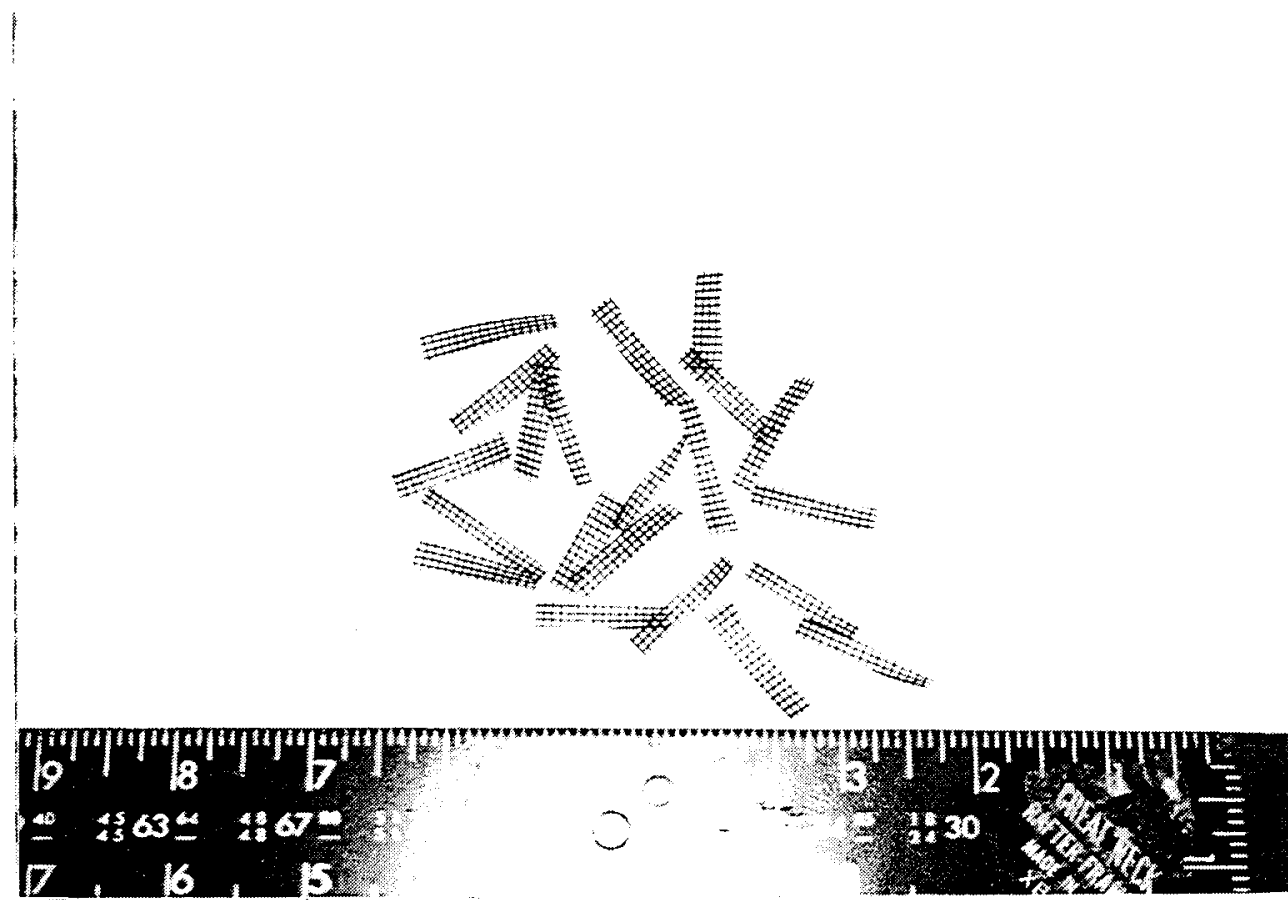

Figure 64. Screen fibers 


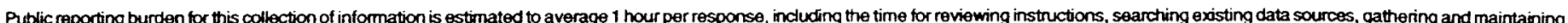

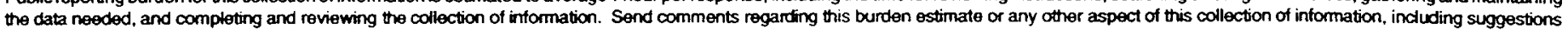

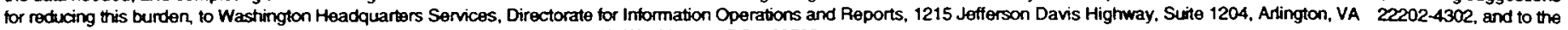
Office of Management and Budget, Paperwork Reduction Project (0704-0188), Washington, DC 20503.

\begin{tabular}{l|l} 
1. AGENCY USE ONLY (Leave blank) & 2. REPORT DATE
\end{tabular}

December 1997

4. TITLE AND SUBTITLE

Effects of Short Polymeric Fibers on Crack Development in Clays

6. AUTHOR(S)

Stacy Shulley, Dov Leshchinsky, Hoe I. Ling

7. PERFORMING ORGANIZATION NAME(S) AND ADDRESS(ES)

University of Delaware

Newark, DE 19716

\section{REPORT TYPE AND DATES COVERED}

Final report

\section{FUNDING NUMBERS}

8. PERFORMING ORGANIZATION REPORT NUMBER

Technical Report REMR-GT-25

10. SPONSORINGMONITORING AGENCY REPORT NUMBER

U.S. Army Corps of Engineers

Washington, DC 20314-1000

11. SUPPLEMENTARY NOTES

Available from National Technical Information Service, 5285 Port Royal Road, Springfield, VA 22161.

12a. DISTRIBUTIONAVAILABILTTY STATEMENT

12b. DISTRIBUTION CODE

Approved for public release; distribution is unlimited.

13. ABSTRACT (Maximum 200 words)

Many levees are constructed of clay soils which have a tendency to shrink and swell when subjected to periods of drying and wetting. Desiccation cracking occurs allowing percolation of rain water which may result in shallow surface slides. The purpose of this research was to assess the feasibility of using randomly distributed short polypropylene fibers to reduce the development of desiccation cracks in clay. Tests were conducted on laboratory prepared clays with a wide range of plasticity indices as well as natural clay samples. The fibers were effective in reducing the amount of desiccation cracking that occurs in clay samples. The fibers were effective in reducing the amount of desiccation cracking that occurs in clays subjected to drying. However, when subjected to wet/dry cycles, the fibers were not effective. The fibers increased the tensile strength of the clay and provided a ductile behavior that was not present in the samples without fibers. The fibers has no effect in reducing clay surface disintegration due to erosion. Limited testing with a grid-like fiber, with a bearing capacity failure in pullout as opposed to adhesion for the polypropylene fiber, indicated a modified fiber design could better interact with clays.

\section{SUBJECT TERMS}

Levees

Polypropylene fibers

Desiccation cracks
Slope stability

Erosion

Rainfall
15. NUMBER OF PAGES

102

16. PRICE CODE \begin{tabular}{|l|l|l|}
\hline $\begin{array}{l}\text { 17. SECURITY CLASSIFICATION } \\
\text { OF REPORT } \\
\text { UNCLASSIFIED }\end{array}$ & $\begin{array}{l}\text { 18. } \\
\text { SECURIY CLASSIFICATION } \\
\text { OF THIS PAGE } \\
\text { UNCLASSIFIED }\end{array}$ & $\begin{array}{l}\text { 19. } \\
\text { SECURITY CLASSIFICATION } \\
\text { OF ABSTRACT }\end{array}$ \\
\hline
\end{tabular}

NSN 7540-01-280-5500
Standard Form 298 (Rev. 2-89) Prescribed by ANSI Std. Z39-18 298-102 
